\title{
Application of cathodoluminescence and quantitative color analysis to the study of glass for forensic purposes
}

Heidi D. Nawrocki

West Virginia University

Follow this and additional works at: https://researchrepository.wvu.edu/etd

\section{Recommended Citation}

Nawrocki, Heidi D., "Application of cathodoluminescence and quantitative color analysis to the study of glass for forensic purposes" (2008). Graduate Theses, Dissertations, and Problem Reports. 2675. https://researchrepository.wvu.edu/etd/2675

This Thesis is protected by copyright and/or related rights. It has been brought to you by the The Research Repository @ WVU with permission from the rights-holder(s). You are free to use this Thesis in any way that is permitted by the copyright and related rights legislation that applies to your use. For other uses you must obtain permission from the rights-holder(s) directly, unless additional rights are indicated by a Creative Commons license in the record and/ or on the work itself. This Thesis has been accepted for inclusion in WVU Graduate Theses, Dissertations, and Problem Reports collection by an authorized administrator of The Research Repository @ WVU. For more information, please contact researchrepository@mail.wvu.edu. 


\title{
Application of Cathodoluminescence and Quantitative Color Analysis to the Study of Glass for Forensic Purposes
}

\author{
Heidi D. Nawrocki
}

Thesis submitted to the

Eberly College of Arts and Sciences

at West Virginia University in partial fulfillment of requirements

for the degree of

\section{Master of Science \\ in \\ Chemistry}

\author{
Suzanne C. Bell, Ph.D, Chair \\ Keith B. Morris, Ph.D \\ Harry O. Finklea, Ph.D. \\ Department of Chemistry \\ Morgantown, WV \\ 2008
}

Keywords: glass, refractive index, cathodoluminescence, quantitative color analysis 


\begin{abstract}
Application of Cathodoluminescence and Quantitative Color Analysis to the Study of Glass for Forensic Purposes
\end{abstract}

\author{
By Heidi Nawrocki
}

Forensic analysis of glass has traditionally relied on the use of refractive index (RI) measurements and physical methods for matching. The current study utilized cathodoluminescence (CL) spectroscopy, combined with RI and quantitative color analysis. $C L$ is a phenomenon that occurs when light is emitted from a material upon electron bombardment. Scanning electron microscopy coupled with CL detection was used for analysis. Standard glass samples from NIST were used for method development, while samples obtained from the Crime Scene Complex at West Virginia University and headlight glass samples from Jordan Auto Parts in Pennsylvania were used to evaluate the method. Additionally, a breaking and entering scenario was carried out. Replicate CL spectra were obtained from each sample, as well as refractive index measurements. Results indicate that the combination of $\mathrm{CL}, \mathrm{RI}$, and color analysis allows for the successful differentiation of samples. 


\section{Acknowledgements}

I would first like to sincerely thank my advisor, Dr. Suzanne Bell, for all of her help and guidance during my time as a graduate student. Her sense of humor and "go get 'em" attitude was of great help when my motivation was wavering. I would also like to thank Dr. Harry Finklea for his constant support and guidance, not only during my time at West Virginia University, but also for helping me to solidify the decision to attend WVU for my MS. Also, I would like to thank Dr. Keith Morris for his continual input of new ideas for research, sense of humor and singing abilities, and most of all, his support and guidance.

I am also thankful for the help of two hard working undergrads, Marci Smeltz and Travis Warner. Their assistance with data acquisition is much appreciated.

I would also like to thank Max Houck and the Forensic Science Initiative for financial support, endless guidance, and the opportunity to work with great instrumentation. The support from the National Institute of Justice is also greatly appreciated.

I would not be where I am today without the support of an awesome family. I want to thank my mom and dad, Vickie Wanto and Keith Barron for always believing in me. They've supported all of my endeavors and for that, I am eternally grateful. And last, but not least, I want to thank my husband, Dan, for being a constant source of love and support. Without him by my side, I would not be where I am today. 


\section{Table of Contents}

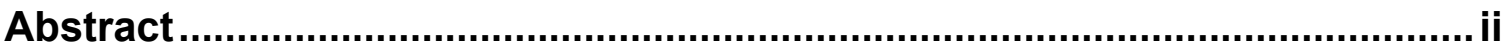

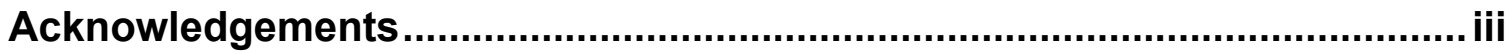

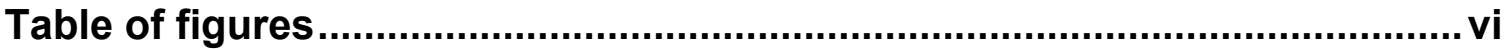

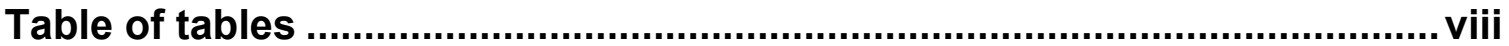

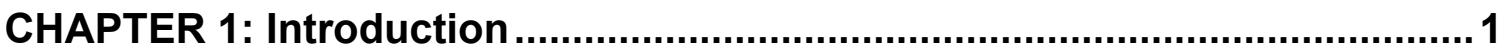

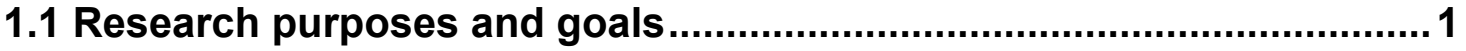

1.2 Traditional methods of forensic glass analysis.................................. 1

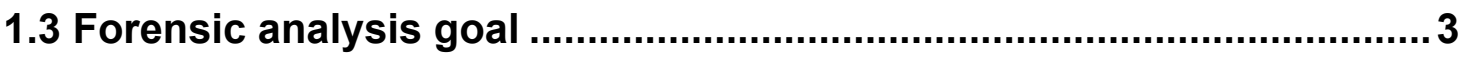

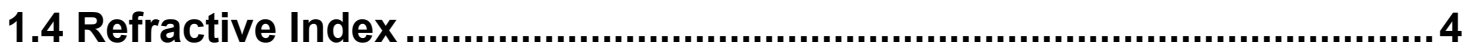

1.4.1 Chemical and physical basis ....................................................... 4

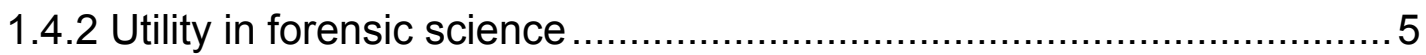

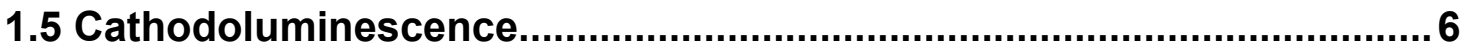

1.5.1 Background and history of cathodoluminescence ............................... 6

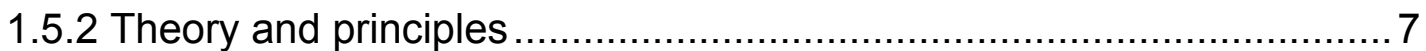

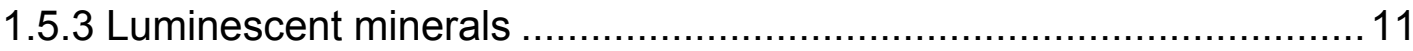

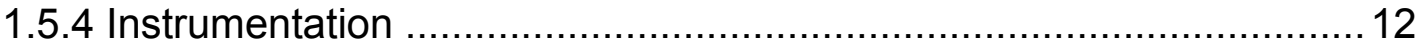

1.5.5 Scanning electron microscopy and CL......................................... 13

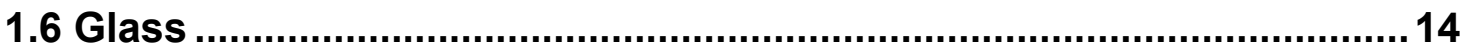

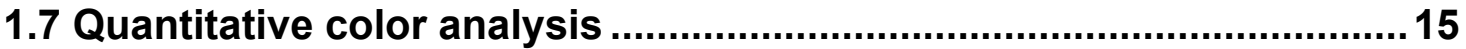

1.7.1 Background information and forensic applications............................15

1.7.2 CIE LAB color space and conversions ............................................16

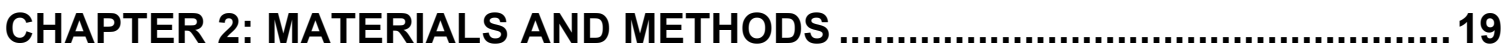

2.1 Method validation and experimental set up .........................................19

2.1.1 SEM/CL operating conditions....................................................... 19

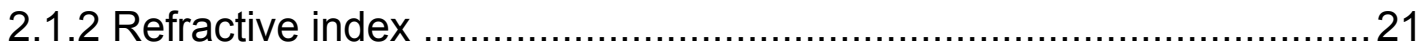

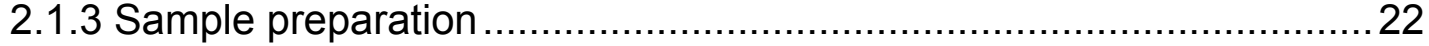




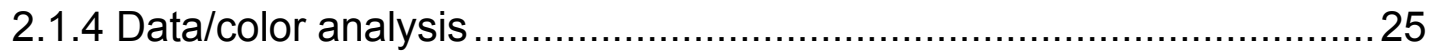

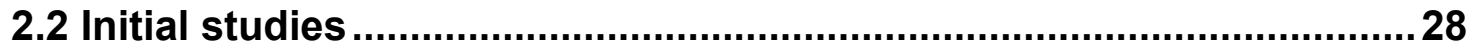

2.3 Color study using standard glass samples ........................................29

2.4 Method validation study using standard samples .............................29

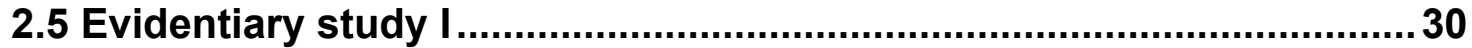

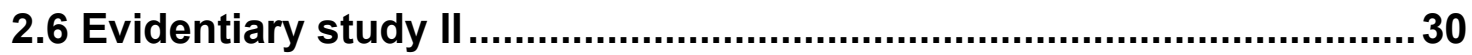

2.7 Window break simulation study ........................................................... 30

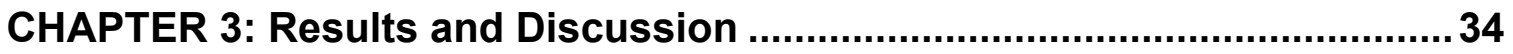

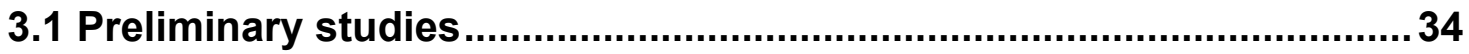

3.2 Method development and validation..................................................... 38

3.3 Refractive index measurements .......................................................... 43

3.4 Evidentiary study I differentiation using $C L$ and LAB coordinates .... 45

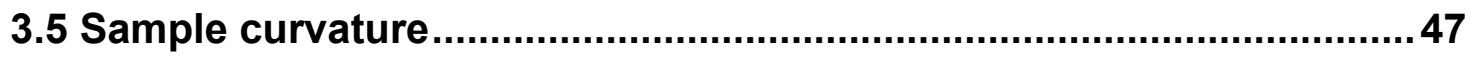

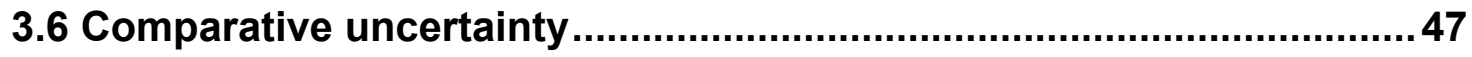

3.7 Evidentiary study II differentiation using CL and LAB coordinates ...51

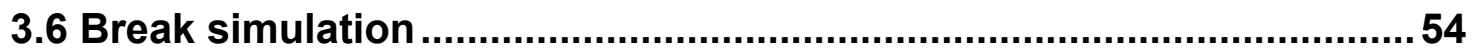

CHAPTER FOUR: Conclusions and Future Work......................................58

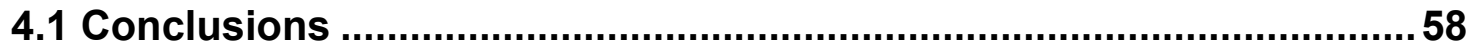

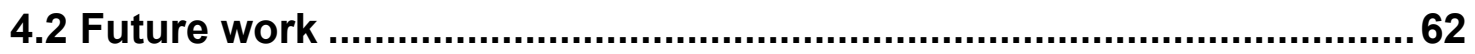

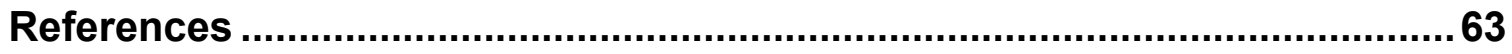

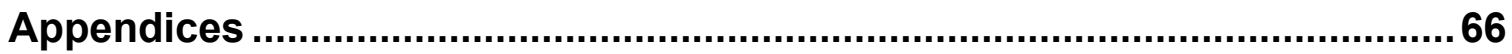




\section{Table of Figures}

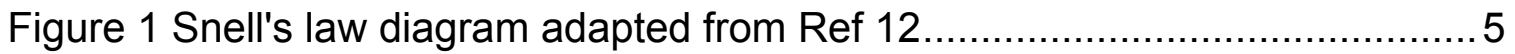

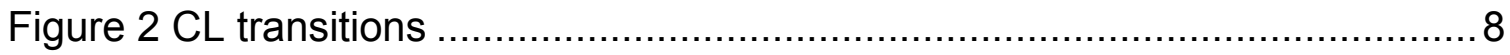

Figure 3 Conversion of luminescent spectrum to $L A B$ values and plotted in $L A B$ space - adapted from Ref. 36 ..................................................... 18

Figure 4 Schematic of light path through MonoCL CL detector ........................19

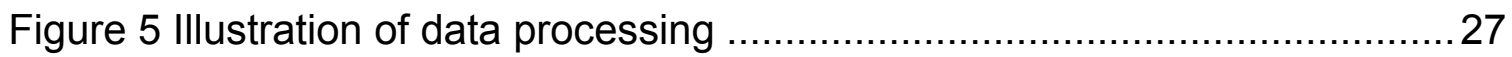

Figure 6 Double sided windowpane before break simulation ........................... 31

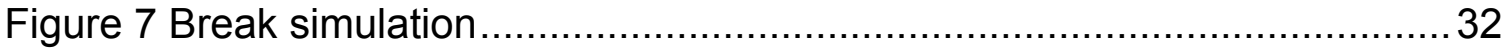

Figure 8 Picture demonstrating sample collection from break simulation ...........33

Figure 9 Spectrum of carbon coated NIST1830 ............................................. 34

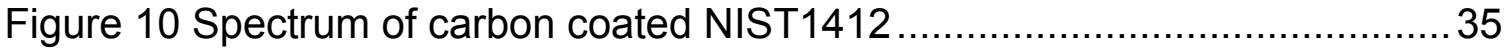

Figure 11 Comparison of NIST1830 and mineral standard ................................36

Figure 12 Comparison of NIST1412 and mineral standard ............................... 37

Figure 13 NIST1830 Sn-side same area and different area spectra ...................39

Figure 14 Comparison of five replicate technique on NIST1830 Sn-side and

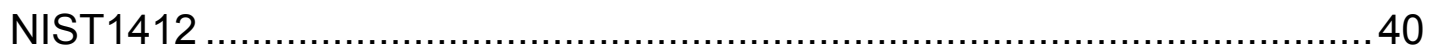

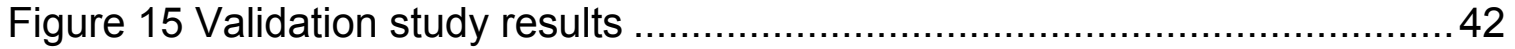

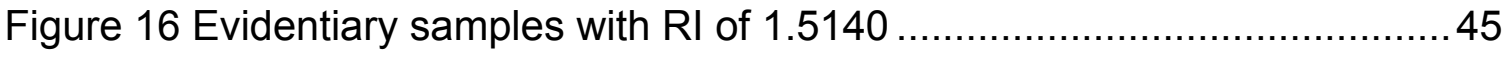

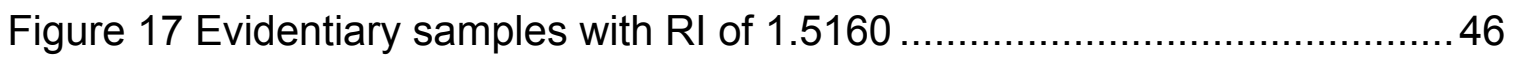

Figure 18 Comparative volume of uncertainty ............................................ 48

Figure 19 intra-sample variations of evidentiary samples ...............................49

Figure 20 intra-sample variations of evidentiary samples over all LAB space ....50

Figure 21 Automobile headlight glasses with RI of $1.474 \ldots \ldots \ldots \ldots \ldots \ldots \ldots \ldots \ldots \ldots . . . .51$

Figure 22 Plot of $L$, $a$, and $b$ values for RI group 1.474 without associated

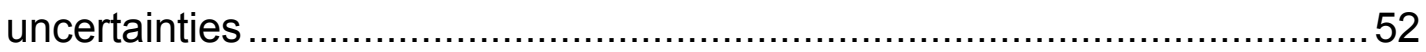

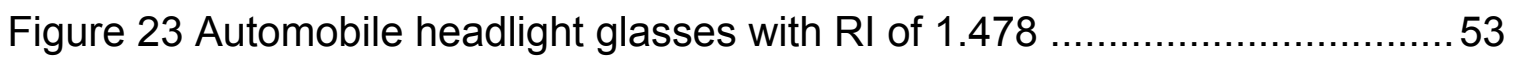

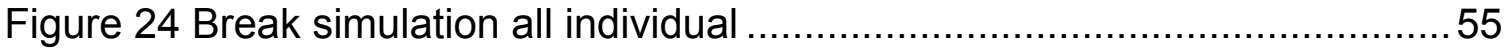


Figure 25 Break simulation all combined - note scale .....................................56

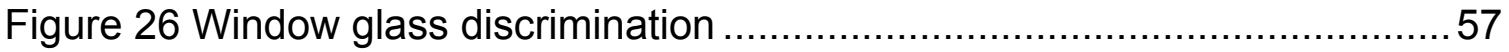

Figure 27 Successive classifications of evidentiary samples from CSC ............60

Figure 28 Successive classifications of headlight glass samples .....................61

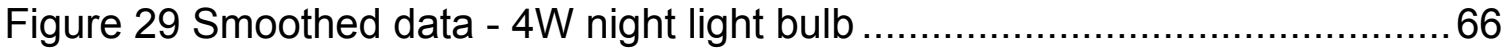

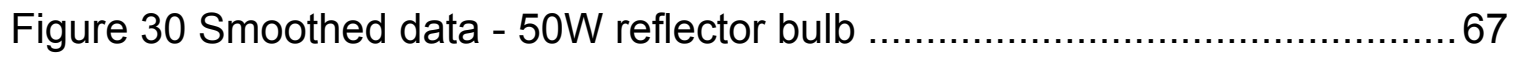

Figure 31 Smoothed data - Decorative bowl ................................................68

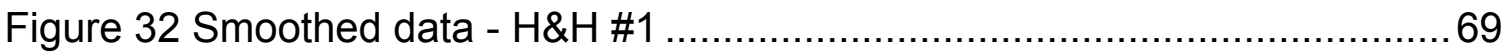

Figure 33 Smoothed data - H\&H \#2 Sn-side ................................................ 70

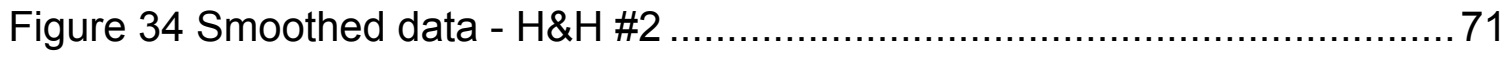

Figure 35 Smoothed data - Holiday cup ................................................... 72

Figure 36 Smoothed data - HumVee glass ................................................. 73

Figure 37 Smoothed data - Listerine bottle ............................................... 74

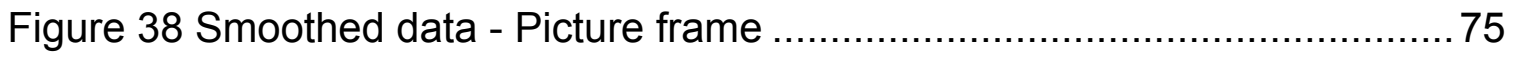

Figure 39 Smoothed data - Drinking glass ………...................................... 76

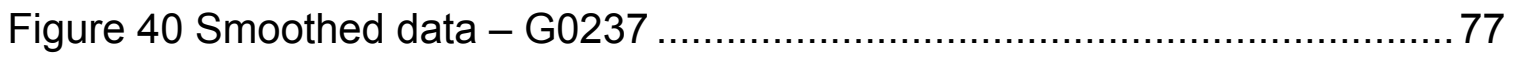

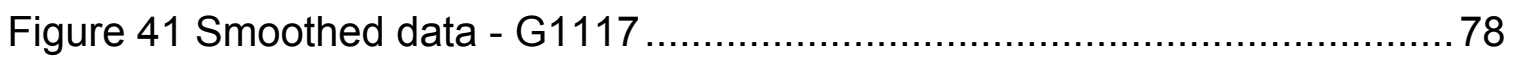

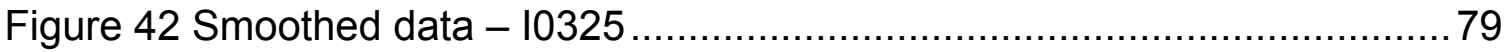

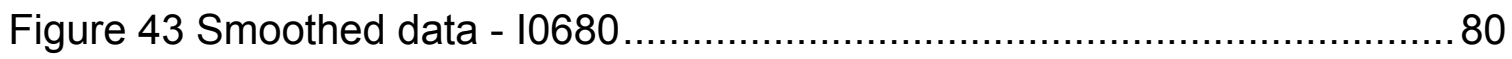

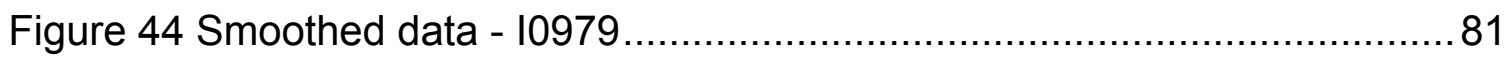

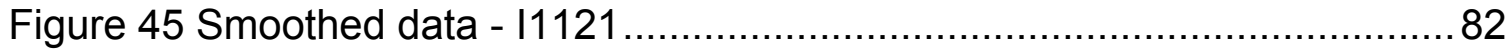

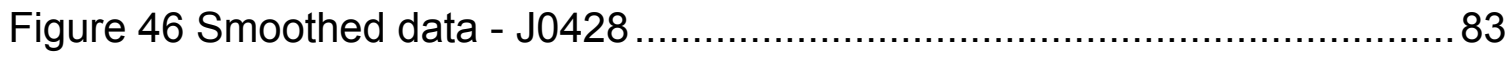

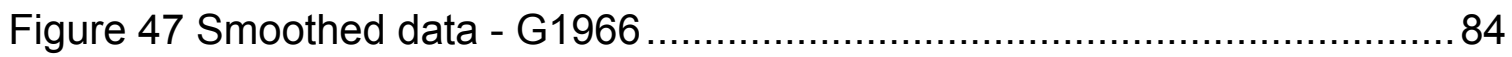

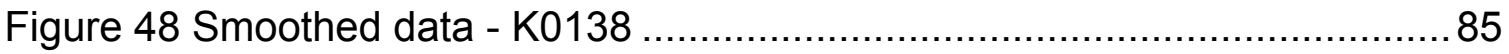




\section{Table of Tables}

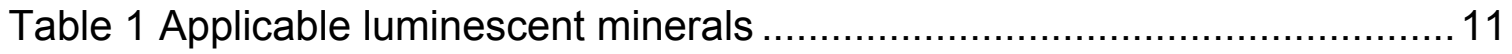

Table 2 Common luminescent bands in glass .............................................. 12

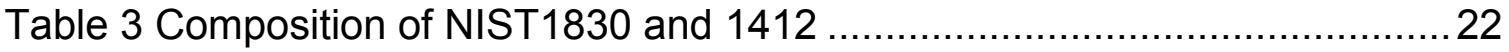

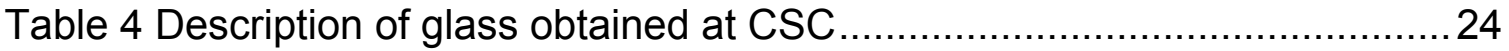

Table 5 Description of automobile headlight samples .....................................25

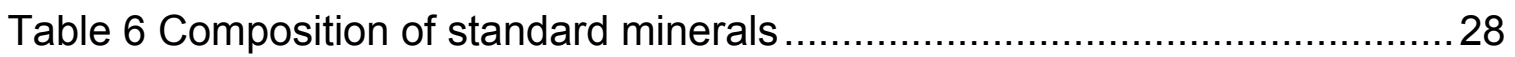

Table 7 Samples collected from break simulation ............................................ 32

Table 8 RI measurements of CSC glass samples........................................ 43

Table 9 RI measurements of automobile headlight glass ................................ 44

Table $10 \mathrm{~L}$, $\mathrm{a}$, and $\mathrm{b}$ values for all break simulation samples...........................54

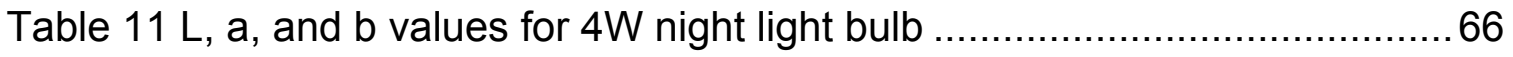

Table $12 \mathrm{~L}$, $\mathrm{a}$, and $\mathrm{b}$ values for $50 \mathrm{~W}$ reflector bulb......................................... 67

Table $13 \mathrm{~L}$, $a$, and $b$ values for Decorative bowl ................................................68

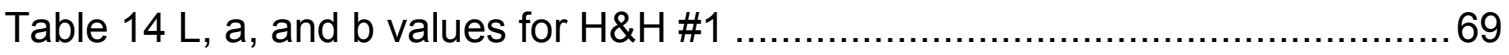

Table $15 \mathrm{~L}$, a, and b values for H\&H \#2 Sn-side ........................................... 70

Table $16 \mathrm{~L}$, $a$, and $b$ values for $\mathrm{H} \& \mathrm{H} \# 2$...................................................... 71

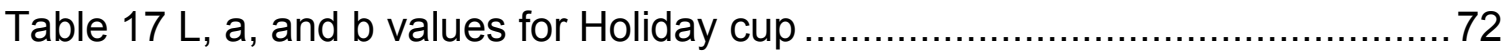

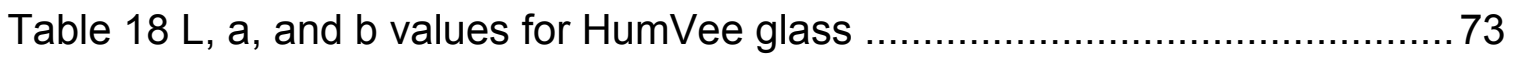

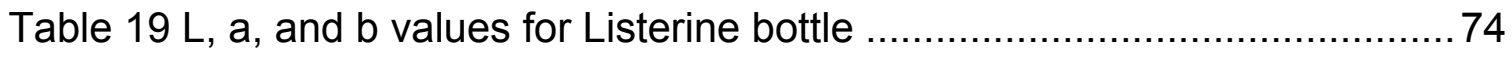

Table $20 \mathrm{~L}$, $a$, and $b$ values for Picture frame ………............................... 75

Table $21 \mathrm{~L}$, $a$, and b values for Drinking glass ............................................... 76

Table $22 \mathrm{~L}$, a, and b values for G0237 .................................................... 77

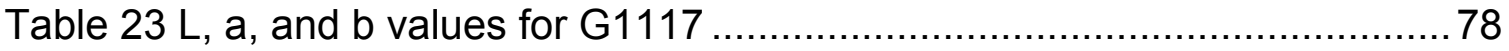

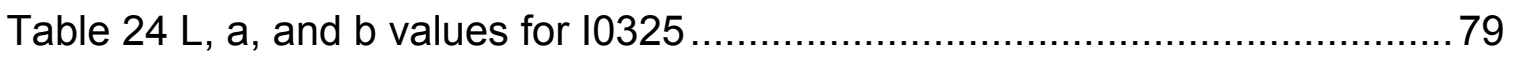

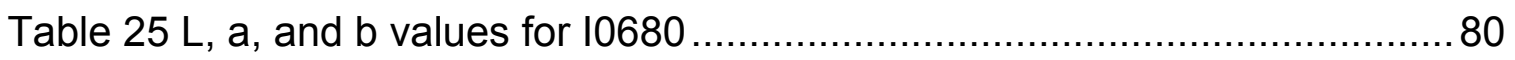

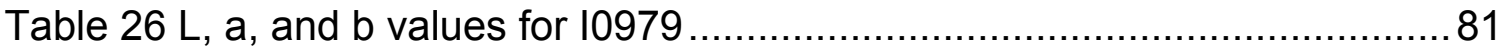

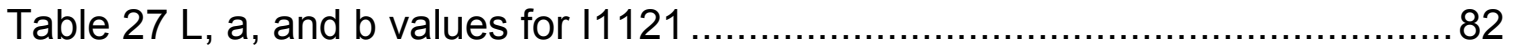




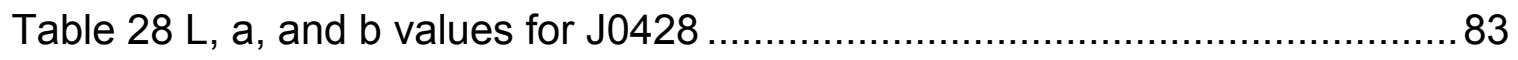

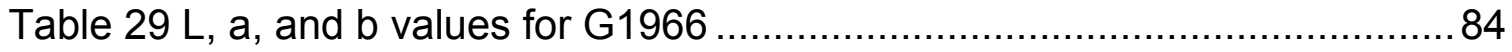

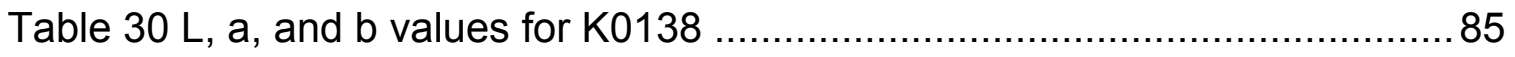




\section{CHAPTER 1: Introduction}

\subsection{Research purposes and goals}

Glass is a common piece of evidence encountered at crime scenes, whether at the scene of a burglary or a hit and run. To preserve the integrity of the evidentiary samples, care must be taken to analyze the samples nondestructively. The purpose of this research is to develop a technique capable of non-destructively analyzing glass evidence.

The goals of this research were:

1. Investigate the use of cathodoluminescence $(\mathrm{CL})$ as a non-destructive technique for forensic glass classification

2. Assess the validity of CL using NIST standard glass samples

3. Validation of methodology of technique using NIST samples

4. Analyze common types of evidentiary glass including household, window, and automobile headlight glass using $\mathrm{CL}$

5. Simulate a breaking and entering scenario and analyze glass collected

6. Apply quantitative color analysis to results obtained

\subsection{Traditional methods of forensic glass analysis}

Forensic glass analysis usually relies on refractive index (RI) measurements and physical matching. Physical matching is possible when two pieces of glass can be fit together, much like a puzzle. Properties such as color and thickness may also be useful in matching glass from a crime scene to a 
piece of control glass. Using oil and microscopy, RI measurements accurate to the third decimal place are common. Some laboratories utilize automated refractive index measurement instrumentation (Glass Refractive Index Measurement or GRIM) capable of providing accuracy to five decimal places and thus greater discrimination between glasses. Unfortunately, the GRIM instrumentation is costly and unavailable to many forensic laboratories. Accordingly, glass evidence often receives less attention than other types of transfer evidence, even though it is a fairly common type of physical evidence [1].

To address this problem, other analytical techniques have been explored. Many of these reports describe elemental analyses such as laser ablation inductively coupled plasma mass spectrometry (LA-ICP-MS) and inductively coupled mass spectrometry (ICP-MS) [2-5], time of flight secondary ion mass spectrometry (TOF-SIMS) [6],scanning electron microscopy equipped with energy dispersive spectroscopy (SEM-EDS) [7] , and phosphorescence [8]. Refractive index has also been combined with elemental techniques for analysis $[9,10]$.

LA-ICP-MS and ICP-MS are both powerful techniques in that they are capable of detecting a host of elements at trace levels, in the $\mathrm{ng} / \mathrm{g}$ to low $\mu \mathrm{g} / \mathrm{g}$ range. A disadvantage of using ICP-MS is the need for harsh acid digestion of glass samples. This advantage is overcome by using LA-ICP-MS, which is capable of analyzing solid samples. A disadvantage to LA-ICP-MS, however, is elemental fractionation which results in ablation products that are not stoichiometrically comparative to sample composition [2-5]. TOF-SIMS is a 
relatively new analytical technique used to analyze glass. Current research confirms previous findings about variation of RI of float and non-float surfaces of glass compared to the RI of the bulk. Work is continuing with this technique [6].

SEM-EDS is another powerful technique that has shown much success in differentiating glass samples. One study analyzed a sample set comprised of 81 samples. The authors compared elemental ratios, such as $\mathrm{Zn} / \mathrm{Ca}, \mathrm{As} / \mathrm{Ca}$, and $\mathrm{Sr} / \mathrm{Ca}$ as a means for discrimination. Results from this study demonstrate that combining refractive index measurements with elemental analysis techniques is a powerful combination that allows for more discrimination than by using refractive index alone [7].

Some success has been found with phosphorescence analysis. One study showed that there appears to be no correlation between refractive index and phosphorescent characteristics of a sample. Therefore, refractive index and phosphorescence may be seen as complimentary methods. A downside to phosphorescence is the need for low temperature analysis, as well as sample size constraints [8].

\subsection{Forensic analysis goal}

The goal of forensic analysis of trace evidence, such as glass, is to link a known sample to a questioned sample. This is achieved through successive classification. In glass analysis, for example, physical matching or refractive index may be the first step of an analysis. Several samples may be classified using one of these two methods alone. Remaining samples may then be analyzed using another elemental technique as described above to further 
classify samples. The end goal of a forensic analysis is to link a questioned sample to a known sample, or associate a level of uncertainty that two samples may have originated from a common source.

\subsection{Refractive Index}

\subsubsection{Chemical and physical basis}

When light interacts with the surface of a piece of glass, the light is partially transmitted and partially reflected. Refraction occurs in the transmitted part and is characterized by the refractive index of a material. Refractive index $(\eta)$ is defined as the ratio of the velocity of light in the medium of interest to the velocity of light in a vacuum. Refractive index is also related to the frequency of electromagnetic (EM) radiation hitting the surface of a material [11].

Glass responds to this high frequency EM radiation via coupling of electrons in the glass to the oscillating electric field. The refractive index is related to the dielectric constant of the system. The refractive index is dependent on the chemical composition of the glass. Refractive index may also be influenced during the manufacture of glass - during glass production, glasses undergo an increase in density and consequently refractive index increases [11].

When light passes from a less dense medium to a denser medium, the light bends toward the normal to the interface. This situation is shown in Figure 1. The light bends away from the normal if it travels from a more dense medium to a less dense medium. 


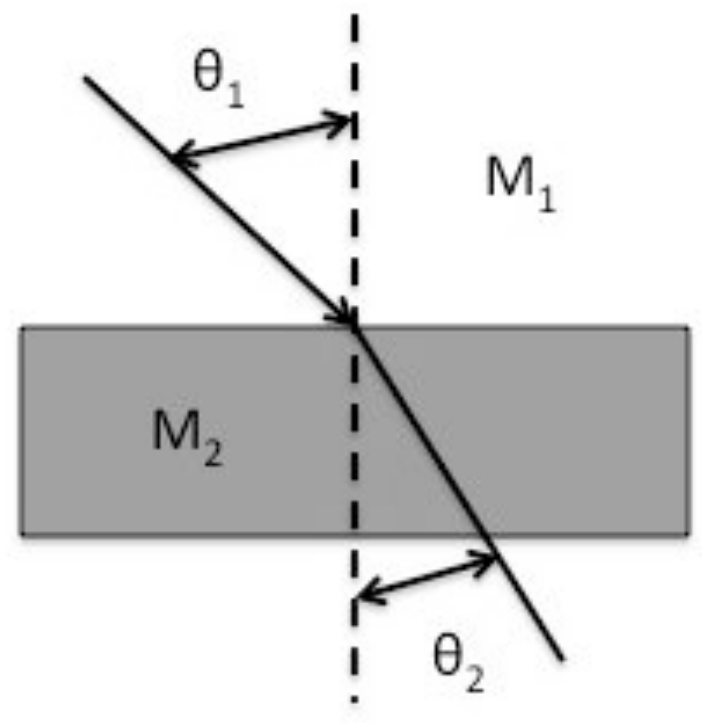

Figure 1 Snell's law diagram adapted from Ref 12

Snell's law describes refractive index. The following relationships describe refractive index: $\sin \theta_{1} / \sin \theta_{2}=\eta_{1} / \eta_{2}=v_{1} / v_{2}$. Refractive indexes are generally measured and reported in air, therefore the above relationship may be rearranged to give: $\left(\eta_{2}\right)_{\text {air }}=\left(\sin \theta_{1}\right)_{\text {air }} / \sin \theta_{2}$. Calculations may then be made to determine the refractive index of a material [12]. In the lab, refractive index measurements may be performed using density gradients.

\subsubsection{Utility in forensic science}

$\mathrm{RI}$ has been used in the analysis of glass samples for decades in forensic science $[13,14]$. Research has shown that the surface RI may be different than that of the bulk glass. In regards to float glass, the RI of the float surface may be higher than the bulk glass and the non-float surface may be lower than the bulk glass [15]. The results were obtained using GRIM instrumentation and therefore 
the variation was seen in the third decimal point. Another study confirmed that RI of the float surface of a piece of glass differs from that of the bulk. The same study also found that the RI varies amongst recovered glass and control glass for a particular crime scene [16]. Thus, RI measurements can be problematic.

To improve discrimination powers, $\mathrm{RI}$ has also been combined with instrumental techniques for discrimination. The narrow range of refractive index of some glass types has made difficult the discrimination of glass based on RI alone. Window glass, for example, has a RI range of 1.515 to 1.518 , which make discrimination between window glasses difficult [11].

Discrimination may be possible when $\mathrm{RI}$ is paired with other instrumental techniques. In one study, RI was highly varied from fragments across a pane of glass. When the RI results were combined with results from energy dispersive spectroscopy and emission spectrography results, most fragments were successfully discriminated, thus improving the discrimination power [11].

\subsection{Cathodoluminescence}

\subsubsection{Background and history of cathodoluminescence}

Cathodoluminescence $(\mathrm{CL})$ is a promising non-destructive alternative for forensic glass analysis. Luminescence can be induced when high-energy electrons (10-20 kV) impact a surface, causing the emission of light in the visible, near-infrared, and infrared regions of the electromagnetic spectrum. The first publication mentioning CL was in 1869 by Crookes [17]. Widely used in geological sciences, CL has been applied to determine structures of minerals, 
pottery, ceramics, and in the semi-conductor industry for the characterization of defects. Characteristic CL spectra of rare earth elements have been investigated using various minerals such as calcite, zircon, and carbonates. CL is also widely used to determine mineral growth. While CL spectroscopy is used in geological work, CL microscopy has also been applied to determine emission colors of various rare earth element-containing minerals. In the semi-conductor industry, $\mathrm{CL}$ is applied to determine thickness variations in quantum wells of semiconductors as well as determining various impurities that may be present in a semi-conductor [18-21].

\subsubsection{Theory and principles}

The mechanism of cathodoluminescence is complex and therefore not completely understood. CL is a surface technique, with an electron penetration depth of 2-3 nm [22]. Under electron bombardment, electrons in the solid sample can be excited from the valence band to the conductance band of a material. The valence band is formed by the overlap of the highest occupied molecular orbitals of adjacent atoms of a material. This band contains the valence electrons of all the atoms. Empty outer orbitals or the lowest unoccupied molecular orbitals, on the other hand, overlap to form the conductance band [12]. Relaxation of the excited state can follow several paths, leading to different types of luminescence.

While $C L$ is not fully understood, the general principle involves the transition of valence band electrons as shown in the schematic in Figure 2. 


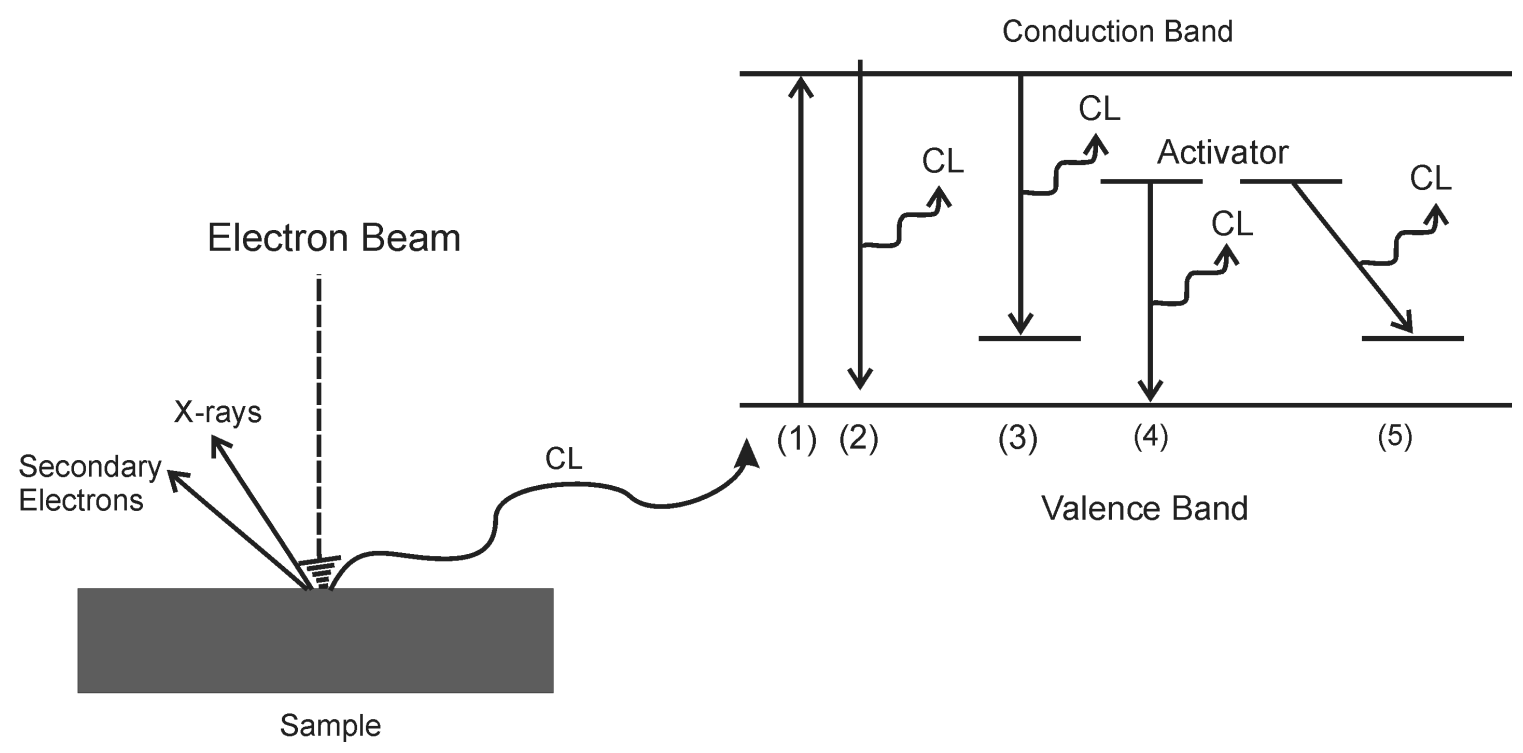

Figure 2 CL transitions

Transition 1 in the diagram is the excitation of an electron from valence band to conduction band. Transition 2 is associated with the direct electron-hole recombination. This recombination results in intrinsic luminescence. This intrinsic luminescence results from direct recombination of electron hole pairs and is generally associated with the lattice of the material being bombarded. The energy of this transition is equal to the band gap energy of the material, $E_{g}$. Intrinsic luminescence is sometimes weak and may be masked by extrinsic luminescence [23, 24].

The recombinations shown in transitions $3-5$ occur in the in energy levels of the band gap, otherwise known as the forbidden zone. Additional energy levels are therefore present for transitions to occur. These recombinations are characteristic of activators that may be present in a material, such as rare earth elements or transition metals, and are termed extrinsic luminescence. Activators serve to assist weakly luminescent materials by increasing luminescence. This 
luminescence has a higher likelihood of occurring due to the multiple pathways through which an electron may relax back to the valence band and is the reason why extrinsic luminescence is generally stronger than intrinsic luminescence. Intrinsic luminescence commonly results in broad spectral bands, while extrinsic luminescence results in sharp spectral lines [25].

Both intrinsic and extrinsic luminescence produces peaks in a CL spectrum. However, unlike Moseley's law for peak positioning in energy dispersive spectroscopy that assigns a characteristic peak in the spectrum based on atomic number of an element, there is no law governing the position of peaks in a CL spectrum. This limitation hinders widespread use of the CL technique [25].

Extrinsic luminescence is generally due to the presence of transition metals or rare earth elements. These elements emit and absorb strongly in the visible range. Partially filled $3 \mathrm{~d}$ shells are characteristic of transition metals, while partially filled $4 \mathrm{f}$ shells are characteristic of rare earths. The partially filled shells allow for shielding by the outer electron shells. This shielding effect means that the energy levels are not strongly altered by the crystal field due to other ions present in a material. This results, therefore, in relatively narrow $\mathrm{CL}$ spectral lines [26].

The energy and width of each peak are dependent on the temperature, pressure, and interaction between the activator ion and lattice ions. At room temperature, CL bands may be broadened by coupling of the localized energy levels of the activator to the lattice vibrations of the material. CL emissions are 
therefore affected and broadened by the host crystal [25]. This broadening may be circumvented by cooling samples to liquid helium temperatures which reduces vibrations in the lattice of the sample and allows for more defined peaks to be resolved. This is critical in applications where peak positioning of luminescent centers is necessary [24].

For practical applications of CL, interest lies in peak broadening and shifts due to the crystal field strength of the material $\left(D_{q}\right)$. Crystal field strength is determined by investigating the influence of the ligands of an activator or the crystal structure on the energy levels of the activator ions. Some activators have a strong effect on the surrounding crystal and may therefore lose energy through vibrational energy. The energy loss happens in the time between the activator excitation by an electron and emission of a photon. A Stoke's shift, which is a wavelength shift to lower frequencies, occurs because of the decrease in emission energy in comparison to excitation energy. An activator's peak positioning is therefore dependent upon on its interaction with the surrounding crystal structure, which may cause the peak to be shifted [24]. This peak shift may be useful in assigning peak positions. Many luminescent systems have been identified and peaks have been assigned. These characterizations have mainly been carried out on rare earths present in a material [22].

Some rare earths feel only a weak interaction with the surrounding crystal field due to shielding by $5 p$ and 6 s electrons. The peak position of these rare earths is relatively consistent, therefore making their identification relatively easy [24]. In addition to activators, there are also elements that function as 
quenchers. Quenchers have the opposite effect of activators by decreasing luminescent signal. Some examples of sensitizers and quenchers have been characterized. $\mathrm{Mn}^{2+}$ has been identified as an important activator in carbonates, while $\mathrm{Fe}^{2+}$ has been identified as a quencher [27]. $\mathrm{Fe}^{2+}$ has shown to be an effective quencher in calcite [28].

\subsubsection{Luminescent minerals}

There are many luminescent minerals that may be analyzed via CL. Minerals of interest to this research are included in Table 1.

\begin{tabular}{|c|c|c|}
\hline Mineral & Formula & Luminescent region \\
\hline Quartz & $\mathrm{SiO}_{2}$ & Blue \\
\hline Zincite & $\mathrm{ZnO}$ & Blue \\
\hline
\end{tabular}

Table 1 Applicable luminescent minerals

A study by Townsend, et al [21], identified at least 10 similar emission bands from silica glass, crystalline quartz, and float glass. These bands occur in the range of $300-800 \mathrm{~nm}$ and are outlined in Table 2 . 


\begin{tabular}{|c|c|}
\hline Clear float glass & Silica and quartz \\
\hline $299 \mathrm{~nm}$ & $400 \mathrm{~nm}$ \\
\hline $337 \mathrm{~nm}$ & $417 \mathrm{~nm}$ \\
\hline $368 \mathrm{~nm}$ & $440 \mathrm{~nm}$ \\
\hline $400 \mathrm{~nm}$ & $465 \mathrm{~nm}$ \\
\hline $440 \mathrm{~nm}$ & $510 \mathrm{~nm}$ \\
\hline $465 \mathrm{~nm}$ & $535 \mathrm{~nm}$ \\
\hline $535 \mathrm{~nm}$ & $625 \mathrm{~nm}$ \\
\hline $625 \mathrm{~nm}$ & $650 \mathrm{~nm}$ \\
\hline $725 \mathrm{~nm}$ & \\
\hline
\end{tabular}

Table 2 Common luminescent bands in glass

These bands may be due to intrinsic electron-hole recombinations or intrinsic oxygen defect sites within the silicate structural unit. These bands were identified using deconvolution techniques, as the CL spectra that result from glass exhibit broad peaks, which are characteristic of intrinsic luminescence [21].

\subsubsection{Instrumentation}

There are two main sources of electrons for CL: cold cathode and hot cathode. Cold cathode CL is commonly performed using an external electron source coupled to an optical microscope. There is no high vacuum involved in cold cathode CL. Therefore, the air that is introduced around the sample serves to dissipate any charge that may build up on the surface of the sample. An advantage of this method is that the sample does not have to be carbon coated. A disadvantage, however, is the low luminescence response from some materials.

Hot cathode CL, on the other hand, is operated with a heated filament under vacuum. This is achieved by coupling $C L$ to a scanning electron microscope (SEM), an instrument widely used and reasonably available to the 
forensic community. Since the SEM is operated under vacuum, it may be necessary that samples receive a thin coating of carbon to dissipate any charge that may accumulate on the surface. The electron beam is more intense in hot cathode CL and may result in more signal [24]. The present study used variable pressure SEM, which may be likened to cold cathode $C L$ in that air is introduced into the chamber to assist in the dissipation of charge buildup on the surface of the sample.

\subsubsection{Scanning electron microscopy and CL}

The combination of scanning electron microscopy (SEM) and CL is a powerful one. Electrons may be generated in the SEM via thermionic emission or the heating of a hairpin tungsten filament to very high temperatures. Current is applied across a tungsten hairpin filament and accelerating voltages range anywhere from 1 to $30 \mathrm{kV}$. Secondary electron images (SEI) may be acquired which gives insight to the topographical nature of samples. Comparison of SEI and $\mathrm{CL}$ images may provide more information about the sample. Depending on the nature of the detector used in the CL system, color images may be acquired. This allows for determination of luminescence color directly from the image. Grayscale images may also be collected and bright areas indicate high luminescence intensity.

Sample preparation for SEM is relatively simple. Samples may be coated with a thin coating of gold or carbon in an effort to make the sample more conductive. Once coated, samples are placed on a conductive sample holder 
with either carbon or copper tape. The sample may then be analyzed in the SEM.

The electrons that are generated by the SEM are able to excite luminescence as previously described. The ability to analyze samples in either high vacuum mode with a conductive coating or in variable pressure mode with the possibility of no coating greatly increases the sample types that may be analyzed in the SEM. Since glass is an insulator, variable pressure mode is ideal for the present application.

\subsection{Glass}

The first $\mathrm{SiO}_{2}$ glass was produced in 1839 by Gaudin [29]. Glass may be defined as "an inorganic product of fusion which has cooled to a rigid condition without crystallizing [30]." The basic building block of silicate glass is the silicate tetrahedron. Each tetrahedron contains a silicon atom surrounded by four oxygen atoms. The $\mathrm{SiO}_{4}$ tetrahedron is electronically capable of forming complex silicates. This occurs through complete saturation of the oxygen atoms with electrons. This can occur through one of two ways: neutralization by metals joining the tetrahedron or connection of the tetrahedra through oxygen bridges which results in an octet of electrons [29].

Zachariasen formulated the first theory that gained universal acceptance on glass structure in 1932. Zachariasen devised a set of rules for glass formation. Using these rules, glass may be considered as a random network of oxygen polyhedra that lacks periodicity. Zachariasen's model is therefore referred to as the continuous random network (crn) [29]. Network modifiers may 
be added to a glass, which may break a Si-O-Si linkage. An example of such a network modifier is $\mathrm{Na}_{2} \mathrm{O}$ [12].

One specialized type of glass is float glass. During glass production, one side of the glass is in constant contact with a molten tin bath. The glass is held at a high temperature in order for irregularities to melt out and the tin serves to create a very flat piece of glass. Because tin is reactive with oxygen, the glass is held in a reducing atmosphere of nitrogen and hydrogen [31]. The tin side of a piece of float glass may be identified by fluorescence when placed under a UV light.

Glass is an insulator, which is capable of emitting light in the visible range. The characteristic band gap of insulators, or glass, is wide. These band gaps are in the range of 3 to $3.5 \mathrm{eV}[26]$.

\subsection{Quantitative color analysis}

\subsubsection{Background information and forensic applications}

Quantitative color analysis, based on reflectance spectra obtained in the visible range, has been used as part of trace evidence studies for decades. Recent examples include classification of fiber evidence $[32,33]$ and inks [34, 35]. Quantitative color analysis was first proposed in 1931 by the Commission Internationale d'Eclairage (CIE). Starting from a reflectance spectrum and tables of weights, the spectrum can be converted to weighted combinations of red, green, and blue, which are referred to as tristimulus values. These values may be further converted to a symmetrical space using coordinates referred to as CIE 
LAB. This is one of many conversions and color spaces that can be utilized, but it was selected for this research given its widespread use in forensic science. In this color space, the $L^{*}$ value refers to lightness, while $a^{*}$ and $b^{*}$ describe the hue of the color in terms of red, green, yellow, and blue. For purposes of this work, the luminescent spectrum was treated as a reflectance spectrum. The use of the color space takes out the subjectivity of color [36]. This quantitative color analysis is a specialized type of principal component analysis.

Under the electron bombardment, glasses emit in the UV to near IR regions, $\sim 300-800 \mathrm{~nm}$. Strong emissions are often seen in the visible range of 400-700nm. In effect, by submitting glass to cathodoluminescent conditions, colorless physical evidence takes on color that depends on the mineral content and distribution in the glass.

\subsubsection{CIE LAB color space and conversions}

The conversion of a luminescent spectrum to $L A B$ values and $C I E L A B$ color space is depicted in Figure 3 below. From the initial luminescent spectrum, a smoothed spectrum may be obtained. ASTM tables used for the conversion of reflectance intensity are based reflectance values in the range of 400 to $700 \mathrm{~nm}$ at $10 \mathrm{~nm}$ increments, requiring that the original spectra collected in $1 \mathrm{~nm}$ increments be smoothed and simplified. Tristimulus values may then be calculated using standard observer curves, reflectance at each wavelength, and the power at each wavelength. The tristiumulus values may then be converted to $L A B$ values and plotted in $L A B$ space. 
As can be seen, $a^{*}$ values are from the range of red to green, and $b^{*}$ values are from the range of yellow to blue [37]. Tristiumlus values are calculated from the reflectance, $R$, at each wavelength, values from standard observer curves, and a weighting factor, $P$. The further conversion to $L A B$ coordinates includes the use of values $X_{n}, Y_{n}$, and $Z_{n}$. These values are calculated using a perfect diffuser, or white reference [36]. 


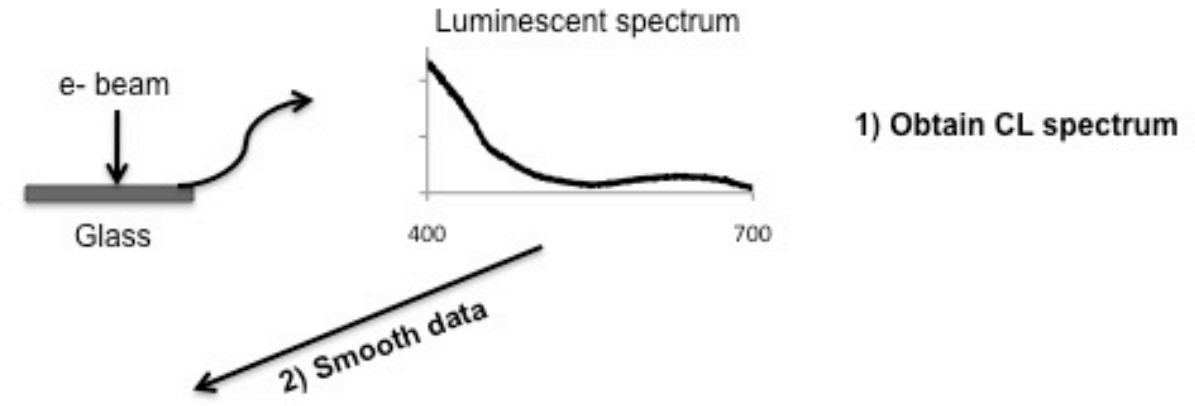

Original data
\begin{tabular}{|l|l|}
\hline 400 & 165190 \\
\hline 401 & 165263 \\
\hline 402 & 160911 \\
\hline 403 & 165017 \\
\hline 404 & 161763 \\
\hline 405 & 159377 \\
\hline 406 & 161665 \\
\hline 407 & 157262 \\
\hline 408 & 156844 \\
\hline 409 & 157175 \\
\hline 410 & 153121 \\
\hline
\end{tabular}

$$
\text { Smoothed data }
$$

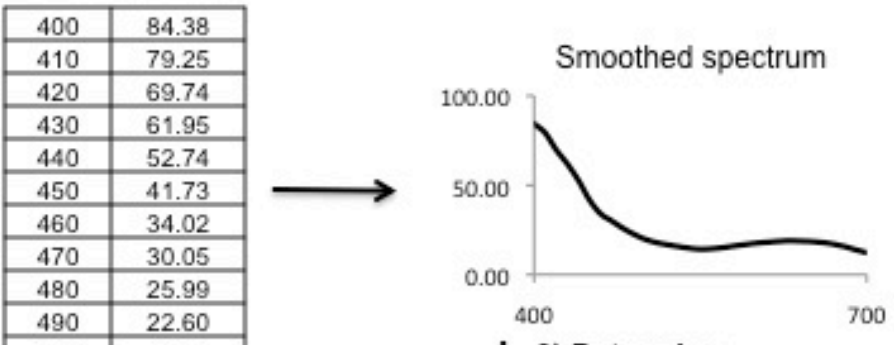

\begin{tabular}{|l|l|l|}
500 & 19.82 & 3 Determine
\end{tabular} illumination and degree

\begin{tabular}{rrrc} 
& $\mathbf{P} \overline{\mathbf{x}}$ & $\mathbf{P} \overline{\mathbf{y}}$ & $\mathbf{P} \overline{\mathbf{z}}$ \\
\hline 400 & 0.251 & 0.023 & 1.090 \\
420 & 3.232 & 0.330 & 15.383 \\
440 & 6.679 & 1.106 & 34.376 \\
460 & 6.096 & 2.620 & 35.355 \\
480 & 1.721 & 4.938 & 15.897 \\
500 & 0.059 & 8.668 & 3.997
\end{tabular}

$X=R_{\lambda}^{*} P_{\lambda} \cdot \bar{x}=21.3450$

$Y=R_{\Lambda}^{*} \cdot P_{\hat{\lambda}} \cdot \bar{y}=17.9053$

$Z=R_{\lambda}^{*} P_{\lambda}^{*} \bar{z}=46.8523$

5) Convert $X Y Z$ to

$\mathrm{LAB}$ values

$\mathrm{L}=116 /\left(\mathrm{Y} / \mathrm{Y}_{n}\right)^{1 / 3}-16=49.381$

$\mathrm{A}=500\left\{\left(\mathrm{X} / \mathrm{X}_{n}\right)^{1 / 3}-\left(\mathrm{Y}-\mathrm{Y}_{n}\right)^{1 / 3}\right\}=22.3974$

$\mathrm{B}=200\left\{\left(Y_{/} / Y_{n}\right)^{1 / 3}-\left(Z^{\prime} / Z_{n}\right)^{1 / 3}\right\}=-39.003$

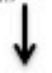

6) Plot values

in $\mathrm{LAB}$ space

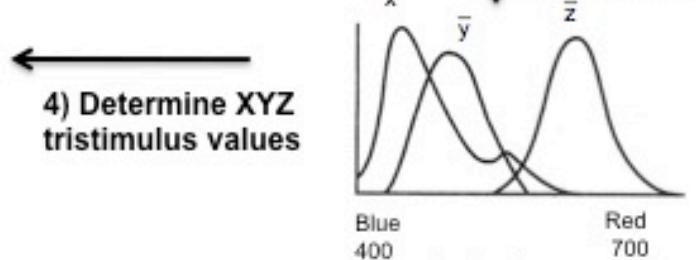

Standard observer curves

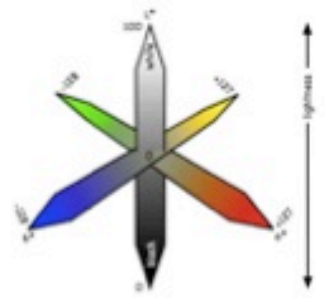

Figure 3 Conversion of luminescent spectrum to $L A B$ values and plotted in $L A B$

space - adapted from Ref. 37 


\section{CHAPTER 2: MATERIALS AND METHODS}

\subsection{Method validation and experimental set up}

\subsubsection{SEM/CL operating conditions}

Analysis of all glass samples was carried out using a JEOL JSM6490-LV scanning electron microscope (JEOL Inc, Tokyo, Japan) equipped with a Gatan MonoCL cathodoluminescence detector (Gatan, Inc, Pleasanton, CA). The MonoCL system is composed of a monochromator and PMT. A schematic is shown in Figure 4.

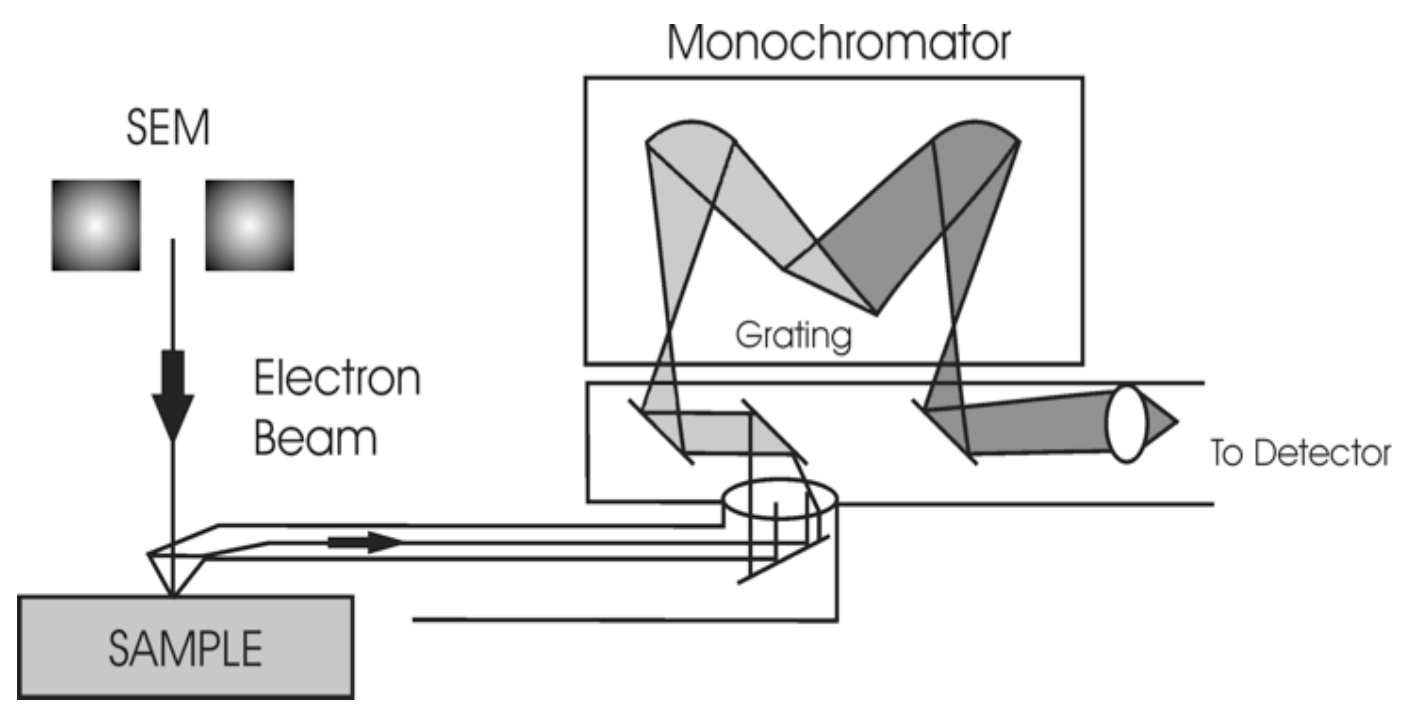

Figure 4 Schematic of light path through MonoCL CL detector

The light is collected using a diamond turned parabolic mirror, collimated, and either directly focused onto the PMT or sent through entrance slits to a monochromator. There are two modes of operation: panchromatic and monochromatic. The panchromatic mode allows for all wavelengths of light to simultaneously hit the detector and the light is not sent through the 
monochromator. The monochromatic mode only allows one wavelength of light through to the PMT, dependent upon the instrument settings. The monochromator is a $300 \mathrm{~mm}$ Czerny-Turner monochromator, with a diffraction grating of 1200 lines $/ \mathrm{mm}$.

The CL software performs a self-calibration upon launch. The grating is motor driven and is moved to a pre-designated position. This position is preprogrammed so that no user input is needed. Wavelength calibration can also be performed using an $\mathrm{Hg}$ lamp placed in the light path. This calibration is done upon installation. This calibration was performed when the system was installed before starting any work. Aside from these two calibration schemes, no calibration standard has been found to be universal for CL [39].

The spectra were obtained using the variable pressure mode of the SEM. This mode allows for atmosphere to be introduced into the chamber to assist in ionizing the charge build up on the surface of a sample. The chamber pressure was set to $30 \mathrm{~Pa}$. Each sample was analyzed using an accelerating voltage of $20 \mathrm{kV}$. A magnification of 500X was used, which allowed for an area of 400 by 175 micrometers to be analyzed. Spot size, which is unit less and may be roughly defined as the size of the electron spot rastering across as sample, was in the range of 60-70 and was dependent upon the sample. Spot size ranges from $0-100$. Instrumental parameters were set so that enough beam current was generated to excite $\mathrm{CL}$ emission. There is no way of measuring beam current in the current instrumental set up. 
The following process was used to optimize signal and acquire spectral data from samples. Spectra were obtained in the range of $300-800 \mathrm{~nm}$, with a dwell time at each wavelength of 3 seconds and step size of $1.0 \mathrm{~nm}$. PMT voltage was set at $\sim 950$ volts for each analysis. This voltage is approximate because voltage is not set by the software, but rather adjusted by the user turning a knob to adjust the voltage. The optimal voltage was chosen by first acquiring a rough spectrum of the sample. The highest peak was identified and the monochromator was driven to this point. The voltage was then adjusted to maximize the signal at this point. The feature at $391 \mathrm{~nm}$ was chosen for optimization. Total spectral acquisition time for each sample was 30 minutes. Each spectrum was collected in a range of $300-600 \mathrm{~nm}$ and $500-800 \mathrm{~nm}$ and subsequently spliced together. This overlap was satisfactory in that no spectral features were lost during splicing. Slow acquisition times were chosen due to the natural slow response time of the PMT.

\subsubsection{Refractive index}

Refractive index (RI) measurements were made using the Becke line method, which employed an Olympus 31X optical microscope (Olympus America, Inc, Center Valley, PA) and a series of Cargille Certified Refractive Index Liquids (Cargille Lab, Cedar Grove, NJ). The Becke line method is a procedure in which the glass sample of interest is bracketed by the two closest $\mathrm{RI}$ oils. If the RI of the oil is larger than the of the glass, the Becke line, or halo of light seen at the edge of the sample, seems to move out of the glass piece upon 
focusing the sample. Conversely, if the RI of the glass is larger than that of the oil, the halo moves into the glass upon focusing.

Samples were broken into fine pieces using a brown paper bag or piece of white paper and hammer. Small amounts of each sample were mounted on a glass slide with varying refractive index oils. Using the Becke line method, refractive indices accurate to three decimal places were obtained.

\subsubsection{Sample preparation}

Glass samples were obtained from National Institute of Standards and Technology (NIST, Gaithersburg, MD). These samples included NIST1412 (multi-component glass) and NIST1830 (soda-lime float glass) (Table 3).

\begin{tabular}{|c|c|c|}
\hline Constituent & NIST1830 (wt \%) & NIST1412 (wt \%) \\
\hline $\mathrm{SiO}_{2}$ & $73.04+/-0.04$ & $42.38+/-0.18$ \\
\hline $\mathrm{Na}_{2} \mathrm{O}$ & $13.75+/-0.06$ & $4.69+/-0.07$ \\
\hline $\mathrm{CaO}$ & $8.56+/-0.06$ & $4.53+/-0.10$ \\
\hline $\mathrm{MgO}$ & $3.90+/-0.04$ & $(4.69)$ \\
\hline $\mathrm{SO}_{3}$ & $0.26+/-0.01$ & ---- \\
\hline $\mathrm{Al}_{2} \mathrm{O}_{3}$ & $0.12+/-0.02$ & $7.52+/-0.24$ \\
\hline $\mathrm{Fe}_{2} \mathrm{O}_{3}$ & $0.121+/-0.003$ & $(0.031)$ \\
\hline $\mathrm{FeO}$ & $0.032+/-0.032$ & ----- \\
\hline $\mathrm{K}_{2} \mathrm{O}$ & $0.04+/-0.01$ & $4.14+/-0.10$ \\
\hline $\mathrm{TiO}_{2}$ & $0.011+/-0.001$ & ----- \\
\hline $\mathrm{SrO}_{\mathrm{Li}} \mathrm{O}$ & ------ & $4.55+/-0.09$ \\
\hline $\mathrm{B}_{2} \mathrm{O}_{3}$ & ------- & $(4.50)$ \\
\hline $\mathrm{BaO}$ & ---------- & $4.53+/-0.17$ \\
\hline $\mathrm{ZnO}$ & ---------- & $4.67+/-0.16$ \\
\hline $\mathrm{PbO}$ & ---------- & $4.48+/-0.12$ \\
\hline $\mathrm{CdO}$ & ------- & $4.40+/-0.17$ \\
\hline
\end{tabular}

Table 3 Composition of NIST1830 and 1412 
NIST samples were used in preliminary studies, method development, and method validation. These samples were simply mounted on a SEM stub with carbon tape and analyzed. No cleaning prior to analysis was performed because samples were received in a sealed sample bag. NIST1830 was subjected to UV light to determine which side contained residual tin from the float process, as described in chapter 1 . This was done to distinguish the sides for analysis. It has been shown that the two different sides can be differentiated spectroscopically, however [21, 24].

Because $C L$ is a surface technique, one piece of each glass was also coated with a thin layer of carbon to determine the effects on the CL emission. The carbon coating was of unknown thickness, as the laboratory performing the coating did not own a thickness monitor. One piece of each glass was also analyzed without carbon coating.

Ten glass samples were obtained from the Crime Scene Complex (CSC) on the West Virginia University campus. The samples are identified in Table 4. Samples ranged from window glass and container glass to window glass from a HumVee. Samples were individually broken in brown paper bags with a hammer to decrease sample size and stored in a plastic jar until clean as per the following procedure.

Because $C L$ is a surface technique, each glass sample was put through a rigorous cleaning process to ensure that the sample surface was free of any contaminants. After samples were broken to decrease sample size, samples were then sonicated for five minutes in each of the following solvents: deionized 
water and laboratory soap, hexane, chloroform, and methanol. Once samples were clean, they were placed in individual towels and then placed in envelopes until analysis. Each sample was placed on a SEM stub with carbon tape prior to analysis.

\begin{tabular}{|c|}
\hline Typical evidentiary glass \\
\hline Sylvania 50W Reflector Bulb \\
\hline 4W Night Light Bulb \\
\hline Decorative Bowl \\
\hline Clear Drinking Glass \\
\hline Picture Frame Glass \\
\hline H\&H Window Glass \#1 \\
\hline H\&H Window Glass \#2 \\
\hline Holiday Cup \\
\hline HumVee Window Glass \\
\hline Listerine Mouthwash Bottle \\
\hline
\end{tabular}

Table 4 Description of glass obtained at CSC

Ten headlight glass samples were obtained from Jordan Auto Parts in Pennsylvania. The samples are identified in Table 5. All samples are from cars with model years before 1995, which was representative of the junkyard from which the samples were acquired. Three of the samples are from the same 
make and model of Subaru, differing only in model year. Samples were individually broken between two pieces of white paper and stored in a plastic jar until clean. Once samples were cleaned, they were stored in envelopes wrapped in a clean paper towel.

\begin{tabular}{|c|c|c|}
\hline ID & Make/Model & Year \\
\hline JO428 & Subaru Loyale & 1993 \\
\hline I0680 & Subaru Loyale & 1990 \\
\hline I1121 & Subaru Loyale & 1991 \\
\hline I0325 & $\begin{array}{c}\text { Oldsmobile Cutlass } \\
\text { Sierra SL }\end{array}$ & 1990 \\
\hline I0979 & $\begin{array}{c}\text { Oldsmobile Cutlass } \\
\text { Calais S }\end{array}$ & 1989 \\
\hline G0237 & Honda CRX & 1986 \\
\hline G1966 & Plymouth Voyager & 1986 \\
\hline B0829 & Mazda RX7 & 1982 \\
\hline G117 & Nissan pickup truck & 1990 \\
\hline K0138 & Buick LeSabre Custom & 1995 \\
\hline
\end{tabular}

Table 5 Description of automobile headlight samples

\subsubsection{Data/color analysis}

Data analysis was conducted using Excel spreadsheets and Matlab version 7.6 (The Mathworks, Cambridge MA). Spectral conversions and calculation of color coordinates were obtained using Matlab downloads available from the company's file exchange or from a color science textbook [38]. Spectra were imported from native instrument format (Figure 5) into Excel as XY files with intensity of emission plotted as a function of wavelength.

ASTM tables used for the conversion of reflectance intensity are based reflectance values in the range of 400 to $700 \mathrm{~nm}$ at $10 \mathrm{~nm}$ increments, requiring that the original spectra collected in $1 \mathrm{~nm}$ increments be smoothed and 
simplified. The danger of such smoothing is the possibility of losing data, but this was taken into account and is addressed below. Accordingly, each raw spectrum was subjected to a simplified moving average smoothing process in which the raw data was converted from 500 data points (wavelength/emission intensity) to 31 data points in the range of 400 to $700 \mathrm{~nm}$ at $10 \mathrm{~nm}$ increments. The emission intensity was normalized to the range of $0-100 \%$. The effect of processing is shown in Figure 5. In the top frame, the full spectrum is shown with intensity values normalized to a percentage of maximum intensity. The area of interest is highlighted in the box and shown in the middle frame. This is the wavelength range over which CIE color coordinate conversions were performed. The lower frame shows the same region after the moving average smoothing. The circles show regions in which some features are lost. 


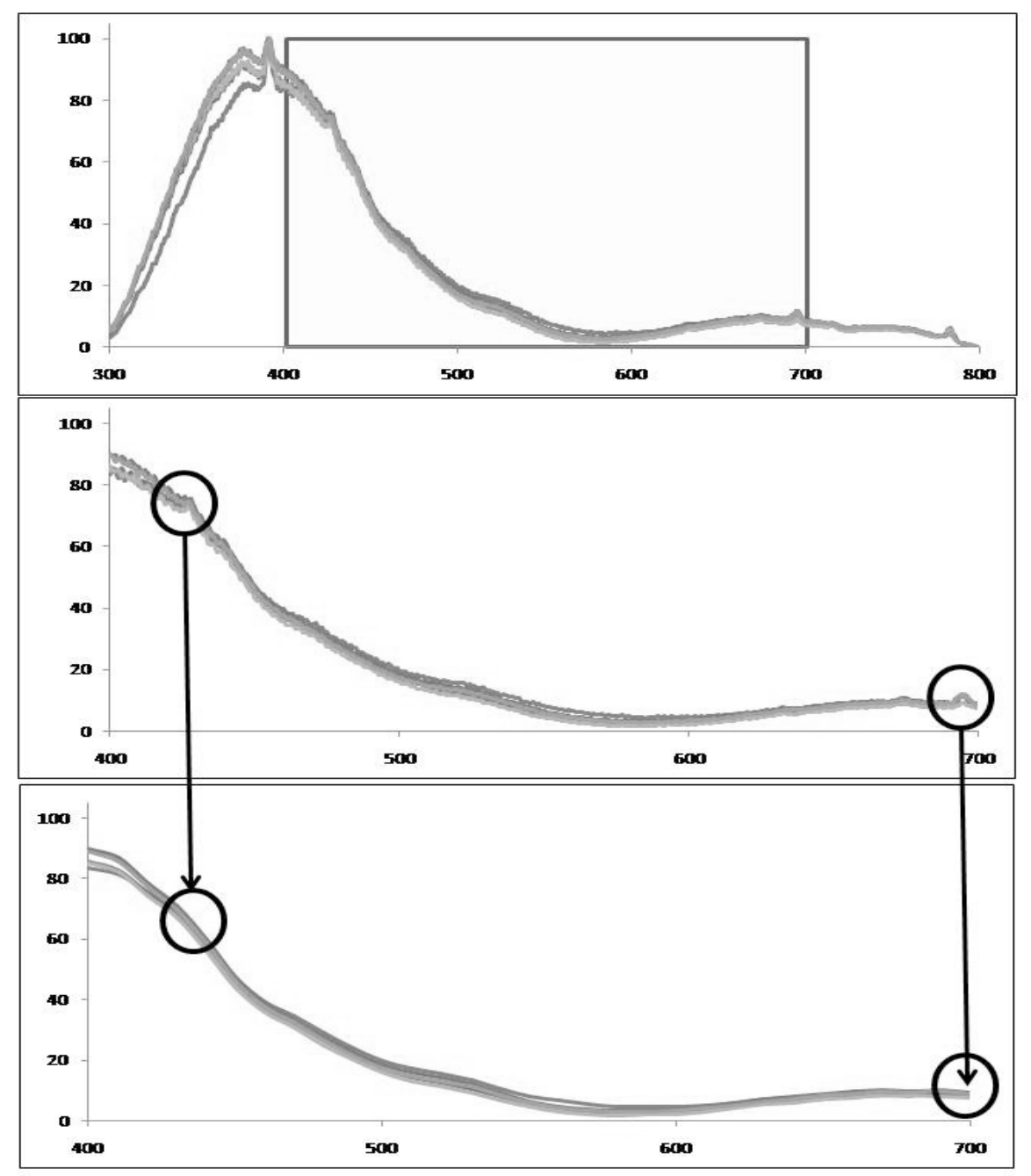

Figure 5 Illustration of data processing

Fundamental to any spectral or quantitative comparison model, such as applied in forensic science, is a detailed characterization of expected uncertainties. To address this, replicate samples were obtained from all glasses at 5 different points on the surface, selected at random. Each spectrum was subjected to the processing described above, resulting in $5 \mathrm{LAB}$ values for each glass sample that were used to generate a $95 \%$ uncertainty ellipse around each point plotted in the LAB color space. Intra- and inter-sample variations were 
evaluated, as was reproducibility of spectra obtained in different areas of the sample over 10 days.

\subsection{Initial studies}

NIST1830 and 1412 were used for initial studies. Spectra were obtained from each sample under two different conditions: as received and with a thin layer of carbon coating. A mineral standard composed of 53 separate minerals (SPI Supplies, West Chester, PA) was analyzed for reference spectra. Minerals analyzed were chosen based on the similarity of composition to that of the standard glasses. These reference spectra were then used to identify potential activator peak positions in sample spectra. Below is a table outlining the composition of the minerals chosen for comparison.

\begin{tabular}{|c|c|c|c|c|c|c|c|c|c|c|c|c|c|c|}
\hline \multirow{2}{*}{$\begin{array}{c}\text { Mineral } \\
\text { Anhydrite }\end{array}$} & \multicolumn{14}{|c|}{ Composition } \\
\hline & 0 & $S$ & $\mathrm{Ca}$ & Sum & & & & & & & & & & \\
\hline & 47.01 & 23.55 & 29.44 & 100 & & & & & & & & & & \\
\hline & $\mathrm{SO}_{3}$ & $\mathrm{CaO}$ & Sum & & & & & & & & & & & \\
\hline & 58.81 & 41.19 & 100 & & & & & & & & & & & \\
\hline \multirow[t]{4}{*}{ Barite } & 0 & $S$ & Sr & $\mathrm{Ba}$ & Sum & & & & & & & & & \\
\hline & 27.33 & 13.8 & 0.26 & 58.62 & 100 & & & & & & & & & \\
\hline & $\mathrm{SO}_{3}$ & $\mathrm{SrO}$ & $\mathrm{BaO}$ & Sum & & & & & & & & & & \\
\hline & 34.45 & 0.31 & 65.45 & 100 & & & & & & & & & & \\
\hline \multirow[t]{4}{*}{ Quartz } & 0 & Si & Sum & & & & & & & & & & & \\
\hline & 53.26 & 46.74 & 100 & & & & & & & & & & & \\
\hline & $\mathrm{SiO}_{2}$ & Sum & & & & & & & & & & & & \\
\hline & 100 & 100 & & & & & & & & & & & & \\
\hline \multirow[t]{4}{*}{ Obsidian } & $H$ & 0 & $F$ & $\mathrm{Na}$ & $M g$ & $A l$ & Si & $\mathrm{Cl}$ & $K$ & $\mathrm{Ca}$ & $\mathrm{Ti}$ & $M n$ & $\mathrm{Fe}$ & Sum \\
\hline & 0.09 & 48.63 & 0.07 & 3.01 & 0.04 & 6.94 & 34.56 & 0.36 & 4.18 & 0.54 & 0.06 & 0.05 & 1.34 & 99.9 \\
\hline & $\mathrm{H}_{2} \mathrm{O}$ & $F$ & $\mathrm{Na}_{2} \mathrm{O}$ & $\mathrm{MgO}$ & $\mathrm{Al}_{2} \mathrm{O}_{3}$ & $\mathrm{SiO}_{2}$ & $\mathrm{Cl}$ & $\mathrm{K}_{2} \mathrm{O}$ & $\mathrm{CaO}$ & $\mathrm{TiO}_{2}$ & $\mathrm{MnO}$ & $\mathrm{FeO}$ & Sum & \\
\hline & 0.8 & 0.07 & 4.06 & 0.07 & 13.11 & 73.94 & 0.36 & 5.04 & 0.76 & 0.1 & 0.06 & 1.72 & 100.1 & \\
\hline
\end{tabular}

Table 6 Composition of standard minerals 
Both NIST1830 and NIST1412 were analyzed with an accelerating voltage of $20 \mathrm{kV}$ and a magnification of $500 \mathrm{X}$. The operating pressure in the low vacuum mode was $30 \mathrm{~Pa}$. CL spectral acquisition time was fifteen minutes. Total area analyzed was 400 by 175 micrometers.

\subsection{Color study using standard glass samples}

NIST1830 and 1412 were used to first assess the validity of color analysis as a technique for differentiation. Each sample was analyzed five times in the same area and five times in different areas of the sample. These replicate analyses allowed for statistical measurements to compare the variation within an area and over five different areas. Results of this work were used to develop and refine the spectral conversions and color analysis used in subsequent work.

\subsection{Method validation study using standard samples}

Method validation was performed by analyzing NIST1412 and 1830 over the course of 10 days. Each sample was analyzed in five different spots daily for 10 days, as described in section 2.1.1. NIST1830 was evaluated on both the tin and non-tin sides. The non-tin side was determined by placing the glass sample under UV light to observe fluorescence. Evidentiary sample $\mathrm{H} \& \mathrm{H} \# 1$ was also analyzed over the course of ten days, with one area analyzed per day. 


\subsection{Evidentiary study I}

Each sample from the CSC was analyzed in five different areas as described in section 2.1.1 after cleaning and RI determination. Subsequent color analysis was performed.

\subsection{Evidentiary study II}

Each sample of headlight glass was analyzed in five different areas as described in section 2.1.1 after cleaning and RI determinations. Subsequent color analysis was performed.

\subsection{Window break simulation study}

A double pane window was obtained from the CSC to use for a break-in simulation. This study was performed to determine if pieces of glass transferred from the broken pane might be correlated with reasonable certainty to the pane itself. Small pieces of glass are generally transferred from glass to person during a situation such as breaking and entering. The glass was placed on a table covered in white paper in Oglebay Hall. The pane was not cleaned prior to analysis. This step was not performed because of the nature of the experiment. $\mathrm{CL}$ is a non-destructive technique and so the analysis of the glass without prior cleaning is one more step in maintaining the integrity of the sample. This will also indicate the effect that dirt on the surface of the glass has on analysis. A figure showing the pane and layout on the lab table is shown below. 


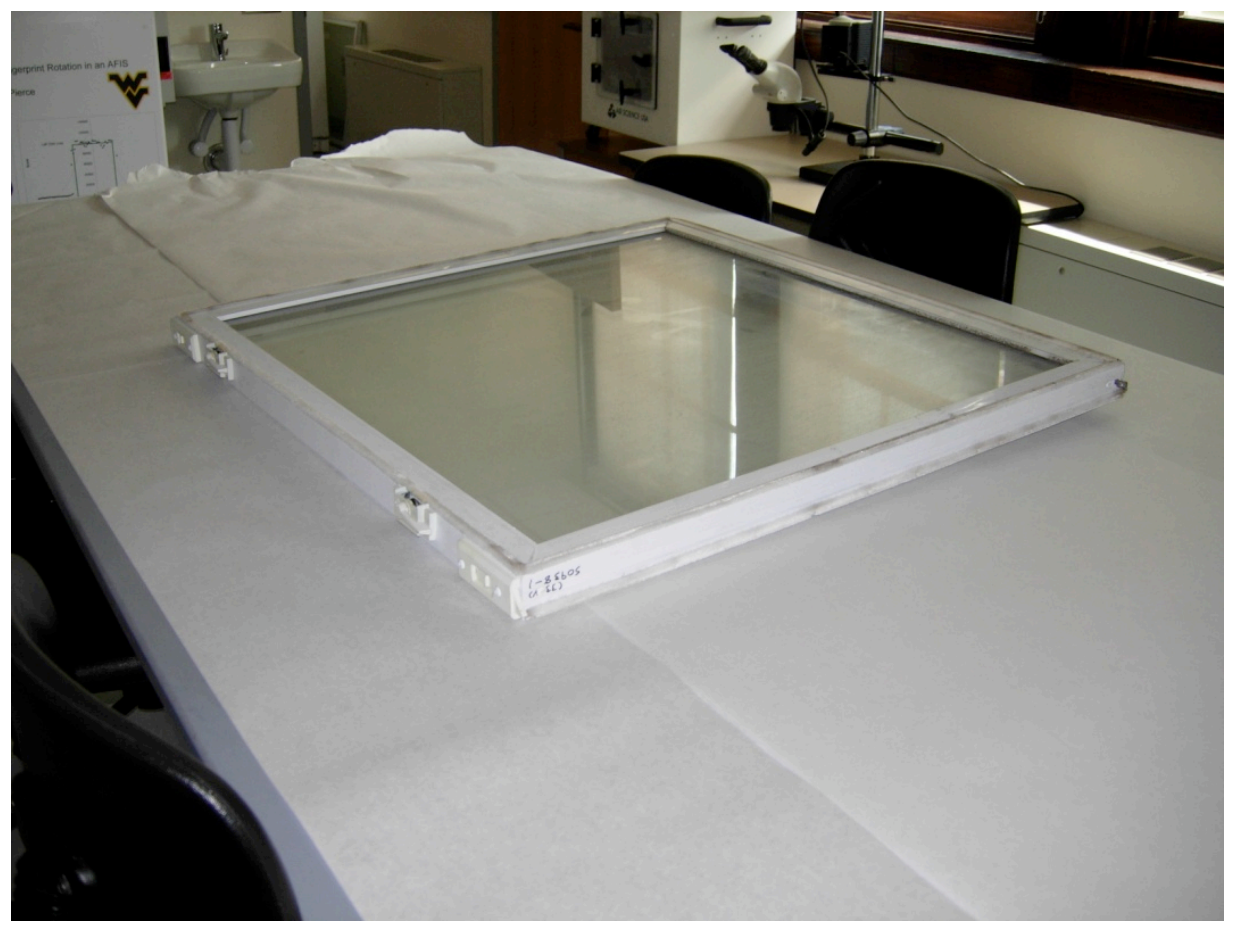

Figure 6 Double sided windowpane before break simulation

To prevent possible injury from flying glass, a Tyvex suit, booties, facemask, face shield, nitrile gloves duct taped to the suit, and thick cryo gloves were worn while breaking the glass. A hammer was used to break through both panes of glass. A figure of the breaking is shown below. 


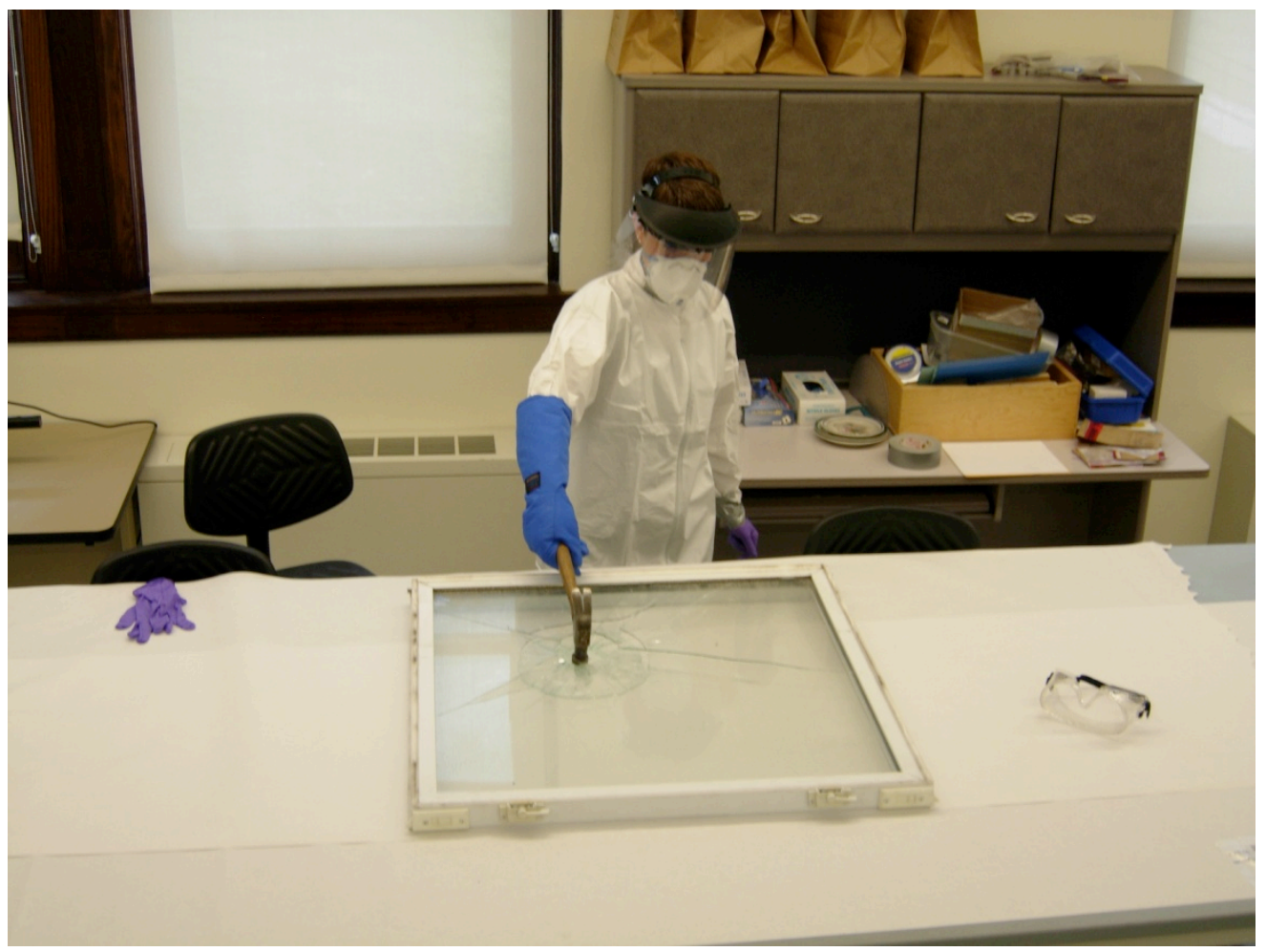

Figure 7 Break simulation

Once the window was broken, samples were collected. The break resulted in a radial fracture of the bottom pane and samples surrounding this break were collected. The photo below shows the result of the break. A description of the samples collected is included in Table 7 and shown in Figure 8.

\begin{tabular}{|c|}
\hline Sample Name \\
\hline Top pane control \\
\hline Bottom pane control \\
\hline Outer edge \\
\hline Misc. spray \\
\hline Inside perimeter on table \\
\hline Pieces in between panes \\
\hline Center of break on table \\
\hline Random piece on top pane \\
\hline Radial sample \#1 bottom pane \\
\hline
\end{tabular}

Table 7 Samples collected from break simulation 


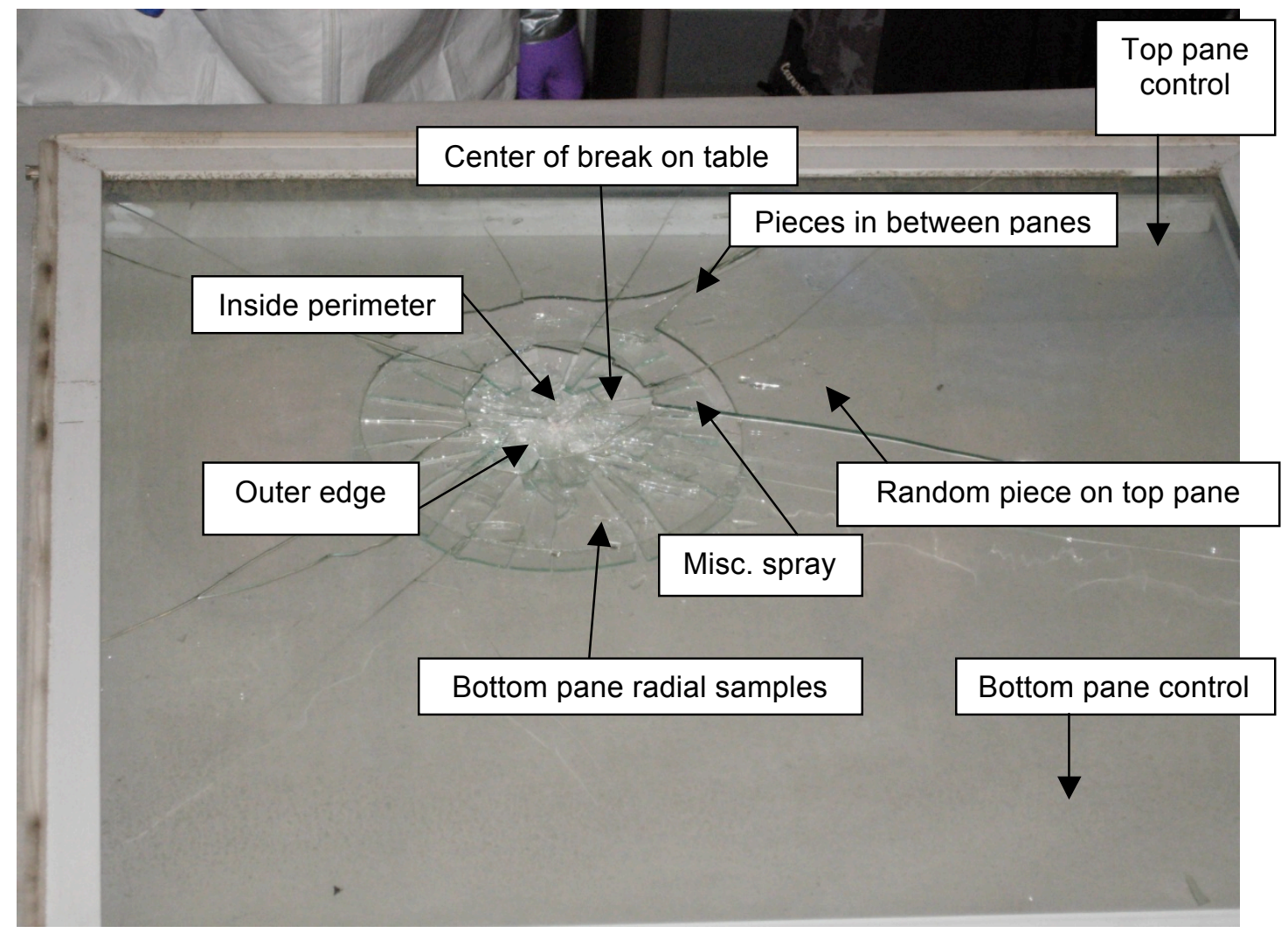

Figure 8 Picture demonstrating sample collection from break simulation 


\section{CHAPTER 3: Results and Discussion}

\subsection{Preliminary studies}

Upon analysis of carbon-coated samples, both NIST1830 and NIST1412 exhibited a broad peak between 300 and $500 \mathrm{~nm}$ likely due to the apparent intrinsic luminescence of silicon dioxide. There are no well-defined spectral peaks present in the emission spectra. The spectra obtained from both glass samples did not provide sufficient variation to distinguish between the two based on visual inspections of spectral pattern alone. An example spectrum from each sample is illustrated in Figures 9 and 10.

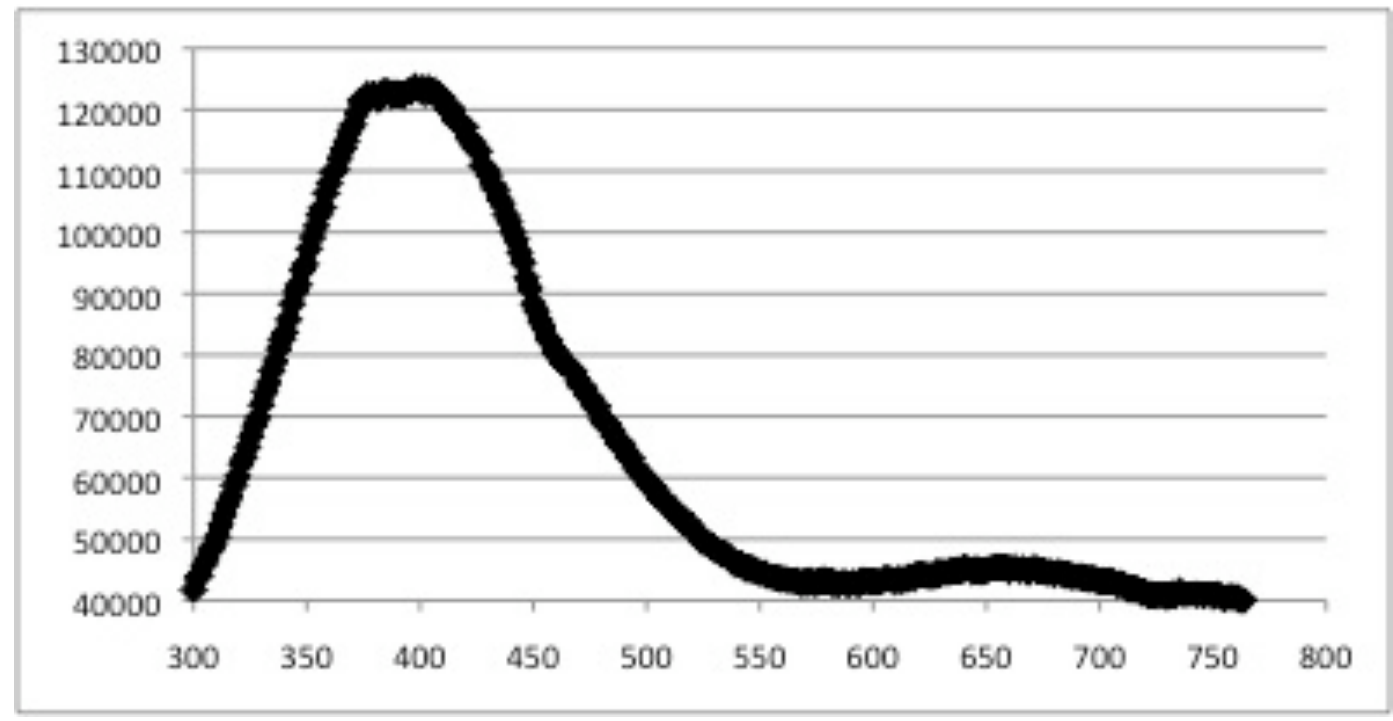

Figure 9 Spectrum of carbon coated NIST1830 


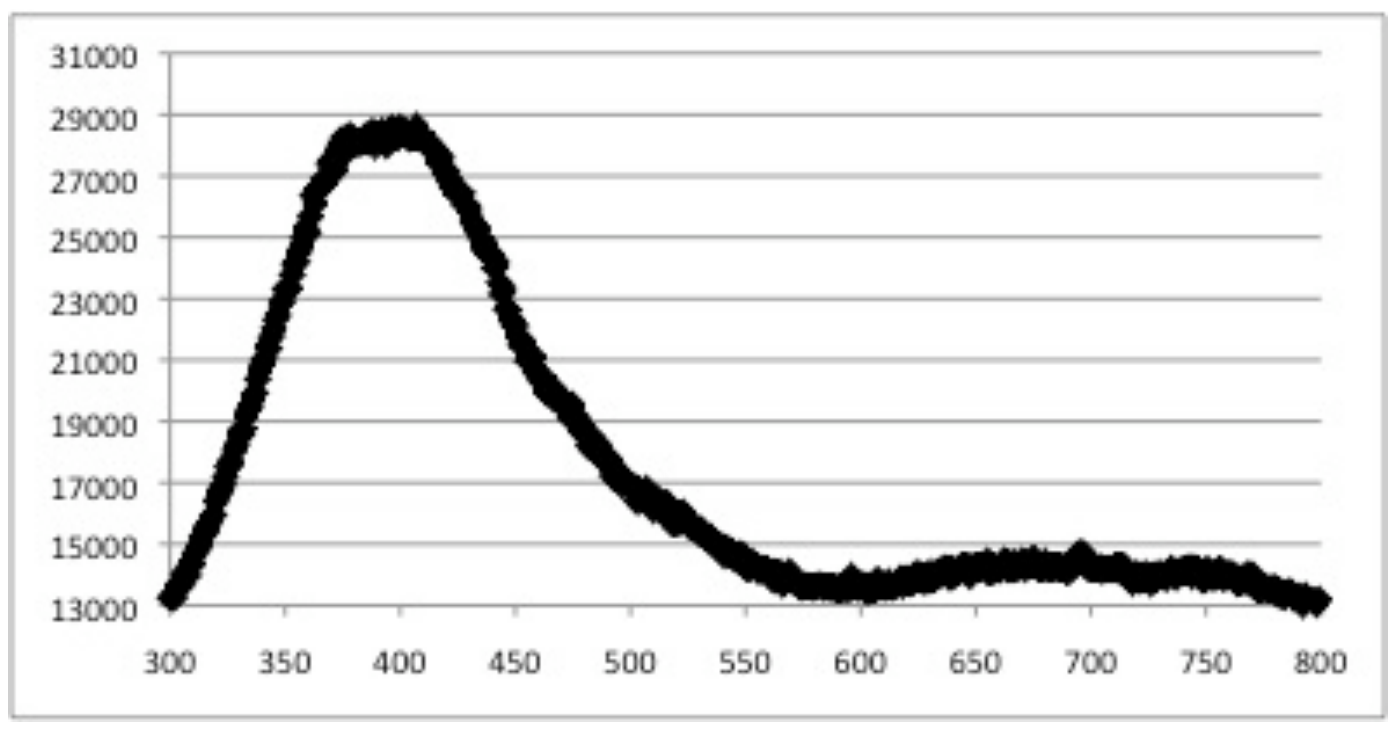

Figure 10 Spectrum of carbon coated NIST1412

Analysis of uncoated NIST1830 and 1412 both exhibited a broad peak between 300 and $500 \mathrm{~nm}$; however, additional smaller bands were visible in the spectra. From the perspective of discrimination, NIST1412 was more promising with peaks found at $391 \mathrm{~nm}, 427 \mathrm{~nm}$, and $782 \mathrm{~nm}$ in both samples. These peaks correlate with similar peaks found in oxygen containing minerals, such as quartz, anhydrite, and barite. Literature investigation revealed that these bands are common in silica glass, crystalline quartz, and float glass. These bands may be the result of two different intrinsic processes: relaxed electron-hole recombination or sites of oxygen defects in the silica structural unit, as indicated in chapter 1 [21]. These bands were not associated with specific transitions in this study. Comparison of NIST1830 and 1412 to the spectra acquired from the mineral standard are shown in Figures 11 and 12 respectively. 


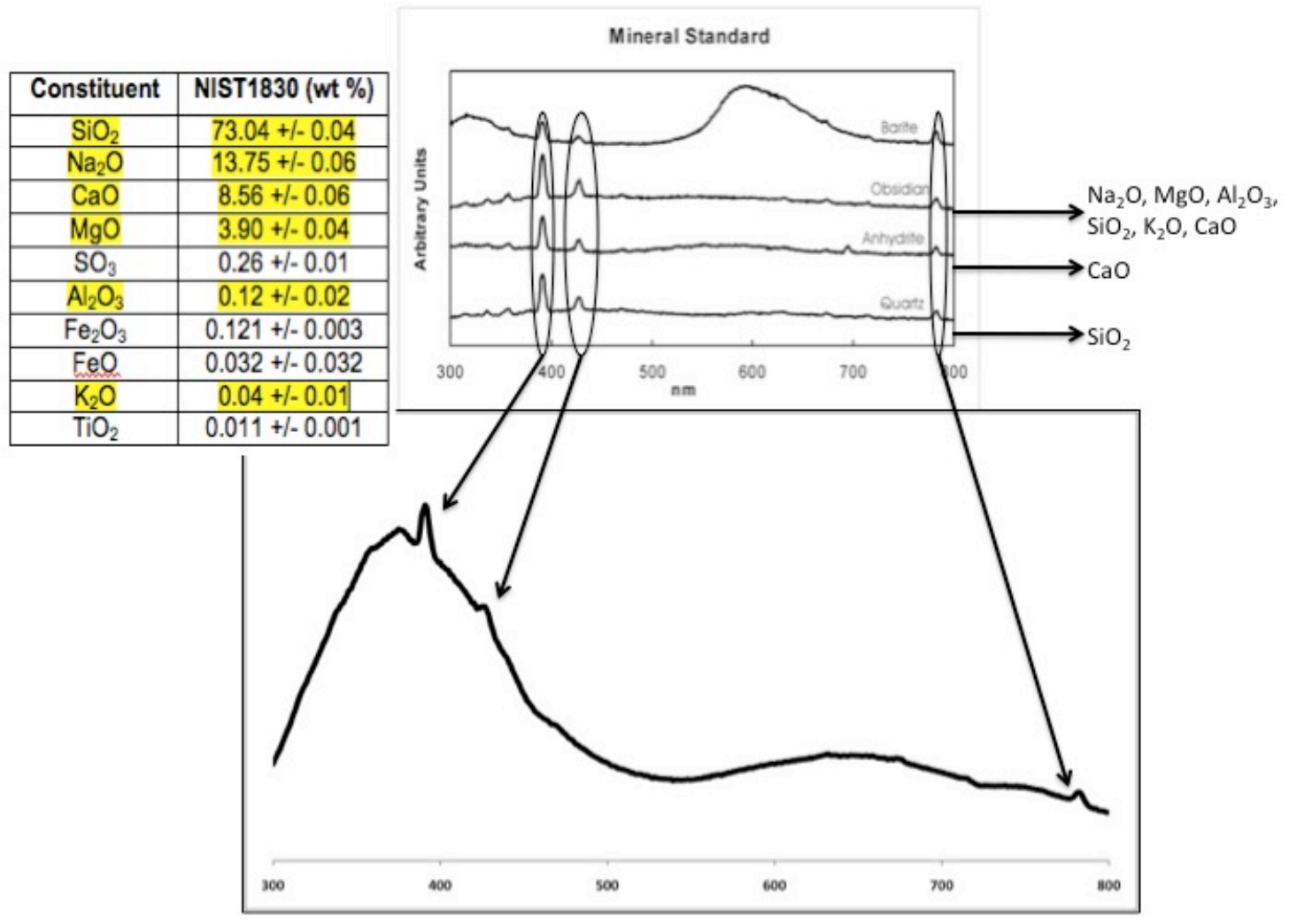

Figure 11 Comparison of NIST1830 and mineral standard 


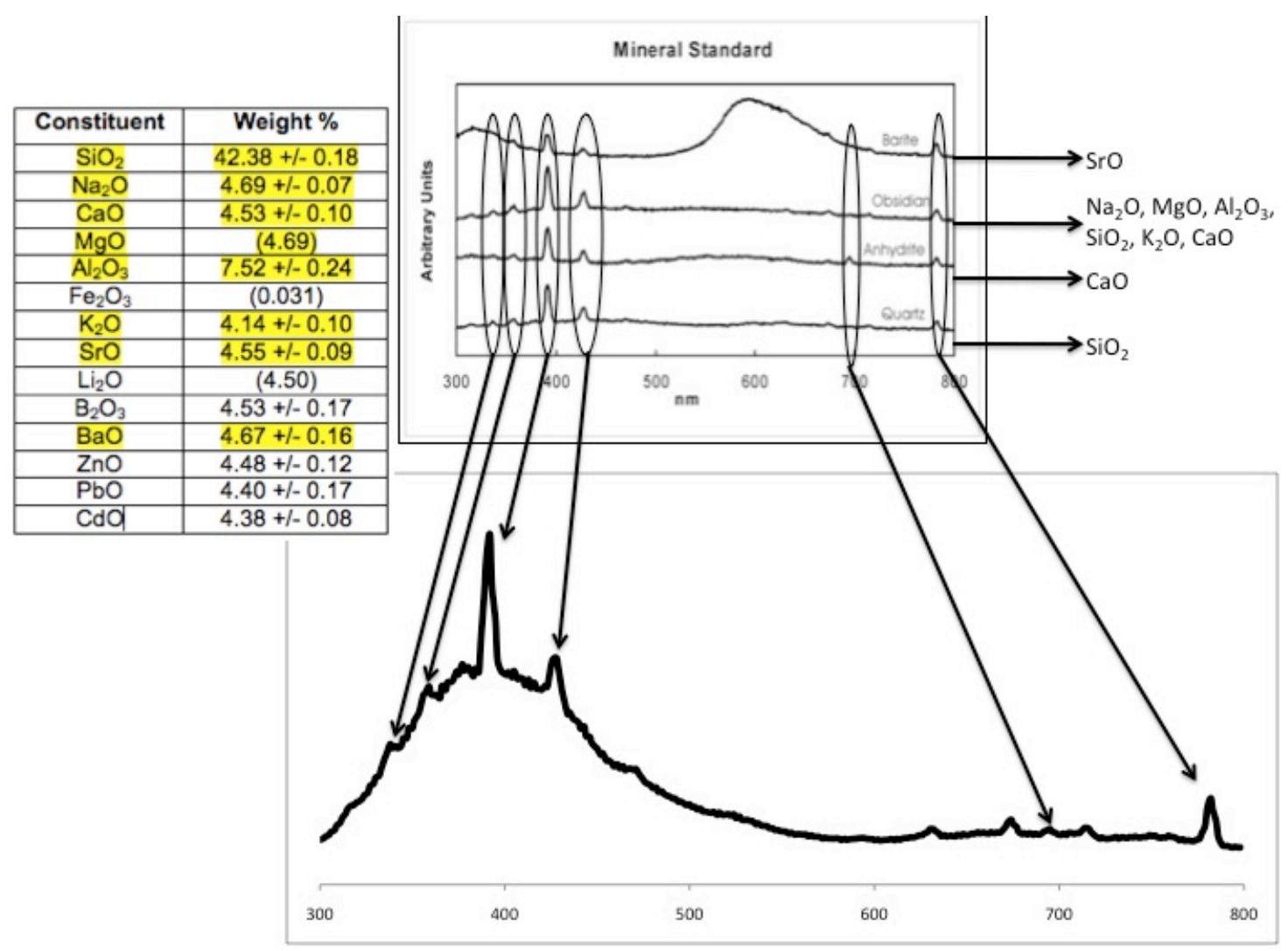

Figure 12 Comparison of NIST1412 and mineral standard

Three separate areas of each sample were analyzed and found to be reproducible. It also appears as though the carbon coating has an effect on the $\mathrm{CL}$ emission. This is an expected result due to the surface nature of $\mathrm{CL}$.

Initial results of this study indicate that CL emission alone may not be sufficient to differentiate between glass samples. As evident in Figures 11 and 12 , analysis of a mineral standard showed that oxide - containing minerals all share the three characteristic peaks that with the spectra of the standard glasses obtained in this study. In particular, quartz, anhydrite, and obsidian were nearly indistinguishable from each other. 


\subsection{Method development and validation}

One of the difficulties in $\mathrm{CL}$ is the lack of a suitable standard or procedure by which instrumental response can be measured and calibrated. No simple way exists to assign a peak to a specific element, mineral, or feature unlike Raman and IR. While a Hg lamp may be used for wavelength calibration, no generally accepted standard exists for CL [39]. Thus, prior to any meaningful classification and discrimination, it is essential to characterize uncertainties that arise from daily variation, sample position, and sample variability. The first step in the process was characterization of intra-sample variation and spectral reproducibility.

NIST samples were analyzed five times in the same area to determine the cumulative beam effect. It was found during the five analyses in the same spot that the overall spectral pattern remained consistent; however the intensity decreased with each successive analysis. This is evident by the numbered spectra show in Figure 13. Number 1 correlates to the first spectrum acquired in the same spot and so on. The decreasing intensity is likely due to charge buildup on the sample or luminescence fading [24]. Figure 13 also illustrates the results when the five replicates were collected over different areas of the sample (dotted lines). For all subsequent analyses, replicate samples were collected at five different locations on each sample. 


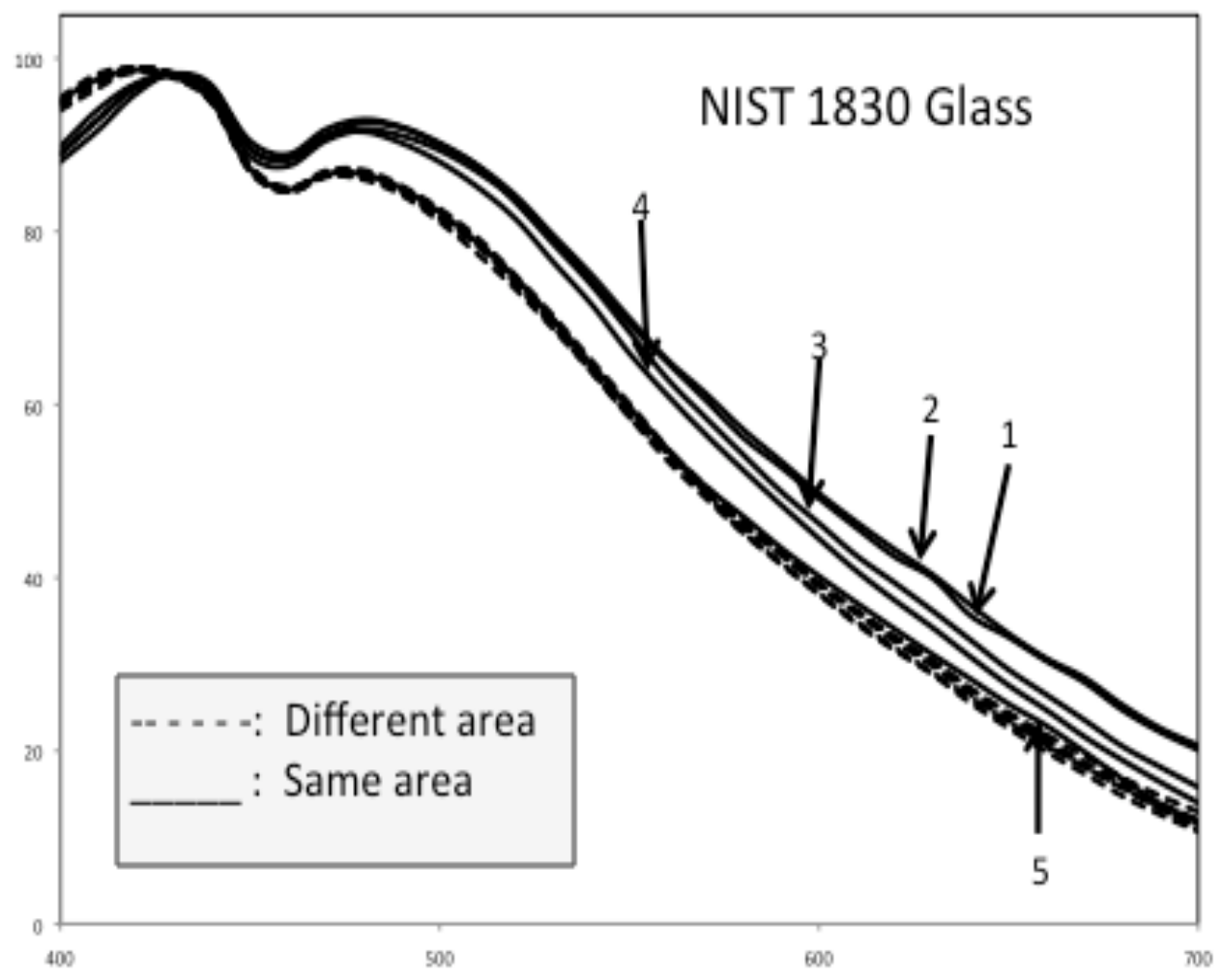

Figure 13 NIST1830 Sn-side same area and different area spectra

The next step in the validation process was examination of the two NIST glasses using the 5 replicate procedure. Results are show $n$ in Figure 14. The resulting spectra are clearly different and the intra-sample variability was significantly different. For NIST1830, the average \%RSD across 5 spectra was $1.7 \%$ compared to nearly $13 \%$ for the NIST1412 glass. These values were calculated by determining the \%RSD at each point in the smoothed spectrum, with $n=31$. As shown in Table 3, NIST1830 has significantly more $\mathrm{SiO}_{2}$ and fewer other oxides compared to NIST1412, which has $42.4 \% \mathrm{SiO}_{2}$ as well as 
several oxides in the $4 \%$ range. The surface of NIST1412 is also rough compared to the flat, smooth surface of NIST1830.

The Sn side was analyzed and may be more homogenous across the surface. This may be due to the residual $\mathrm{Sn}$ remaining on the surface from the float process. Why and how the differences in the chemical composition specifically affect the reproducibility is unknown, but the pattern was consistent throughout the data set.

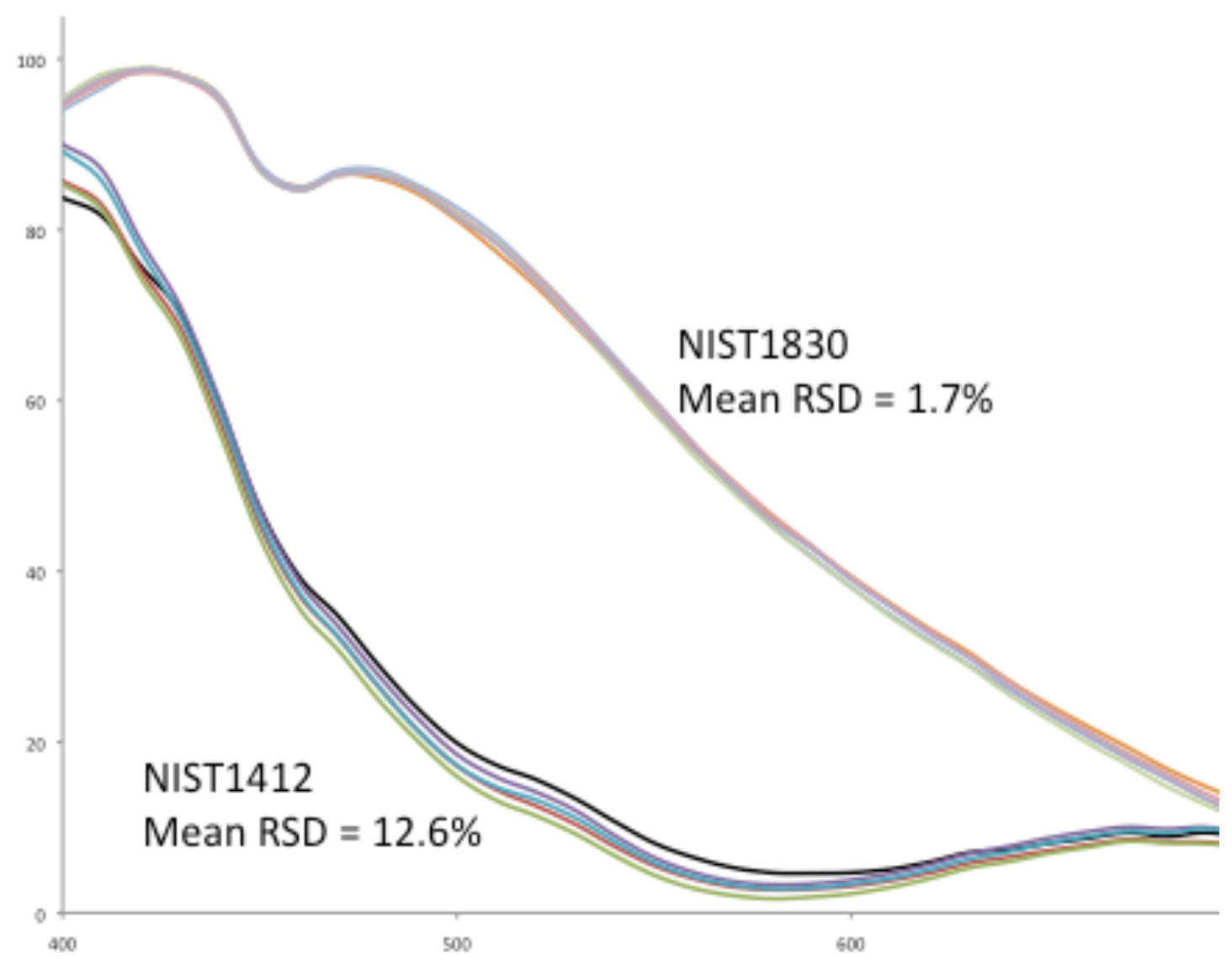

Figure 14 Comparison of five replicate technique on NIST1830 Sn-side and NIST1412 
Each sample was also analyzed in five different areas over the course of 10 days in an effort to validate the method. NIST1830 was analyzed on both the Sn-side and non-Sn side. The resulting spectra were subject to the color analysis described in chapter 2 and the results are shown in Figure 15. An ellipsoid representative of the $95 \%$ confidence interval encloses each data point, which is extrapolated from three values and is assumed to be spherical.

Analyzing both Sn and non-Sn sides of NIST1830 was done to show the impact the Sn has on the resulting luminescent spectrum. In the case where a UV light may be not available, the ability to spectroscopically determine the difference between the two sides of the glass is convenient. Also, in a case where sample size does not permit the use of a UV light, knowledge of the spectroscopic differences is critical. 


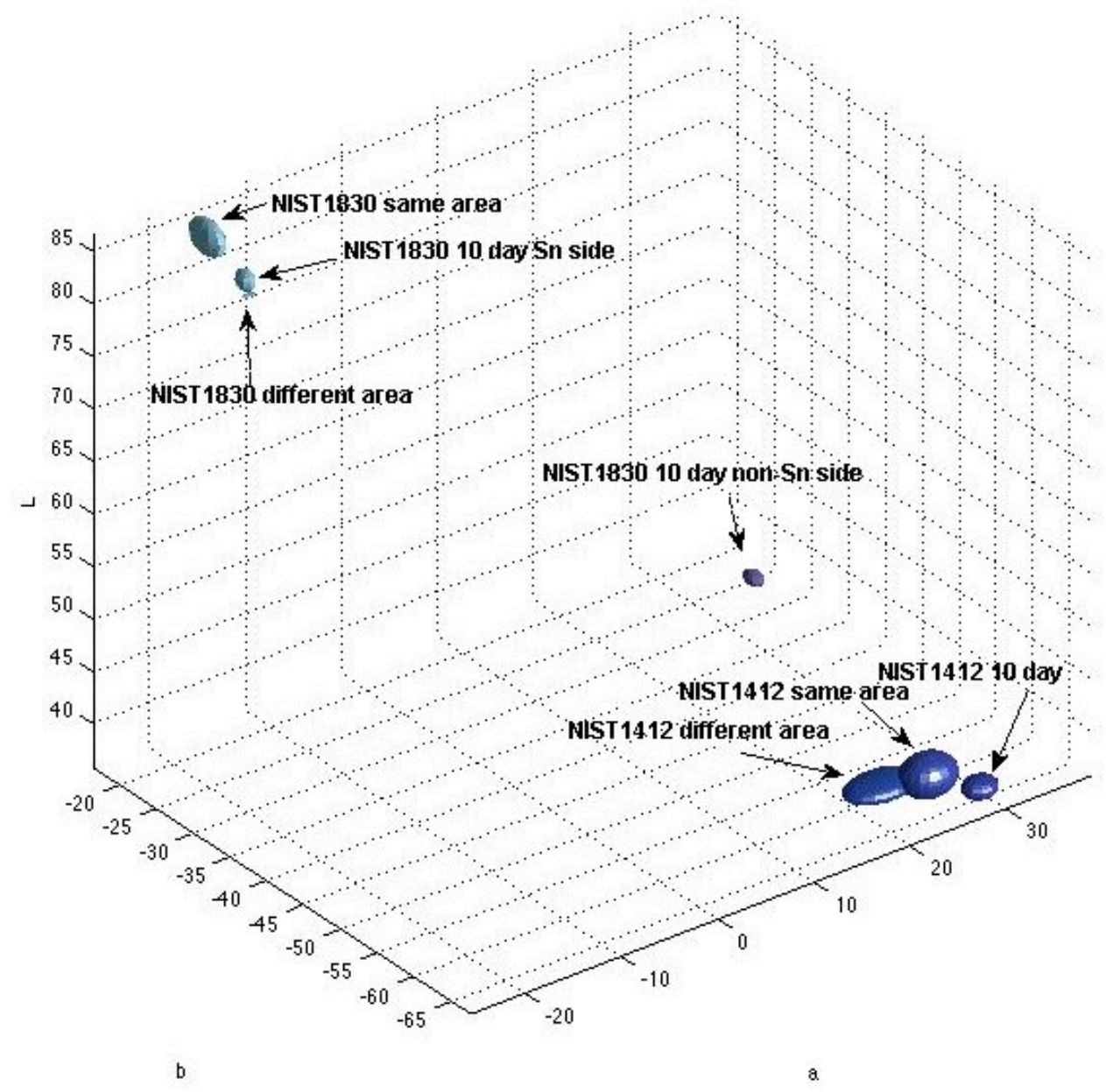

Figure 15 Validation study results

In all three cases, 10-day variation was minimal compared to the same area and different area analyses. The uncertainty ellipses surrounding each point for the 10-day study are much smaller in magnitude than those of the same and different area studies. The 10-day study allowed for each sample to be analyzed a total of 50 times, versus five times for the same and different area analyses. This illustrates the point that the more times a sample is analyzed, the less variation is observed. The variation in the $L$ axis may be attributed to the 
luminescence fading, as evident in the NIST1830 same area. It is clear that the two standard glass samples are differentiated.

\subsection{Refractive index measurements}

Results from refractive index measurements of the evidentiary samples from the CSC and automobile headlights are given in Tables 8 and 9.

\begin{tabular}{|c|c|}
\hline Glass & RI \\
\hline Sylvania 50W Reflector Bulb & N/A \\
\hline 4W Night Light Bulb & 1.5100 \\
\hline Decorative Bowl & 1.5140 \\
\hline Clear Drinking Glass & 1.5140 \\
\hline Picture Frame Glass & 1.5160 \\
\hline H\&H Window Glass \#1 & 1.5160 \\
\hline H\&H Window Glass \#2 & 1.5160 \\
\hline Holiday Cup & 1.5160 \\
\hline HumVee Window Glass & 1.5160 \\
\hline Listerine Mouthwash Bottle & 1.5160 \\
\hline
\end{tabular}

Table 8 RI measurements of CSC glass samples 


\begin{tabular}{|c|c|c|c|}
\hline ID & RI & Make/Model & Year \\
\hline JO428 & 1.476 & Subaru Loyale & 1993 \\
\hline I0680 & 1.474 & Subaru Loyale & 1990 \\
\hline I1121 & 1.474 & Subaru Loyale & 1991 \\
\hline I0325 & 1.478 & $\begin{array}{c}\text { Oldsmobile Cutlass } \\
\text { Sierra SL }\end{array}$ & 1990 \\
\hline I0979 & 1.478 & $\begin{array}{c}\text { Oldsmobile Cutlass } \\
\text { Calais S }\end{array}$ & 1989 \\
\hline G0237 & 1.477 & Honda CRX & 1986 \\
\hline G1966 & 1.478 & Plymouth Voyager & 1986 \\
\hline B0829 & 1.474 & Mazda RX7 & 1982 \\
\hline G1117 & 1.478 & Nissan pickup truck & 1990 \\
\hline K0138 & 1.478 & Buick LeSabre Custom & 1995 \\
\hline
\end{tabular}

Table 9 RI measurements of automobile headlight glass

This distribution of refractive indices in the sample set here is similar to that seen in larger collections $[40,41]$. For the CSC samples, RI allows for samples to be delineated into two groups: those having a RI of 1.5140 and 1.5160. The night light bulb is able to be distinguished based on RI alone. No RI value was determined for the $50 \mathrm{~W}$ reflector bulb. The glass has a frosting, which would be sufficient for differentiation in this data set.

The results from the automobile headlight glass show a wider range of $\mathrm{RI}$ values. Samples with RI of 1.476 and 1.477 allow for these two samples to be discriminated from the sample group. This leaves two RI groups left to be discriminated: 1.474 and 1.478 . RI results also show that RI may not be consistent for a given make and model between model years, as can be seen in the Subaru Loyale. 


\subsection{Evidentiary study I differentiation using $C L$ and LAB coordinates}

As can be seen in the results from the RI measurements, the evidentiary samples from CSC may be delineated into two groups: RI of 1.5140 and 1.5160 . Color analysis, as described in Chapter 1 , was performed to further differentiate samples within the two RI groups. Figure 16 shows the discrimination in the 1.5140 RI group, while Figure 17 shows the RI 1.15160 group.

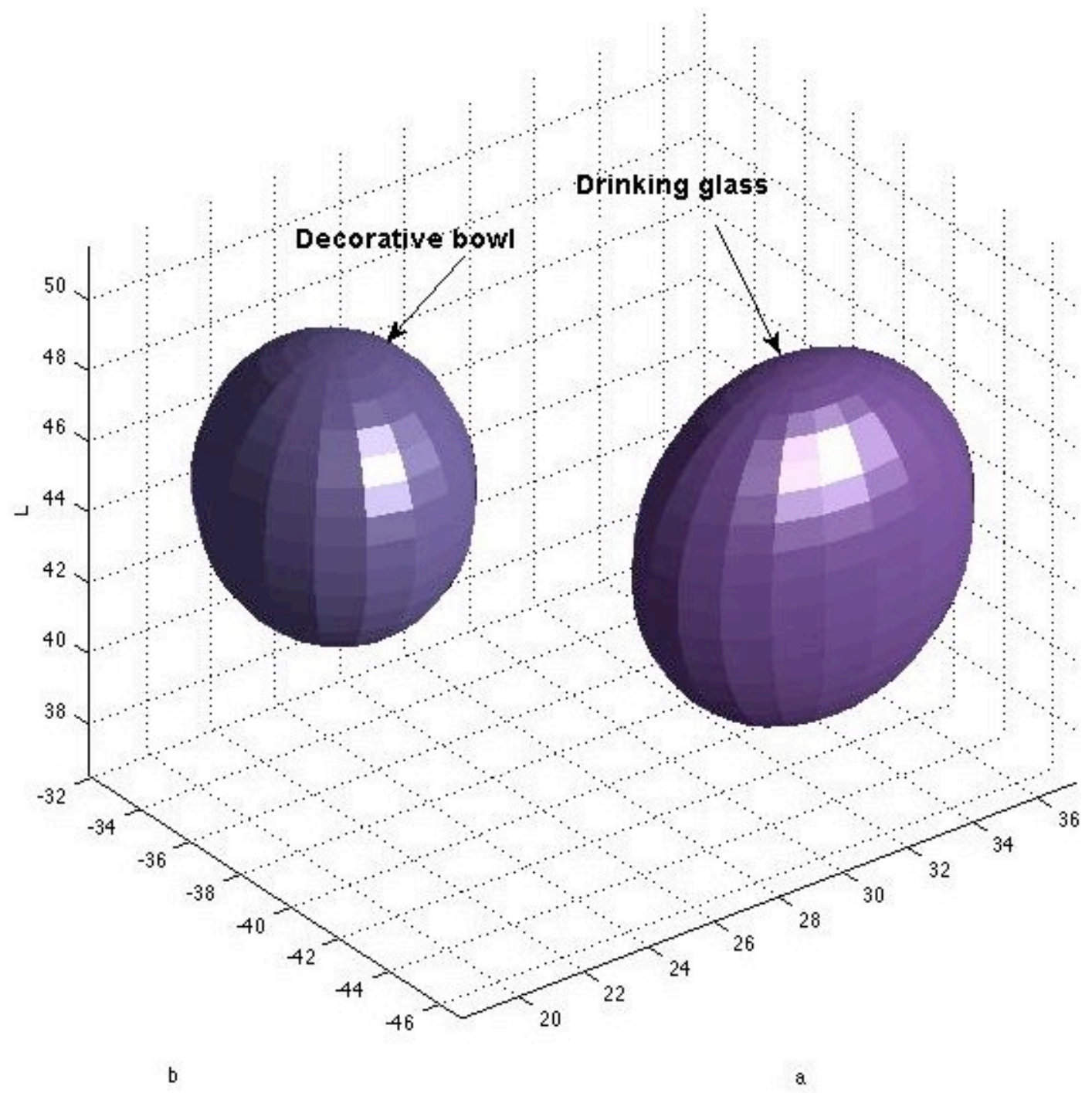

Figure 16 Evidentiary samples with RI of 1.5140 


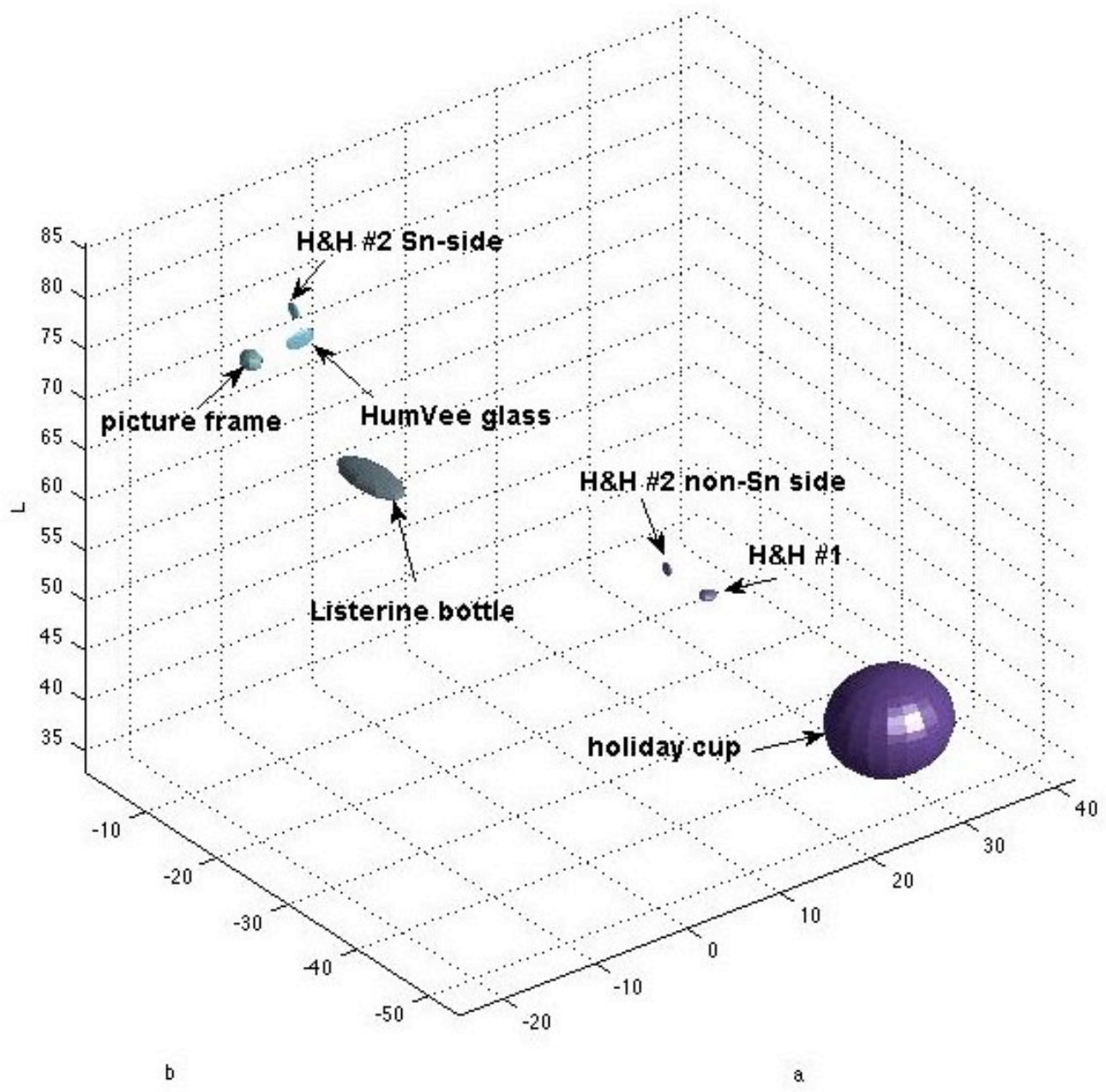

Figure 17 Evidentiary samples with RI of 1.5160

Within each RI group, all individual glass samples were unambiguously differentiated. Samples H\&H \#2, picture frame, and HumVee glass exhibit a more blue color. This may be due to a coating on the side of the glass, such as Sn. $\mathrm{H} \& \mathrm{H} \# 2$, which is a window glass, was analyzed on both the Sn-side and non-Sn side. Also, $\mathrm{H \& H} \# 1$ and $\mathrm{H} \& \mathrm{H} \# 2$ are clearly differentiated although they are from the same manufacturer. 


\subsection{Sample curvature}

The practice of taking 5 replicates uncovered an issue related to sample curvature. Some glass samples exhibited a curved surface (drinking glass and holiday cup), a common situation with glass evidence generally. Interestingly, the curved portion of the samples exhibited a different spectral pattern than the flat areas of the glass. Although the cause of this pattern is unknown, a possible hypothesis is internal reflections occurring in the curved portion of the glass sample. Steps were taken, such as mounting the sample and tilting and rotating the stage, to ensure that the flat surfaces of these samples were analyzed.

Drinking glass was reanalyzed due to large variation in the spectra obtained from the curved surface. The sample was carefully mounted to the SEM stage using carbon tape to ensure that the flattest portion was perpendicular to the electron beam. Sample positioning was confirmed before each spectrum was acquired. This was critical to verify that flat surfaces were analyzed each time.

\subsection{Comparative uncertainty}

Clearly, the volume of the individual ellipsoids in the color space determines which samples can be distinguished and which cannot. The volume depends on reproducibility of the spectra across any given sample. As was shown experimentally, variance was minimized using 5 replicates, but was still dependent on the chemical composition. The scale of expected variation is shown in Figure 18. The smallest volume was obtained with NIST1830 over 5 different areas on the sample. The larger volume associated with the ten-day 
reproducibility study of $\mathrm{H} \& \mathrm{H} \# 1$ is significantly larger and needs to be considered in cases where samples are collected at different times, as might be the case in a database. The data here indicate that samples to be compared using CL must be analyzed as close in time as possible to minimize intra-day variation. However, as shown in Figure 19, the intra-sample variability of some of the evidentiary glasses exceeds that of the $\mathrm{H} \& \mathrm{H} \# 1$ 10-day study.

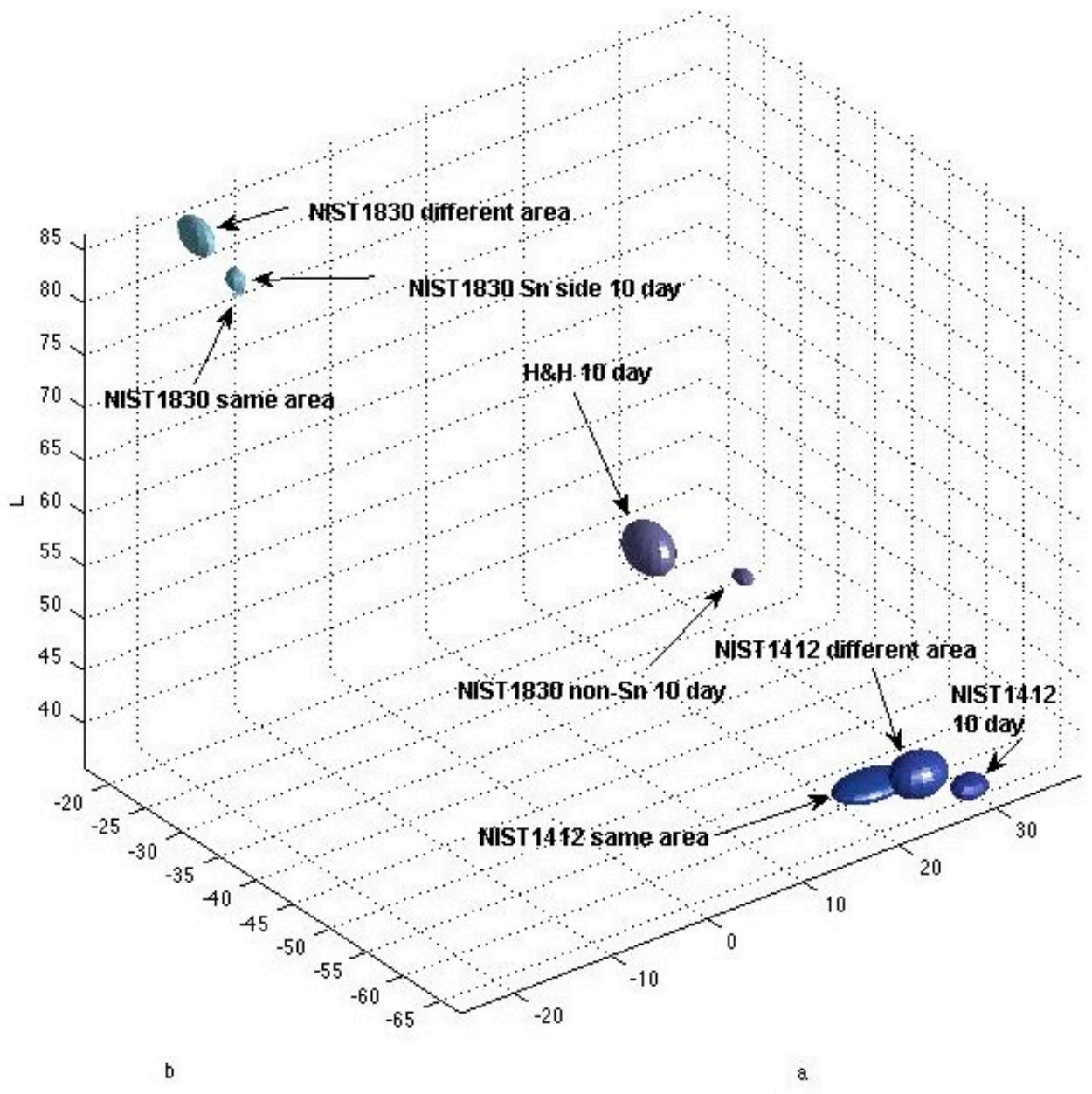

Figure 18 Comparative volume of uncertainty 


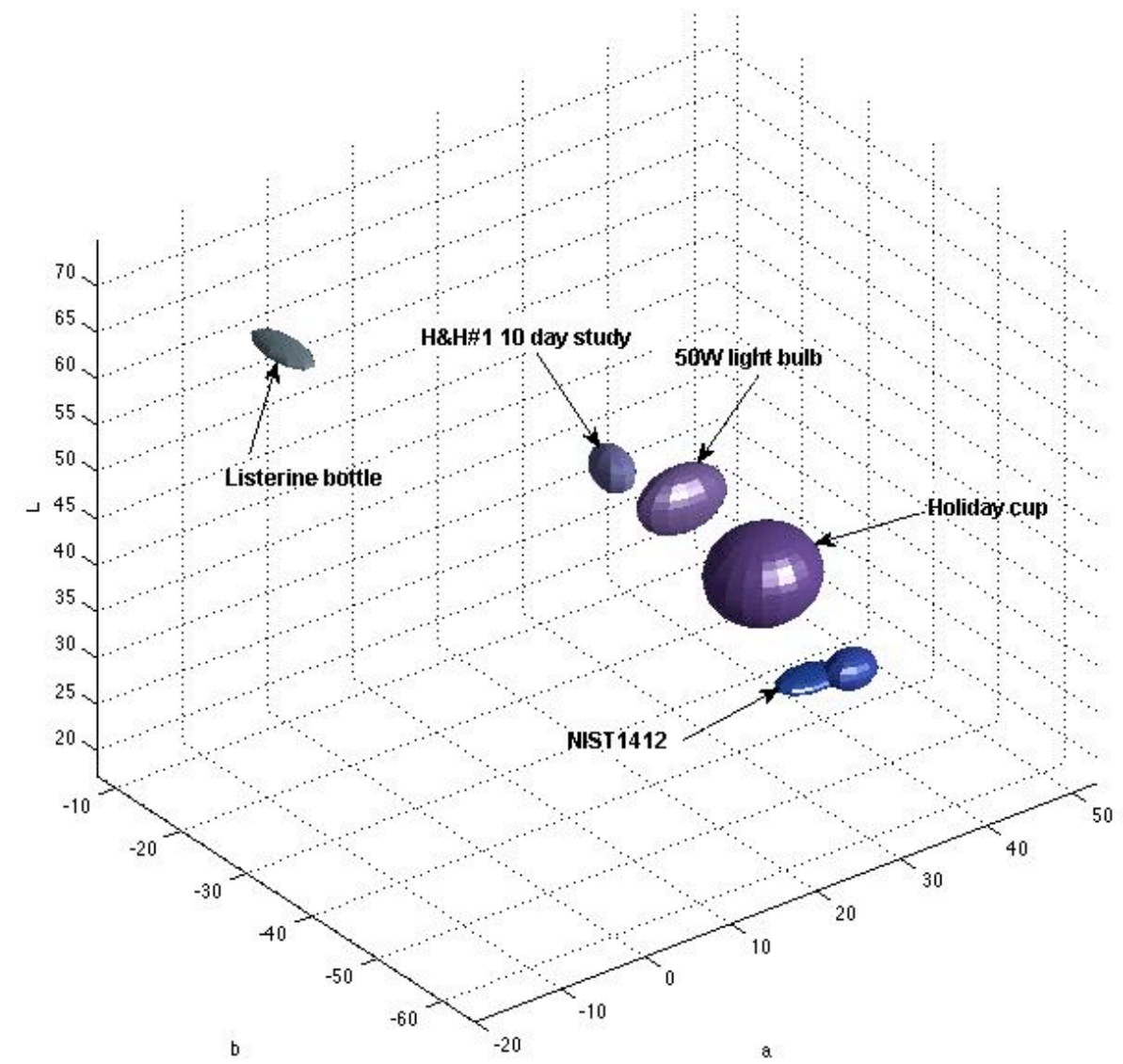

Figure 19 intra-sample variations of evidentiary samples

The volumes of uncertainty surrounding each point seem large relative to scale. However, when the same results are plotted encompassing all of LAB space, it can be seen that these volumes are quite small. This is shown in Figure 20. 


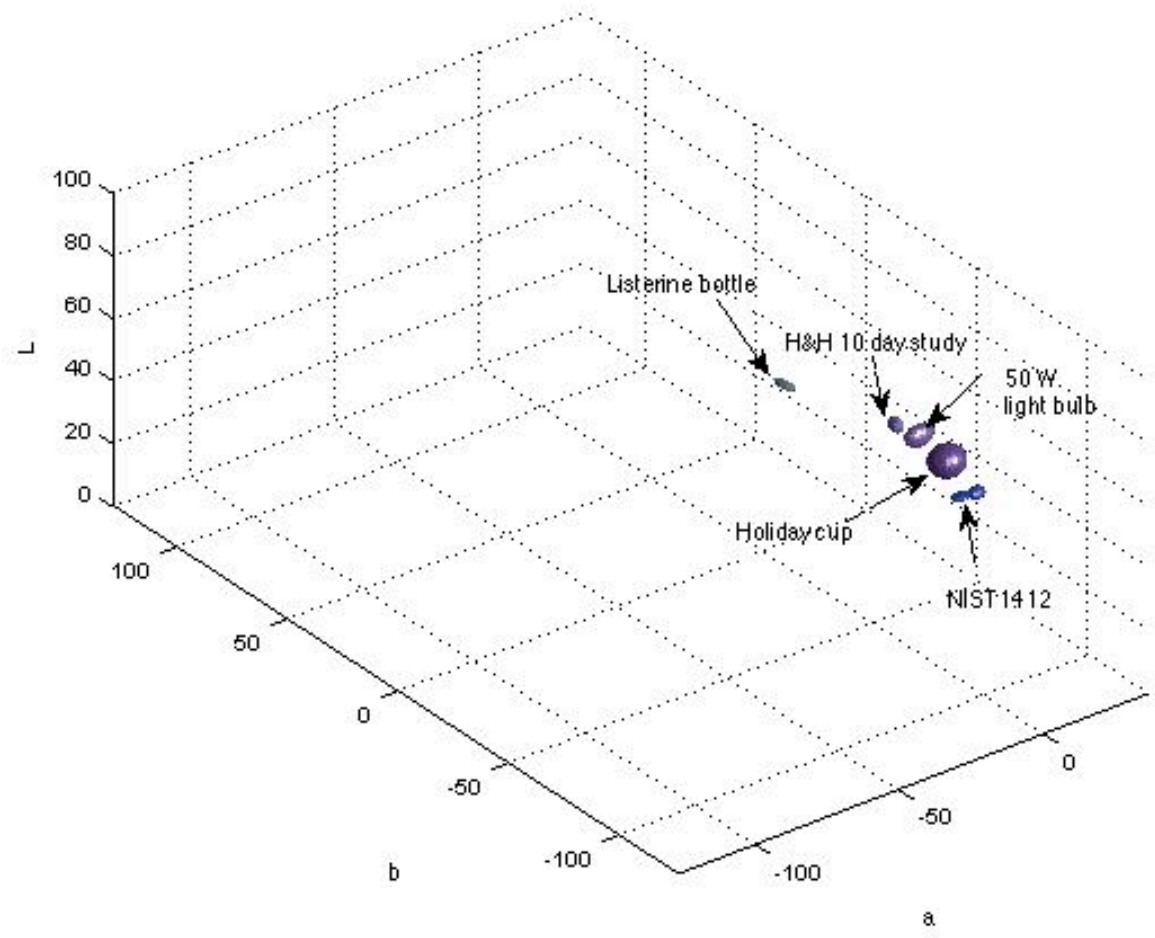

Figure 20 intra-sample variations of evidentiary samples over all $L A B$ space

Results show that the combination of RI and CL was sufficient to differentiate all glass samples. Cathodoluminescence of larger glass collections will inevitably result in many more cases where distinctions cannot be drawn, but clearly the use of $\mathrm{CL}$ as a supplement to simple refractive index measurements greatly increases the ability to classify and distinguish glass samples. 


\subsection{Evidentiary study II differentiation using CL and LAB coordinates}

As can be seen from the results of RI measurements, the headlight glass can be delineated into two groups: RI of 1.474 and 1.478 . Color analysis was carried out on the data and the results are shown in Figures 21 and 23. Figure 21 shows the RI 1.474 group, while Figure 23 shows the RI 1.478 group.

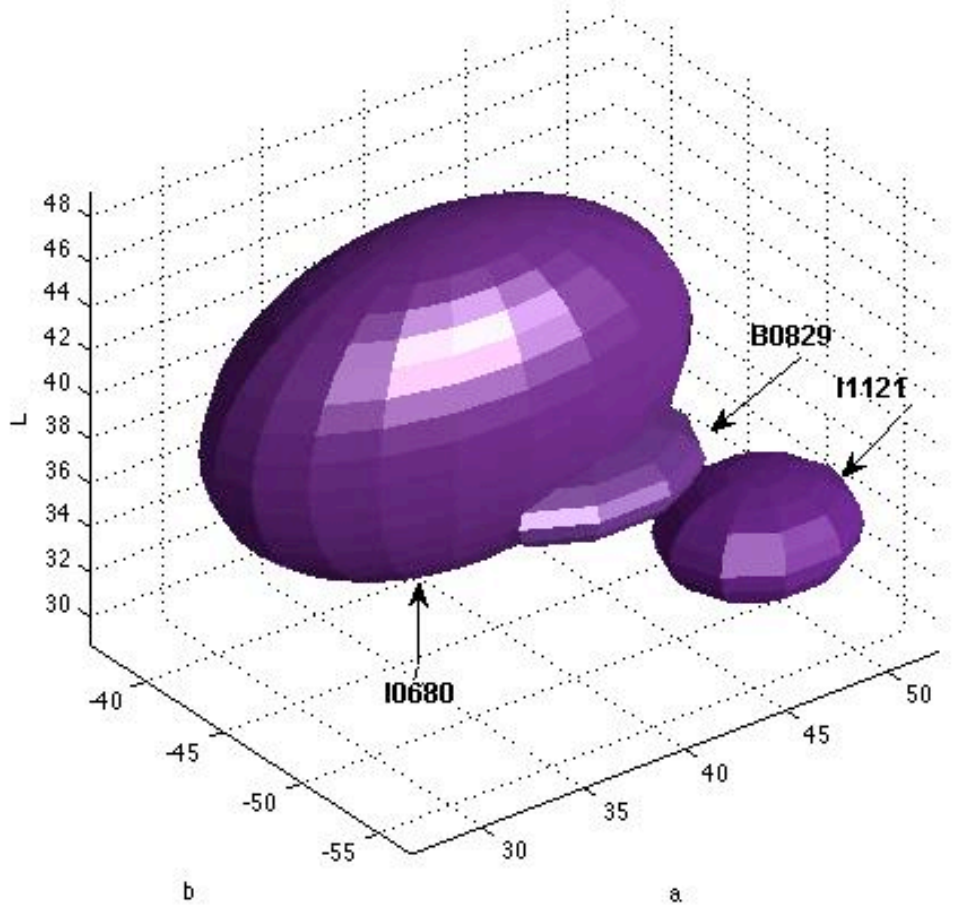

Figure 21 Automobile headlight glasses with RI of 1.474

As can be seen in figure 21 , differentiation between the three samples in the RI 1.474 group is impossible. All samples have large relative uncertainties. Figure 22 illustrates the importance of using uncertainty ellipses. L, a, and b values are plotted without any associated uncertainty. Without the uncertainty accounted for, all three samples are clearly differentiated. However, this accounts for no variation in the samples, which is critical for this application. 


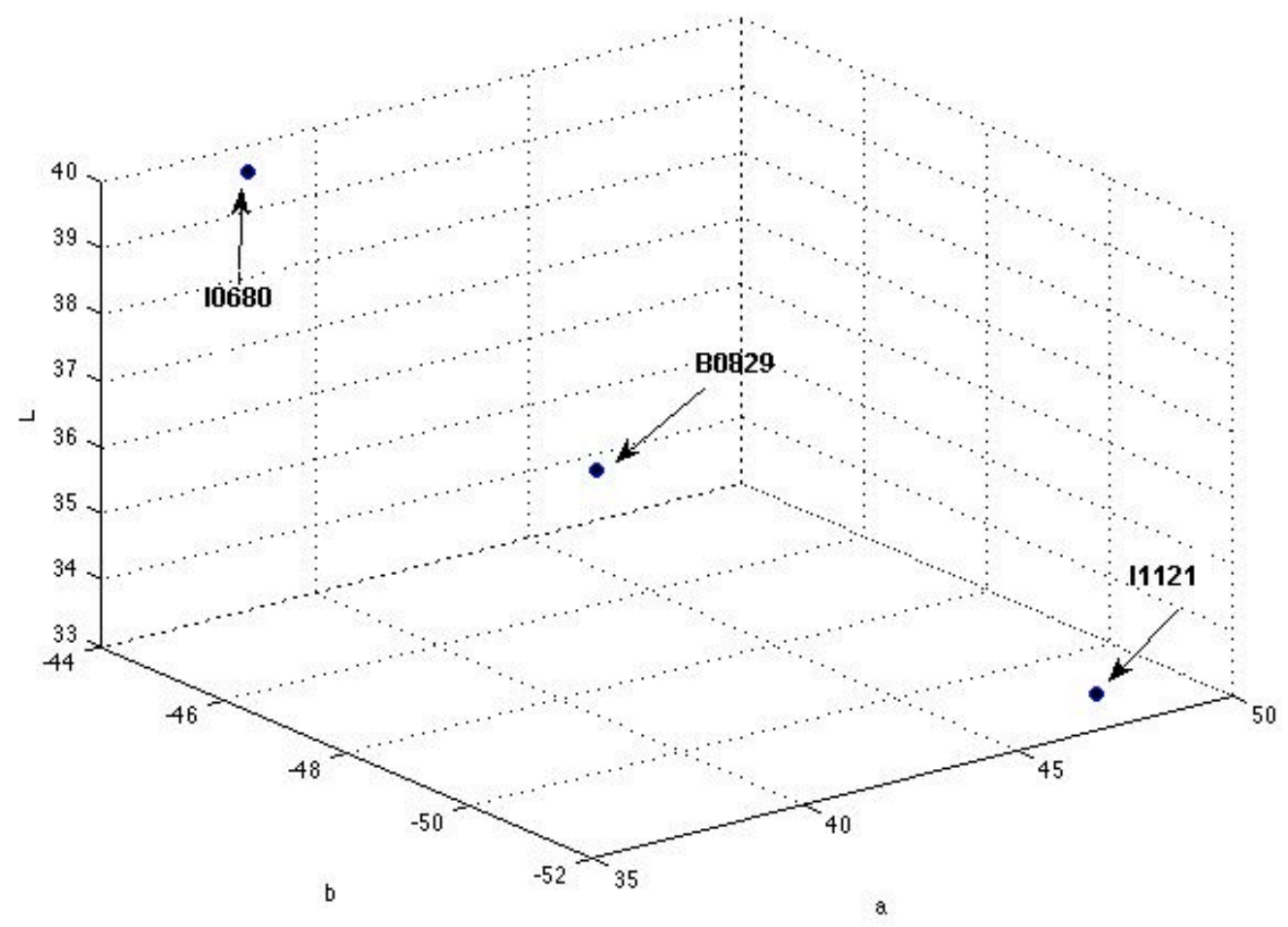

Figure 22 Plot of $L$, $a$, and $b$ values for $R I$ group 1.474 without associated uncertainties

Further investigation of the data and samples revealed no apparent reason for the variation across these samples. Samples were inspected visually for noticeable curvature or surface defect that may affect $C L$ emission. All samples investigated were flat with no apparent deviations that may have affected the $C L$ emission. The instrument and log books were both inspected for any obvious errors. No instrumental problems were found or recorded. For 10680, spectra from area 4 and 5 were not similar to areas one through three. There is no apparent reason for this variation. The spectral shape is consistent, but the intensity differs. This may be due to an unrecorded instrumental error. 
The data from these samples suggest that spectra may not be reproducible across a sample of headlight glass. Headlight glass may also have some sort of proprietary coating that may affect the CL emission.

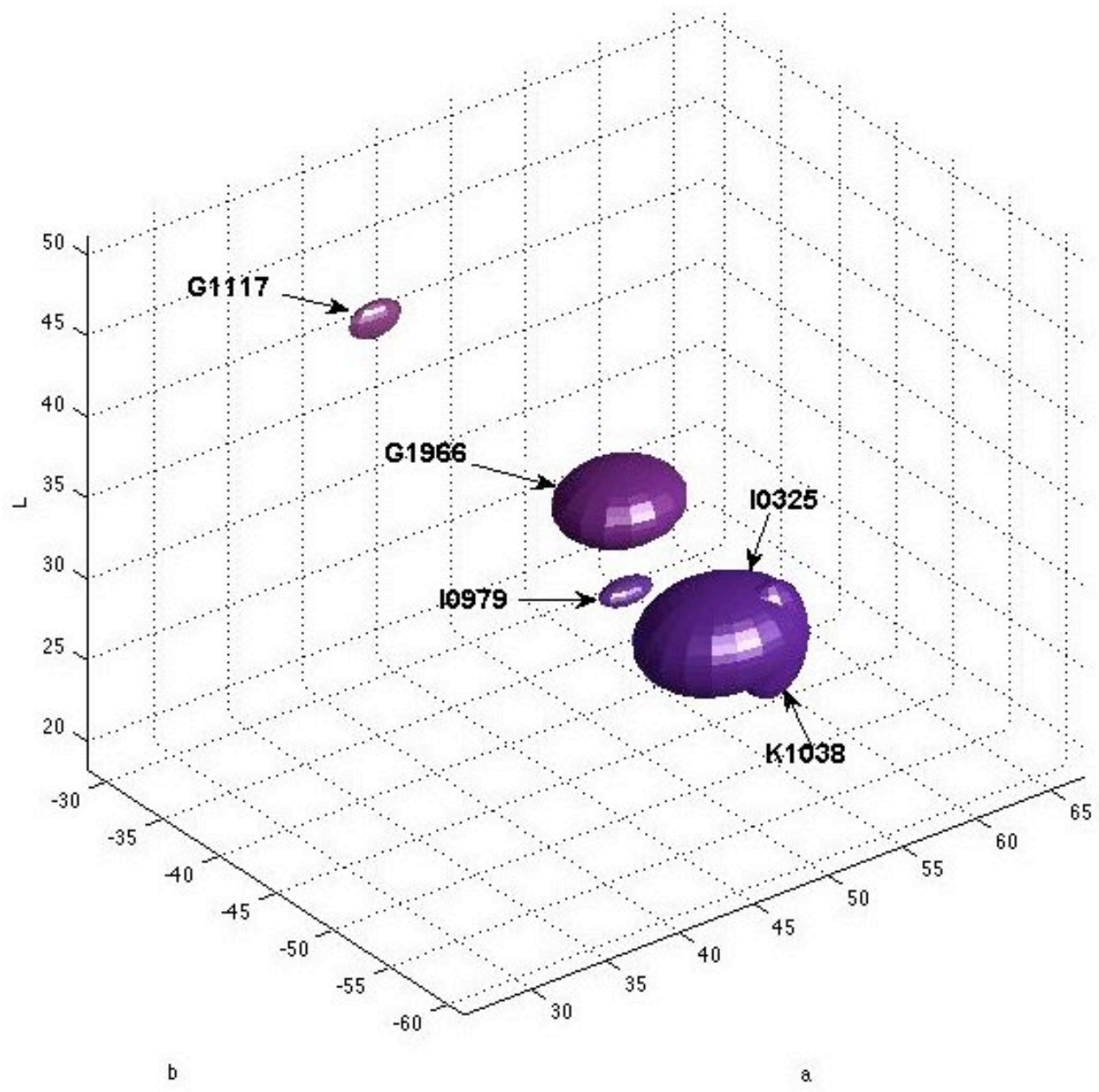

Figure 23 Automobile headlight glasses with RI of 1.478

As can be seen in Figure 23, three out of the five glass samples can be successfully differentiated in the RI 1.478 group. 10325 and K0138 overlap, making it impossible to differentiate the two samples. Upon further investigation of the data, I0325 has a large variation within the five replicate spectra. As with 
10680 above, the sample was investigated visually for noticeable surface curvature or surface defect that may affect CL emission. The sample was found to be flat, with no deviations across the surface. The instrument and log books were both inspected for any obvious errors. No instrumental problems were found or recorded. Again, results from this RI class also indicate that spectra may not be reproducible across a headlight glass sample.

\subsection{Break simulation}

Results from the break simulation are shown in Figure 24 . When each separate sample is plotted individually, samples can be discriminated. When investigating the values obtained for $\mathrm{L}, \mathrm{a}$, and $\mathrm{b}$, it can be seen that the values are quite similar over the 9 samples. The average values of $L, a$, and $b$ are plotted together and the resulting ellipse is shown in Figure 25. When the average of each value is obtained and plotted against other window glass

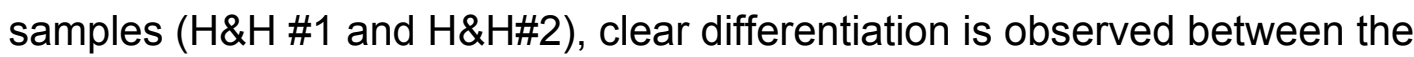
three samples as can be seen in Figure 26.

\begin{tabular}{|c|c|c|c|c|c|c|}
\hline Sample & avg a & avg b & avg L & $\mathbf{9 5 \%} \mathbf{~ a}$ & $\mathbf{9 5 \%} \mathbf{~ b}$ & $\mathbf{9 5 \%} \mathbf{~}$ \\
\hline outer edge possible top pane & 15.44 & -39.68 & 50.94 & 0.5600 & 0.6507 & 0.5350 \\
\hline top pane conrol non-Sn side & 14.80 & -37.32 & 53.15 & 1.1087 & 1.6032 & 0.9909 \\
\hline bottom pane control non-Sn side & 14.20 & -38.09 & 50.35 & 2.0550 & 1.9258 & 1.7113 \\
\hline misc spray & 16.68 & -37.82 & 52.82 & 0.7974 & 0.4480 & 0.4514 \\
\hline inside perimeter on table & 16.86 & -39.88 & 52.32 & 0.6379 & 0.5723 & 0.7290 \\
\hline In between panes & 16.76 & -37.70 & 52.68 & 0.6110 & 0.4888 & 0.3518 \\
\hline Center of break on table & 15.75 & -39.62 & 52.28 & 0.8674 & 1.0952 & 0.8900 \\
\hline random pieces on top of pane & 15.38 & -39.43 & 51.68 & 0.7317 & 0.5021 & 0.4345 \\
\hline bottom pane radial 1 & 16.35 & -38.73 & 52.30 & 0.1374 & 0.1062 & 0.1449 \\
\hline AVERAGE & 15.80 & -38.70 & 52.06 & 0.8341 & 0.8214 & 0.6932 \\
\hline
\end{tabular}

Table $10 L, a$, and $b$ values for all break simulation samples 


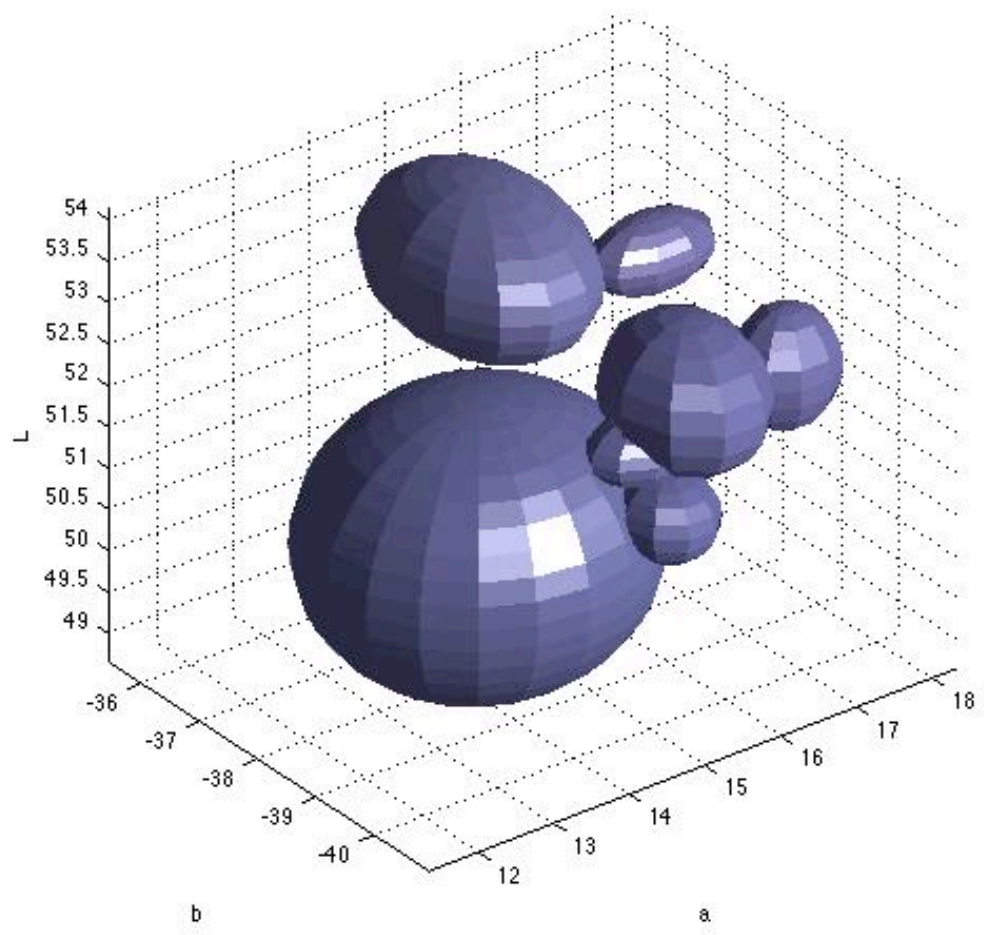

Figure 24 Break simulation all individual 


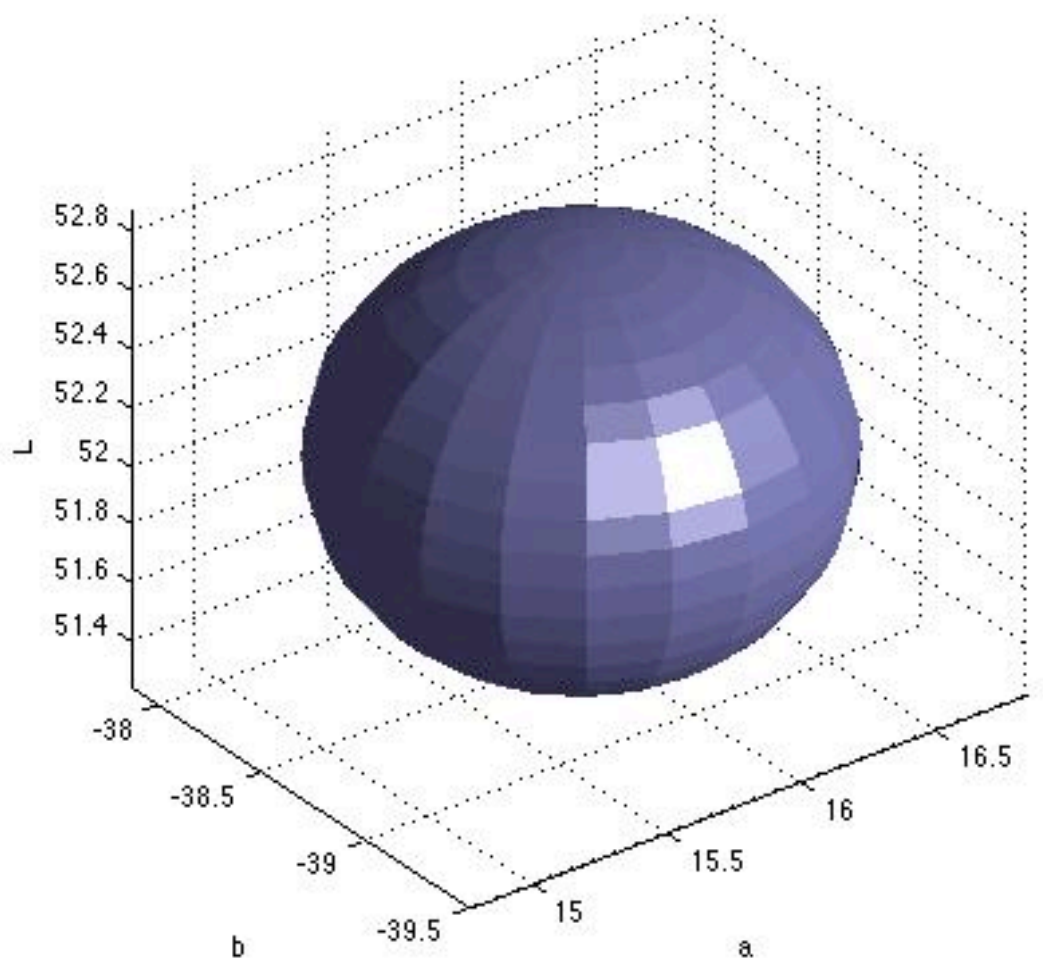

Figure 25 Break simulation all combined - note scale 


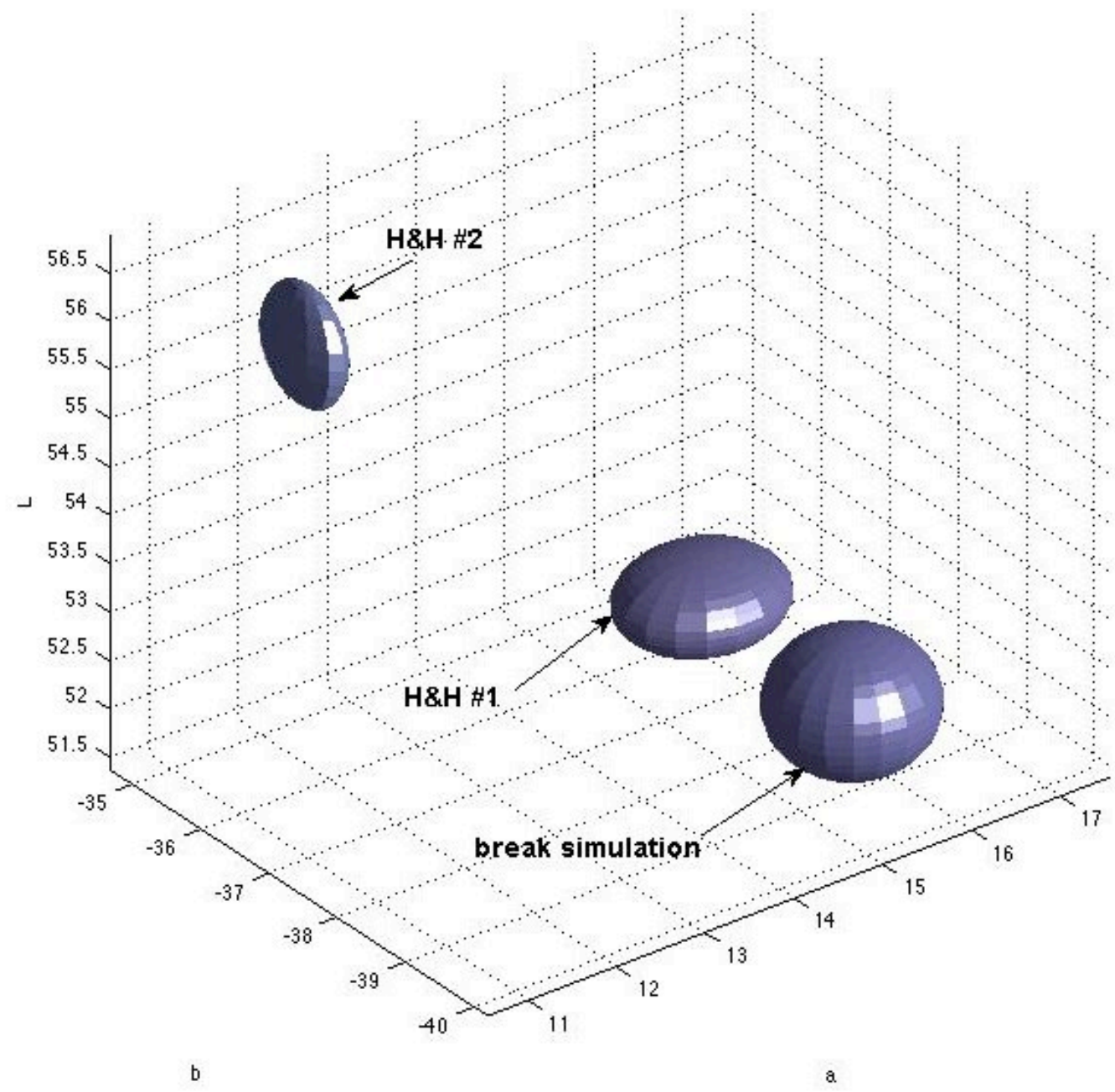

Figure 26 Window glass discrimination 


\section{CHAPTER FOUR: Conclusions and Future Work}

\subsection{Conclusions}

The results of the current study show that the combination of $\mathrm{CL}$ and color analysis provides an alternative means of differentiating glass samples. $\mathrm{CL}-$ SEM is an attractive technique as it is non-destructive and sample preparation is minimal. The CL system may be installed on SEMs that are currently being used, thus making it an attractive option for labs with such capabilities.

It is also possible to purchase a standalone CL system combined with a polarizing light microscope. In comparison to the purchase of a GRIM instrument, a standalone CL system is approximately a third of the cost. This is a cost effective alternative for forensic laboratories wishing to perform glass analyses utilizing the $\mathrm{CL}$ technique.

It is evident from the method validation study that a suitable standard is needed for $\mathrm{CL}$ that facilitates the correlation of spectral features to chemical structure before a large database can be built. The data also suggests that samples be analyzed on the same day to minimize time-dependent variation. This variation was found to be significant in the current study. It is also critical to account for uncertainty in the color measurement. This allows for meaningful comparisons to be made.

It was found that curvature of the sample has a large effect on the spectral patterns obtained. The problem of curvature appears to contribute to a large uncertainty, especially in the $b$ axis. The reason for this is unknown and 
measures must be taken in the future to account non-destructively for this curvature.

Figures 27 and 28 show the ability of the combination of RI and CL/color analysis in the successive classification of evidentiary glass samples. Results from RI measurements enabled the classification of samples from the CSC into 3 groups, while headlight glass samples were able to be classified into 4 groups. Use of CL and color analysis enabled further discrimination of all of the CSC samples and reasonable discrimination of the headlight glass samples. 


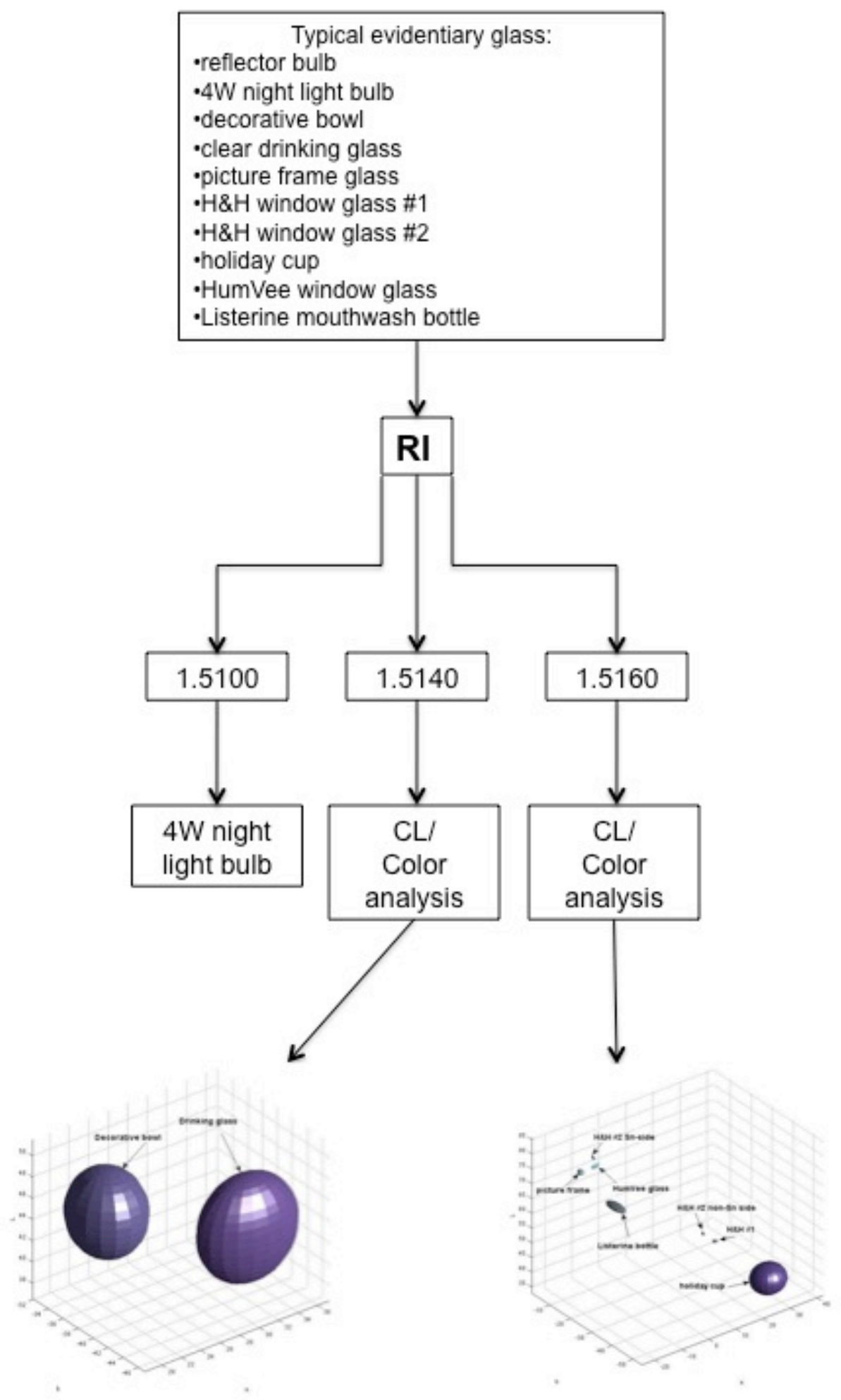

Figure 27 Successive classifications of evidentiary samples from CSC 


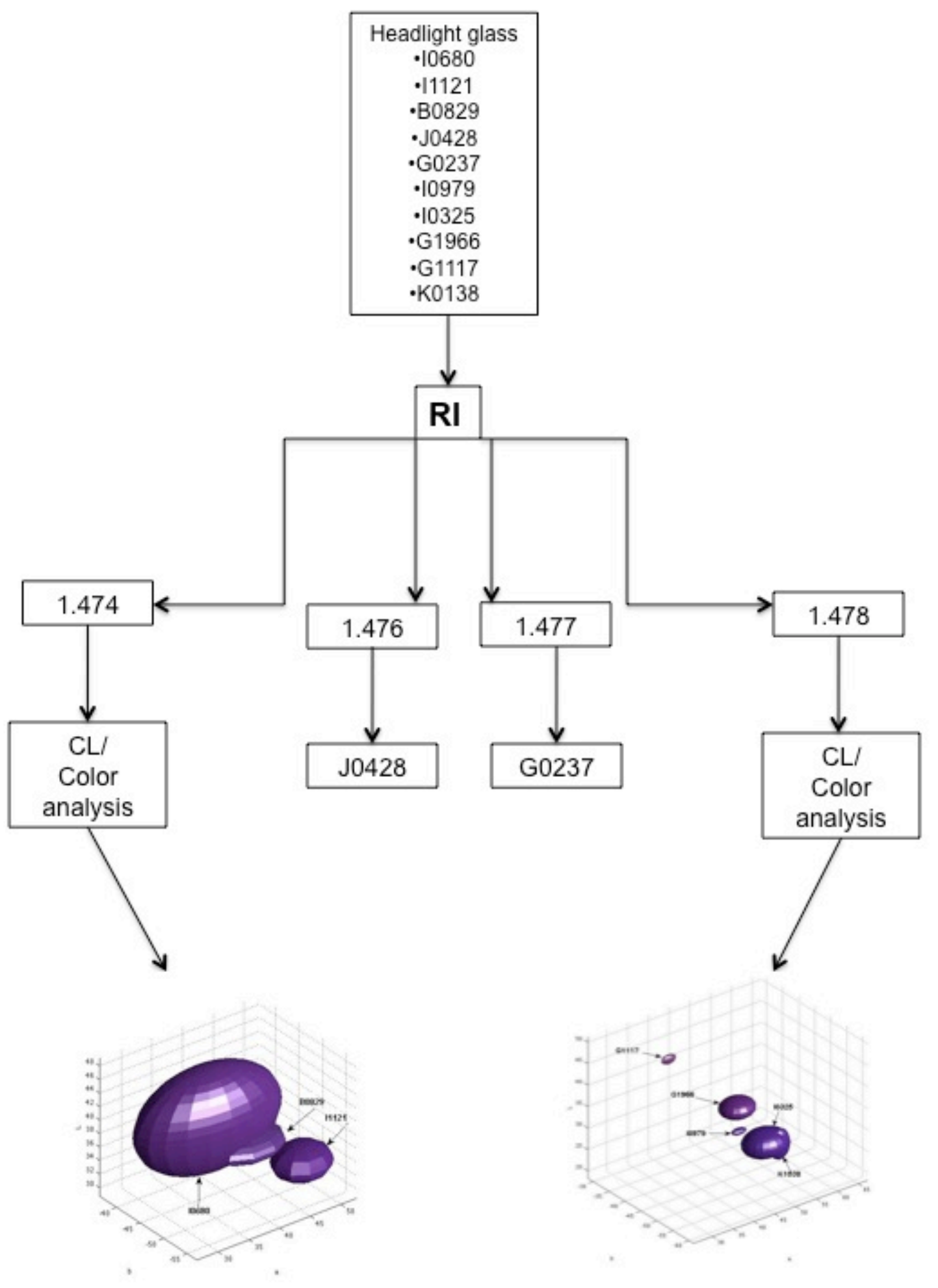

Figure 28 Successive classifications of headlight glass samples 


\subsection{Future work}

Results from this study indicate many areas for future work. Future work may include:

- Investigate the creation of a universal standard for CL. A previous study has shown that a universal standard has been difficult to manufacture as well as consistently analyze between labs [39]. In order for a reliable database of glass spectra and correlated color to be created, a standard is critical.

- Further investigate the issue of sample curvature. Development of methods for handling this issue without destroying possible evidence are critical, as well as determining the underlying cause of the variation.

- Analyzing samples at liquid nitrogen or helium temperatures may also be useful in elucidating more defined peaks in the CL spectra.

- Investigate the effect of sample size. The samples used in this study were large to test the validity of the method. However, samples encountered in case work may be smaller and therefore work needs to be done on this effect. 


\section{References}

1. Lambert, J. Forensic Science International, 1984. 26, 1-23.

2. Trejos, T.; Montero, S.; Almirall, J.R.; Analytical Bioanalytical Chemistry, 2003, 376, 1255-1264

3. Parouchais, T.; Warner, I.M.; Palmer L.T.; Kobus, H. Journal of Forensic Sciences, 1996, 41(3): p. 351-60

4. Bajic, S.J.; Aeschliman, D.B.; Saetveit, N.J.; Baldwin, D.P.; Houk, R.S., Journal of Forensic Sciences, 2005, 50, 1123-7.

5. Trejos, T.; Almirall, J.R. Talanta, 2005, 67, 388-395.

6. Coumbaros, J.; Denman, J.; Kirklbride, K.P.; Walker, G.S.; Skinner, W. Journal of Forensic Sciences, 2008, 53, 312-320.

7. Reeve, V.; Mathiesen, J.; Fong, W. Journal of Forensic Sciences, 1976, 21, 291-306.

8. Calloway, A.R.; Jones,P.F. Journal of Forensic Sciences, 1978, 23, 26373.

9. Almirall, J.R.; Cole, M.D.; Gettinby, G.; Furton, K.G. Science and Justice, 1998, 32, 91-100.

10. Andrasko, J.; Maehly,A.C. Journal of Forensic Sciences, 1978, 23, 25062.

11. Rao, K.J., Structural Chemistry of Glasses. 2002, New York: Elsevier.

12. Skoog, D.A.; Holler, F.J.; Nieman, T.A., Principles of Instrumental Analysis. 5th ed. 1998. USA: Thomson Learning

13. Davis, J.E. The Journal of Criminal Law, Criminology, and Police Science, 1957, 47, 614-19.

14. Davis, J.E., The Journal of Criminal Law, Criminology, and Police Science, 1956, 47, 380-86.

15. Bennett, R.L.; Curran, J.M.; Coulson, S.A; Newton, A.W.N. Science and Justice, 2003, 43, 71-76. 
16. Newton, A.W.N.; Curran, J.M.; Triggs, C.M.; Buckleton, J.S. Forensic Science International, 2004, 14, 185-93.

17. Crookes, W. Philosophical Transactions of the Royal Society of London, 1879, 170, 641-662.

18. Gustafsson, A. Journal of Microscopy, 2006, 224, 72-8.

19. Gustafsson, A.; Pistol, M.; Montelius, L.; Samuelson, L. Journal of Applied Physics, 1998, 84, 1715-1775.

20. Remond, G.; Cesbron, F.; Chapoulie, R.; Ohnenstetter, D.; RoquesCarmes, C.; Schboerer, M. Scanning Microscopy, 1992, 6, 23-68.

21. Townsend, P.D.; Karali, T.; Rowlands, V.A.; Smith, A.; Vazquez, G. Mineralogical Magazine, 1999, 63, 211-226.

22. Marfunin, A.S., Spectroscopy, Luminescence and Radiation Centers in Minerals. 1979, Berlin: Springer-Verlag.

23. Gotze, J., Analytical and bioanalytical chemistry, 2002, 374(4), 703-8.

24. Palenik, C.S. and J. Buscaglia, in Forensic Analysis on the Cutting Edge, R.D. Blackledge, Ed.; Applications of Cathodoluminescence in Forensic Science, John Wiley \& Sons, Inc: Hoboken; pp141-173

25. Holt, D.B.; Datta, S. Scanning Electron Microscopy, 1980, 1, 259-78.

26. Holt, D.B., Scanning Microscopy, 1992, 6, 1-21.

27. Gotte, T.; Richter, D. K. Mineralogical Magazine, 2004, 68, 199-207.

28. Habermann, D. Mineralogy and Petrology, 2002, 76, 247-59.

29. Vogel, W., Glass Chemistry. 2nd ed. 1992, Berlin: Springer-Verlag.

30. Pollard, A.M.; Heron, C., Archaeological Chemistry. 2nd ed. 2008, Cambridge: The Royal Society of Chemistry.

31. Pilkington, L.A.B, Proceedings of the Royal Society of London. Series A, Mathematical and Physical Sciences, 1969, 314, 1-25

32. Grieve, M.C.;Dunlop, J.; Haddock, P. Journal of Forensic Sciences, 1988, 33, 1332-44.

33. Laing, D.K.; Hartshorne, A.W.; Cook, R.; Robinson, G. Journal of Forensic Sciences, 1987, 32, 364-369. 
34. Chaikovsky, A.; Brown, S.; David, L.S.; Balman, A.; Barzovski, A. Journal of Forensic Sciences, 2003, 48, 1396-405.

35. Hammond,D.L. Journal of Forensic Sciences, 2007, 52, 967-73.

36. Ohta, N. and A.R. Robertson, Colorimetry Fundamentals and Applications. 2005, West Sussex, England: John Wiley \& Sons, Ltd.

37. Bell, S., The Chemistry of Color and Colorants, in Forensic Chemistry. 2005, Prentice Hall: Upper Saddle River, NJ.

38. Westland, S. and C. Ripamonti, Computational Color Science Using MatLab. 2004, West Sussex, England: John Wiley \&Sons, Ltd.

39. Hanchar, J.M.; Marshall, D. J. Scanning Microscopy, Supplement, 1995 9, 269-276.

40. Lambert, J.; Evett, I.W. Forensic Science International, 1984, 26, 1-23.

41. Lambert, J.; Satterthwaite, M.; P. Harrison, P. Science and Justice, 1995 $35,273-281$. 


\section{Appendices}

4 W Night Light Bulb

\begin{tabular}{|c|c|c|c|c|c|c|}
\hline & $\mathrm{L}$ & $\mathrm{A}$ & $\mathrm{B}$ & $\mathrm{rL}$ & $\mathrm{rA}$ & $\mathrm{rB}$ \\
\hline Area 1 & 38.31 & 37.00 & -45.51 & & & \\
\hline Area 2 & 41.05 & 32.91 & -40.91 & ST DEV & ST DEV & ST DEV \\
\hline Area 3 & 52.75 & 23.24 & -36.96 & 5.643 & 5.512 & 3.428 \\
\hline Area 4 & 42.19 & 36.41 & -44.78 & & & \\
\hline Area 5 & 40.58 & 32.28 & -42.67 & CONFIDENCE & CONFIDENCE & CONFIDENCE \\
\hline & 42.98 & 32.37 & -42.16 & 4.946 & 4.831 & 3.005 \\
\hline
\end{tabular}

Table $11 \mathrm{~L}$, $a$, and $b$ values for $4 W$ night light bulb

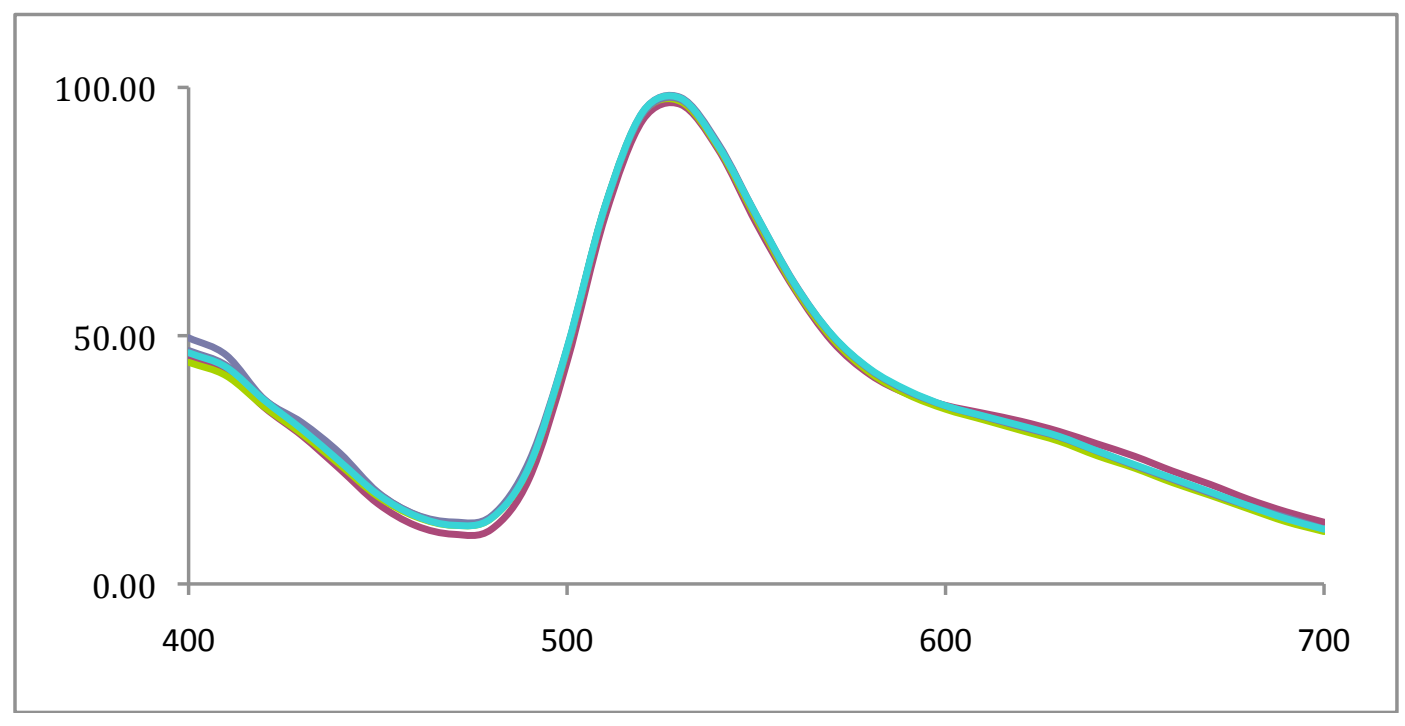

Figure 29 Smoothed data - 4W night light bulb 


\begin{tabular}{|c|c|c|c|c|c|c|}
\hline & $\mathrm{L}$ & $\mathrm{A}$ & $\mathrm{B}$ & $\mathrm{rL}$ & $\mathrm{rA}$ & $\mathrm{rB}$ \\
\hline Area 1 & 40.77 & 31.19 & -40.68 & & & \\
\hline Area 2 & 49.43 & 20.31 & -34.66 & ST DEV & ST DEV & ST DEV \\
\hline Area 3 & 41.24 & 31.08 & -40.22 & 3.855 & 5.682 & 2.966 \\
\hline Area 4 & 44.70 & 24.25 & -36.71 & & & \\
\hline Area 5 & 47.81 & 19.38 & -34.48 & CONFIDENCE & CONFIDENCE & CONFIDENCE \\
\hline & 44.79 & 25.24 & -37.35 & 3.379 & 4.981 & 2.600 \\
\hline
\end{tabular}

Table $12 L$, $a$, and $b$ values for $50 W$ reflector bulb

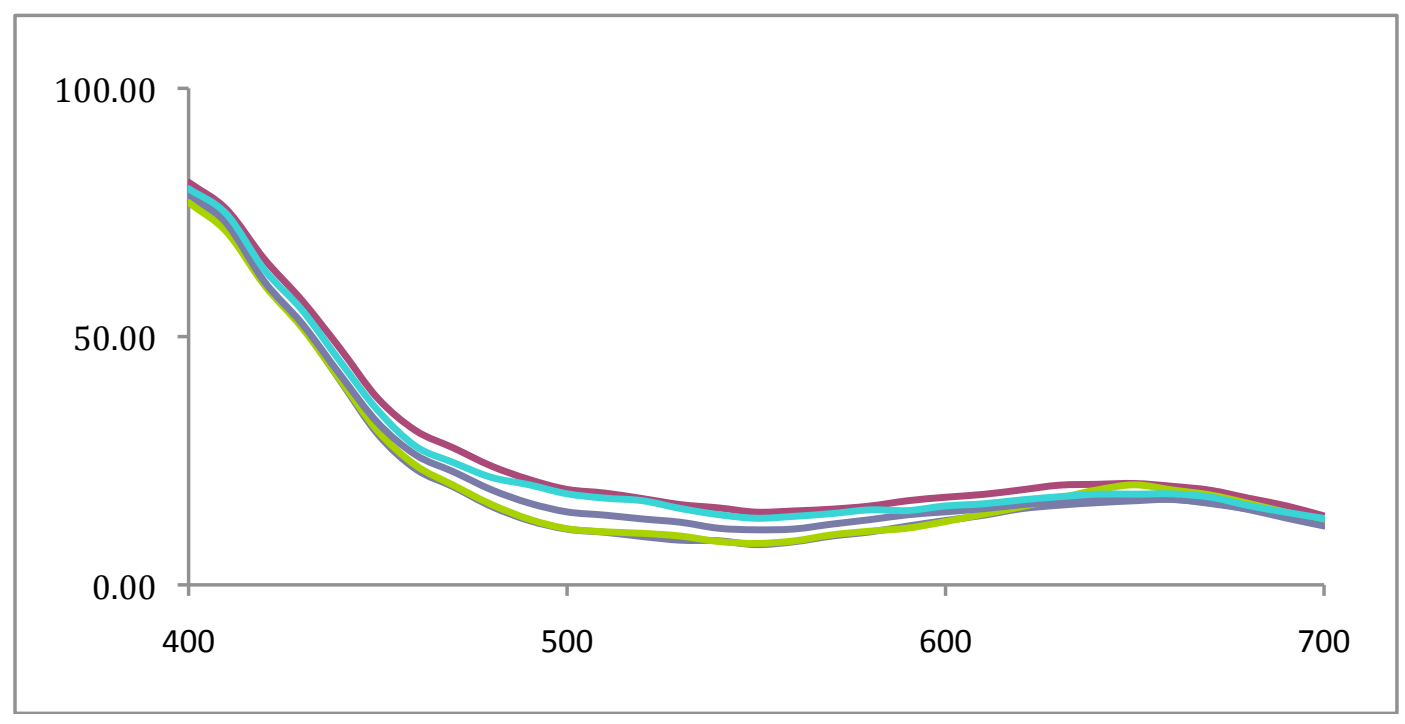

Figure 30 Smoothed data - 50W reflector bulb 


\section{Decorative bowl}

\begin{tabular}{|c|c|c|c|c|c|c|}
\hline & $\mathrm{L}$ & $\mathrm{A}$ & $\mathrm{B}$ & $\mathrm{rL}$ & $\mathrm{rA}$ & $\mathrm{rB}$ \\
\hline Area 1 & 48.86 & 18.09 & -34.33 & & & \\
\hline Area 2 & 47.26 & 20.57 & -36.36 & ST DEV & ST DEV & ST DEV \\
\hline Area 3 & 47.92 & 20.69 & -35.01 & 4.625 & 3.912 & 4.238 \\
\hline Area 4 & 48.04 & 20.24 & -35.36 & & & \\
\hline Area 5 & 37.76 & 28.32 & -45.73 & CONFIDENCE & CONFIDENCE & CONFIDENCE \\
\hline & 45.97 & 21.58 & -37.36 & 4.054 & 3.429 & 3.715 \\
\hline
\end{tabular}

Table $13 L$, $a$, and $b$ values for Decorative bowl

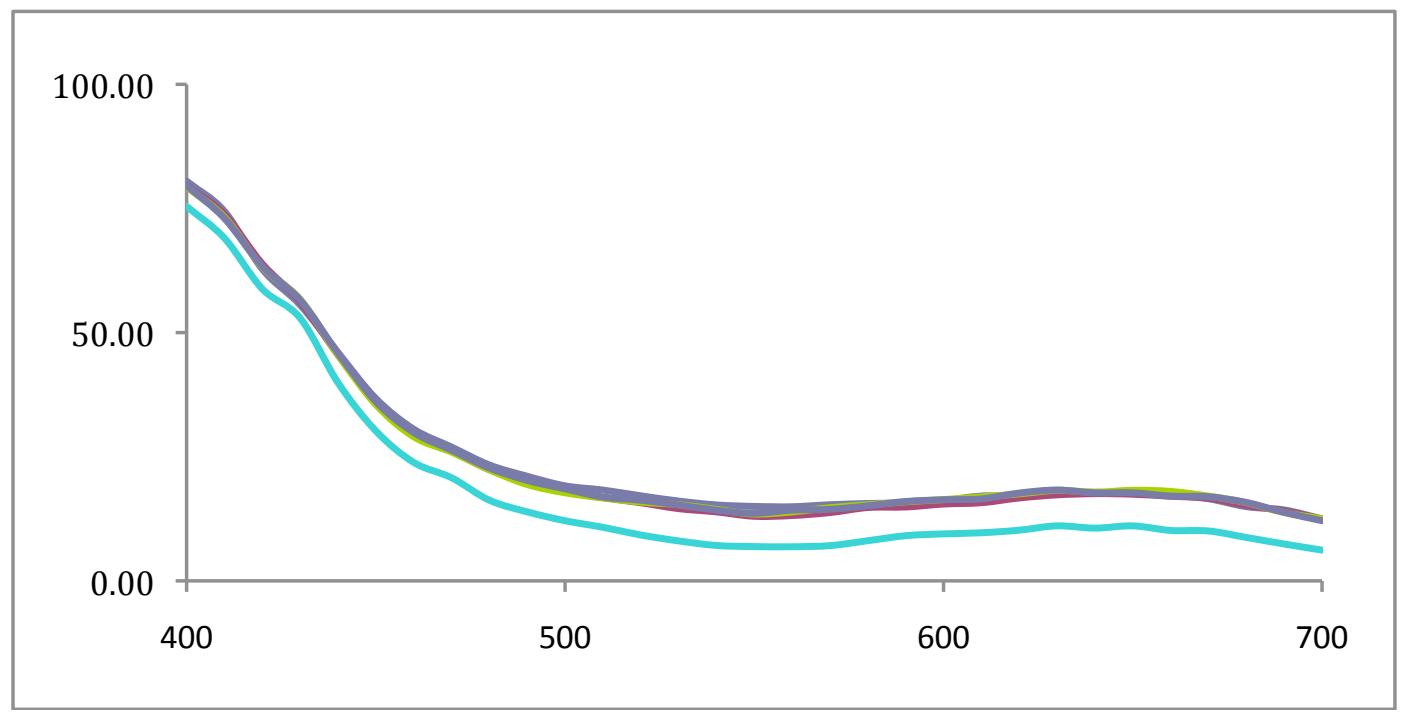

Figure 31 Smoothed data - Decorative bowl 


\section{$H \& H \# 1$}

\begin{tabular}{|c|c|c|c|c|c|c|}
\hline & $\mathrm{L}$ & $\mathrm{A}$ & $\mathrm{B}$ & $\mathrm{rL}$ & $\mathrm{rA}$ & $\mathrm{rB}$ \\
\hline Area 1 & 52.42 & 16.03 & -35.35 & & & \\
\hline Area 2 & 52.35 & 15.23 & -36.11 & ST DEV & ST DEV & ST DEV \\
\hline Area 3 & 51.35 & 15.26 & -37.43 & 0.526 & 0.998 & 0.853 \\
\hline Area 4 & 51.32 & 16.25 & -35.37 & & & \\
\hline Area 5 & 51.83 & 17.68 & -36.33 & CONFIDENCE & CONFIDENCE & CONFIDENCE \\
\hline & 51.85 & 16.09 & -36.12 & 0.461 & 0.874 & 0.748 \\
\hline
\end{tabular}

Table $14 L$, $a$, and $b$ values for $H \& H \# 1$

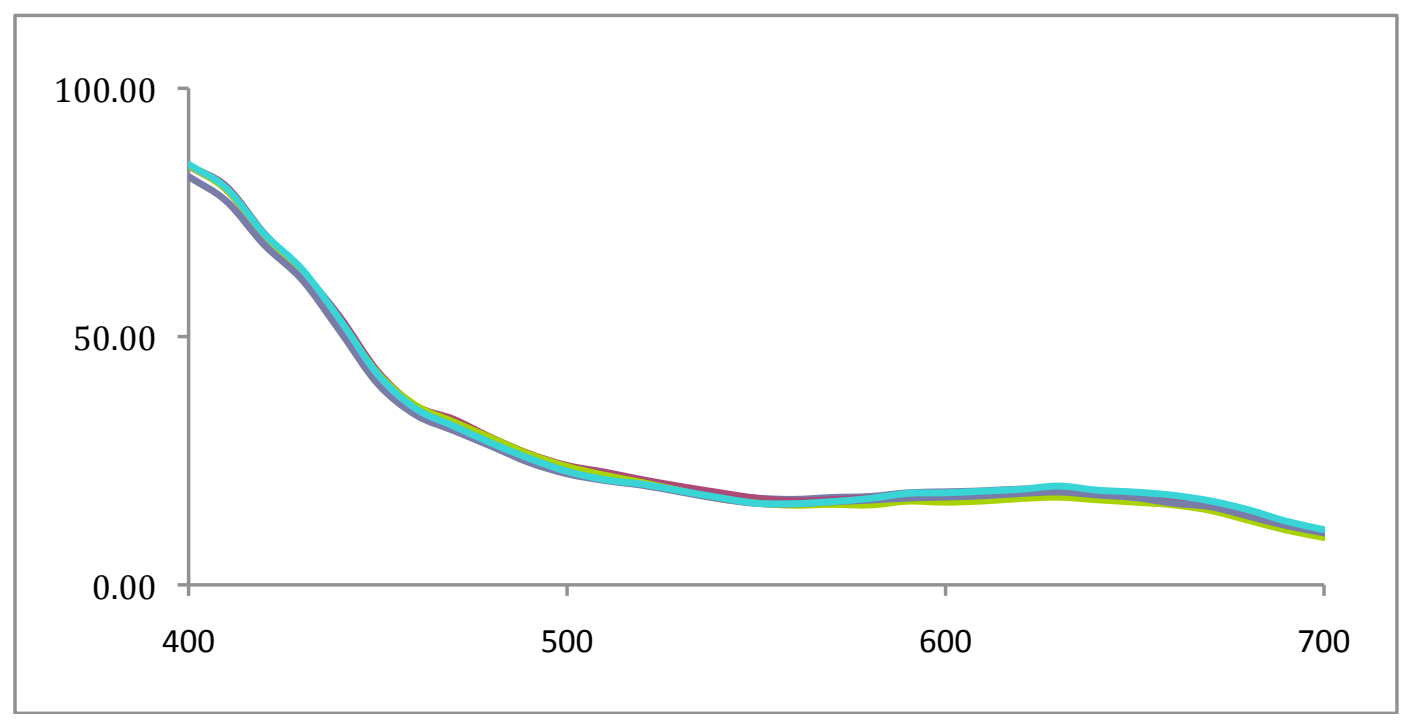

Figure 32 Smoothed data - H\&H \#1 


\begin{tabular}{|c|c|c|c|c|c|c|}
\hline & $\mathrm{L}$ & $\mathrm{A}$ & $\mathrm{B}$ & $\mathrm{rL}$ & $\mathrm{rA}$ & $\mathrm{rB}$ \\
\hline Area 1 & 85.74 & -17.21 & -20.21 & & & \\
\hline Area 2 & 85.49 & -17.16 & -20.40 & ST DEV & ST DEV & ST DEV \\
\hline Area 3 & 85.38 & -17.03 & -20.20 & 0.797 & 0.264 & 0.879 \\
\hline Area 4 & 84.33 & -17.72 & -21.62 & & & \\
\hline Area 5 & 83.92 & -17.25 & -22.07 & CONFIDENCE & CONFIDENCE & CONFIDENCE \\
\hline & 84.97 & -17.27 & -20.90 & 0.699 & 0.232 & 0.770 \\
\hline
\end{tabular}

Table $15 L$, $a$, and $b$ values for $H \& H \# 2$ Sn-side

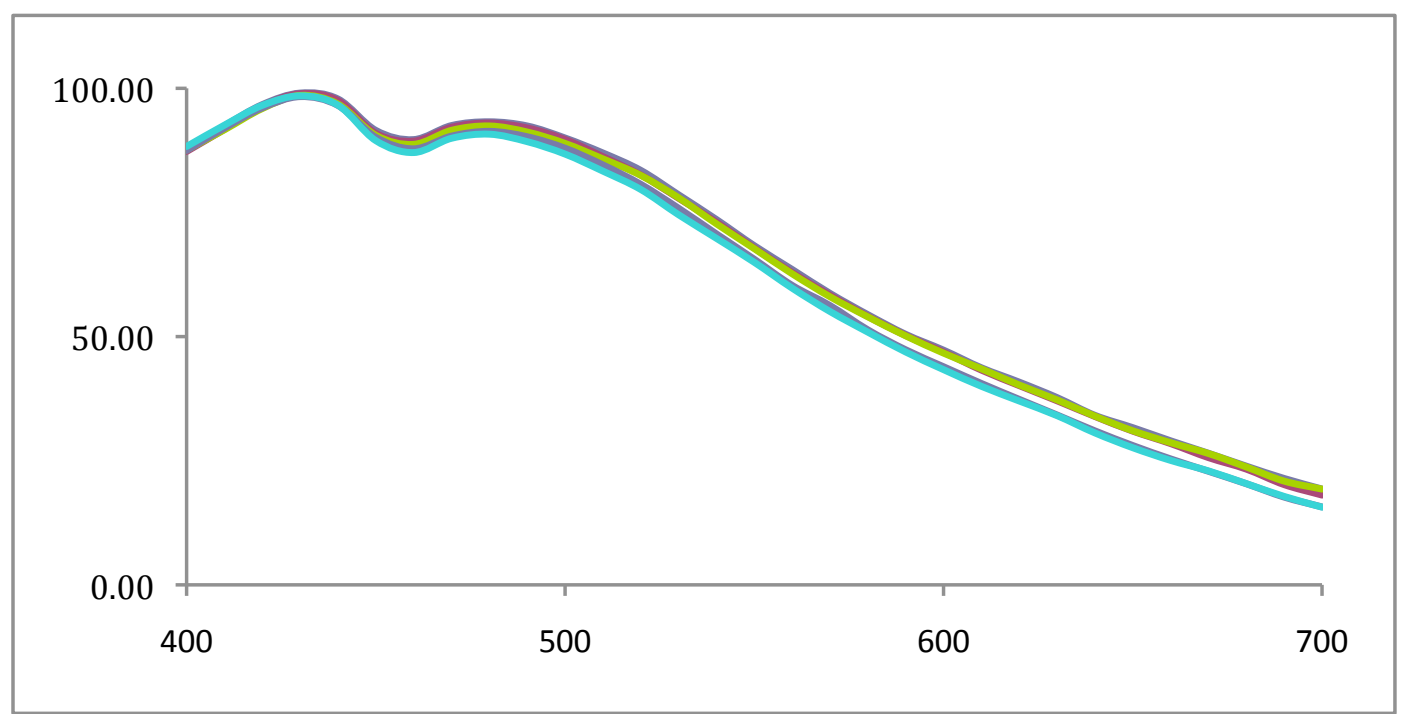

Figure 33 Smoothed data - H\&H \#2 Sn-side 


\section{H\&H \#2}

\begin{tabular}{|c|c|c|c|c|c|c|}
\hline & $\mathrm{L}$ & $\mathrm{A}$ & $\mathrm{B}$ & $\mathrm{rL}$ & $\mathrm{rA}$ & $\mathrm{rB}$ \\
\hline Area 1 & 55.26 & 11.37 & -37.11 & & & \\
\hline Area 2 & 56.61 & 11.08 & -36.46 & & & \\
\hline Area 3 & 56.20 & 11.51 & -36.68 & ST DEV & ST DEV & ST DEV \\
\hline Area 4 & 56.12 & 11.71 & -36.72 & 0.714 & 0.262 & 0.684 \\
\hline Area 5 & 57.20 & 11.13 & -35.30 & CONFIDENCE & CONFIDENCE & CONFIDENCE \\
\hline & 56.28 & 11.36 & -36.45 & 0.626 & 0.230 & 0.600 \\
\hline
\end{tabular}

Table $16 L$, $a$, and $b$ values for $H \& H$ \#2

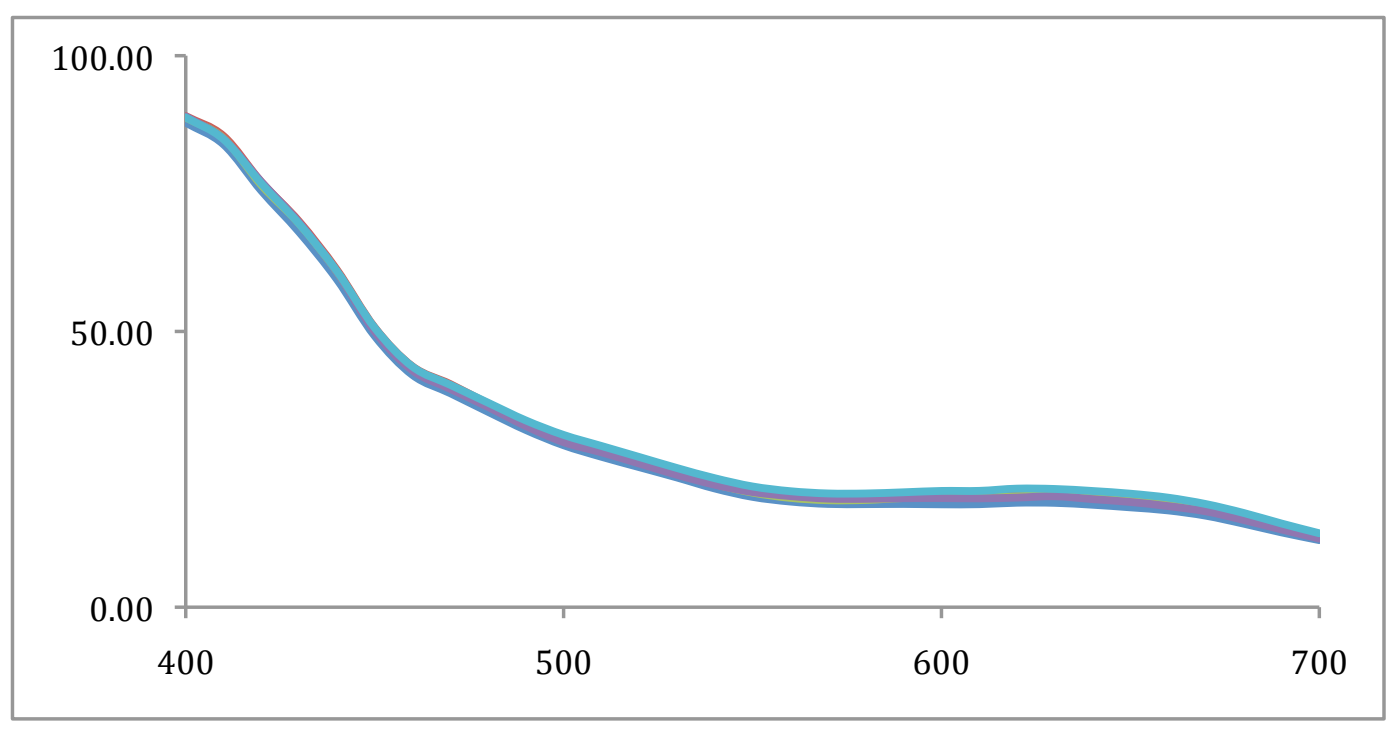

Figure 34 Smoothed data - H\&H \#2 


\section{Holiday Cup}

\begin{tabular}{|c|c|c|c|c|c|c|}
\hline & $\mathrm{L}$ & $\mathrm{A}$ & $\mathrm{B}$ & $\mathrm{rL}$ & $\mathrm{rA}$ & $\mathrm{rB}$ \\
\hline Area 1 & 36.61 & 29.17 & -46.99 & & & \\
\hline Area 2 & 29.14 & 42.16 & -51.72 & ST DEV & ST DEV & ST DEV \\
\hline Area 3 & 37.30 & 26.17 & -41.43 & 5.598 & 6.764 & 6.053 \\
\hline Area 4 & 41.50 & 27.57 & -39.66 & & & \\
\hline Area 5 & 43.73 & 26.24 & -36.57 & CONFIDENCE & CONFIDENCE & CONFIDENCE \\
\hline & 37.66 & 30.26 & -43.28 & 4.907 & 5.929 & 5.306 \\
\hline
\end{tabular}

Table $17 L$, $a$, and $b$ values for Holiday cup

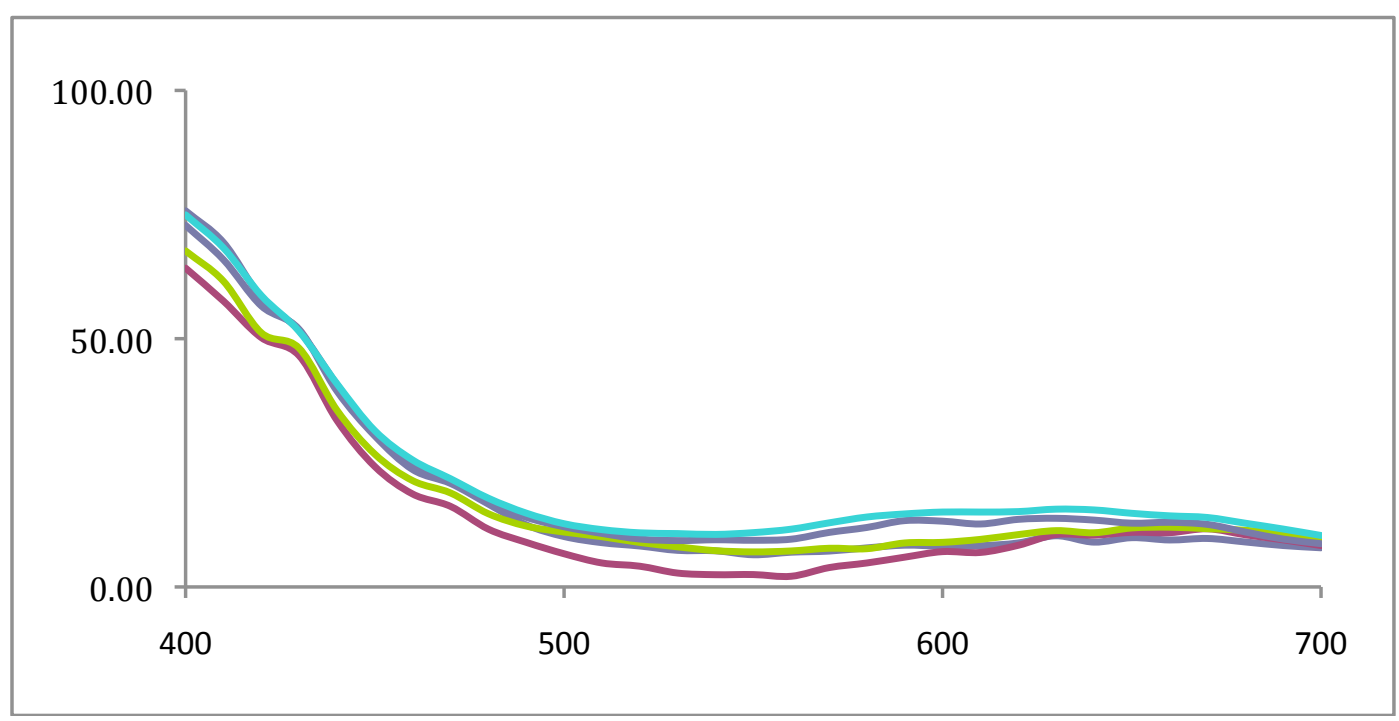

Figure 35 Smoothed data - Holiday cup 


\section{HumVee glass}

\begin{tabular}{|c|c|c|c|c|c|c|}
\hline & $\mathrm{L}$ & $\mathrm{A}$ & $\mathrm{B}$ & $\mathrm{rL}$ & $\mathrm{rA}$ & $\mathrm{rB}$ \\
\hline Area 1 & 81.65 & -16.36 & -22.50 & & & \\
\hline Area 2 & 83.83 & -19.72 & -21.87 & ST DEV & ST DEV & ST DEV \\
\hline Area 3 & 84.13 & -18.85 & -22.11 & 1.153 & 1.718 & 0.278 \\
\hline Area 4 & 81.72 & -15.59 & -22.48 & & & \\
\hline Area 5 & 82.78 & -17.18 & -22.06 & CONFIDENCE & CONFIDENCE & CONFIDENCE \\
\hline & 82.83 & -17.54 & -22.21 & 1.011 & 1.506 & 0.244 \\
\hline
\end{tabular}

Table $18 L$, $a$, and $b$ values for HumVee glass

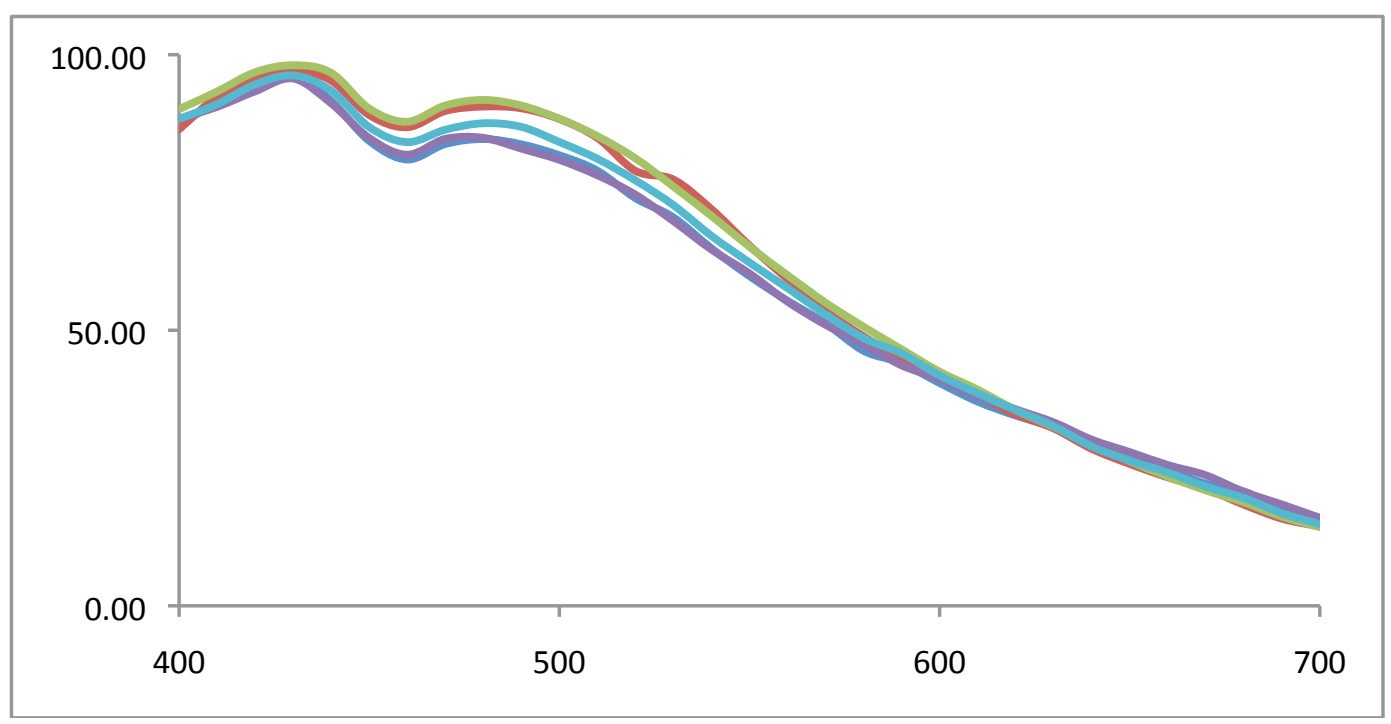

Figure 36 Smoothed data - HumVee glass 


\section{Listerine bottle}

\begin{tabular}{|c|c|c|c|c|c|c|}
\hline & $\mathrm{L}$ & $\mathrm{A}$ & $\mathrm{B}$ & $\mathrm{rL}$ & $\mathrm{rA}$ & $\mathrm{rB}$ \\
\hline Area 1 & 58.32 & -1.388 & -11.17 & & & \\
\hline Area 2 & 60.07 & -5.288 & -2.879 & ST DEV & ST DEV & ST DEV \\
\hline Area 3 & 58.15 & -0.196 & -14.27 & 1.061 & 2.111 & 5.009 \\
\hline Area 4 & 58.50 & -0.697 & -13.78 & & & \\
\hline Area 5 & 57.12 & -0.418 & -15.11 & CONFIDENCE & CONFIDENCE & CONFIDENCE \\
\hline & 58.43 & -1.597 & -11.44 & 0.930 & 1.851 & 4.391 \\
\hline
\end{tabular}

Table $19 L$, $a$, and $b$ values for Listerine bottle

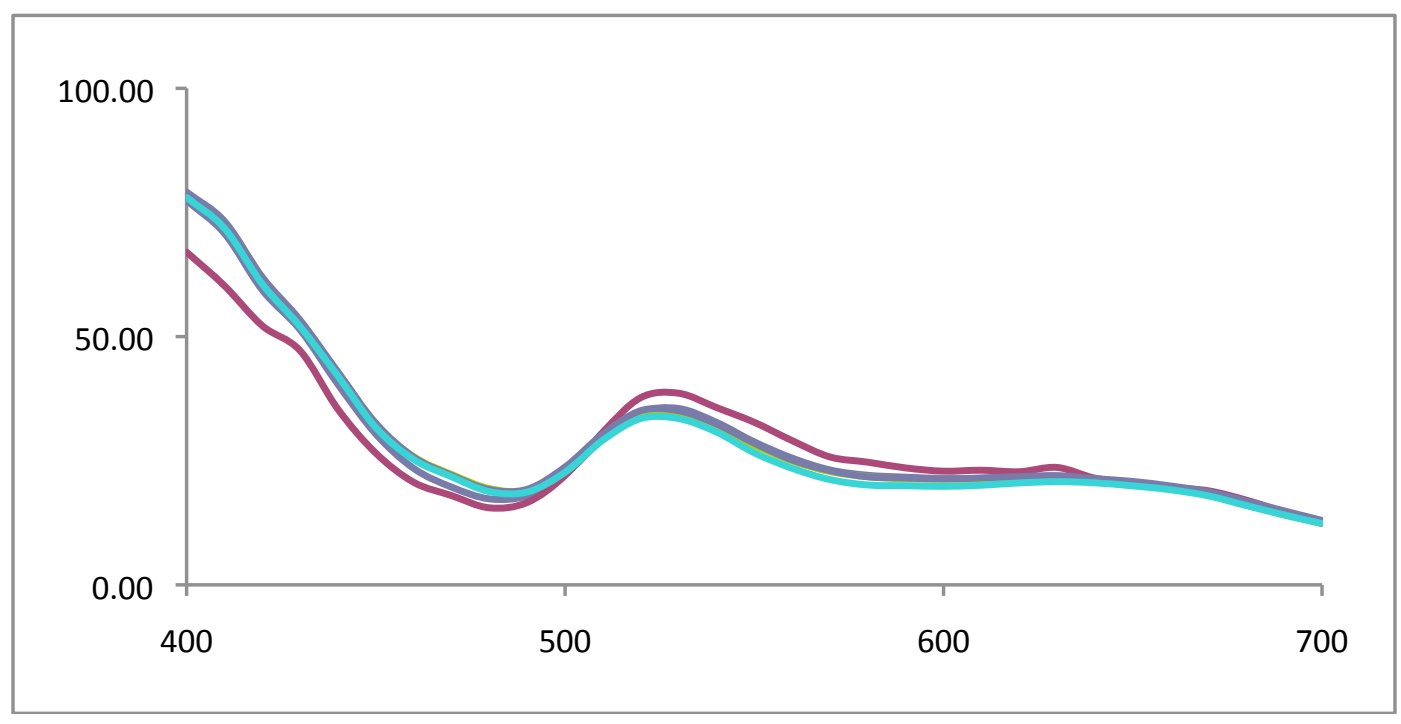

Figure 37 Smoothed data - Listerine bottle 


\section{Picture Frame}

\begin{tabular}{|c|c|c|c|c|c|c|}
\hline & $\mathrm{L}$ & $\mathrm{A}$ & $\mathrm{B}$ & $\mathrm{rL}$ & $\mathrm{rA}$ & $\mathrm{rB}$ \\
\hline Area 1 & 73.68 & -15.18 & -9.085 & & & \\
\hline Area 2 & 75.63 & -14.27 & -12.52 & ST DEV & ST DEV & ST DEV \\
\hline Area 3 & 73.08 & -12.50 & -10.08 & 1.046 & 1.071 & 1.356 \\
\hline Area 4 & 74.43 & -15.04 & -11.49 & & & \\
\hline Area 5 & 75.17 & -14.41 & -11.55 & CONFIDENCE & CONFIDENCE & CONFIDENCE \\
\hline & 74.40 & -14.28 & -10.95 & 0.917 & 0.939 & 1.189 \\
\hline
\end{tabular}

Table $20 L$, $a$, and $b$ values for Picture frame

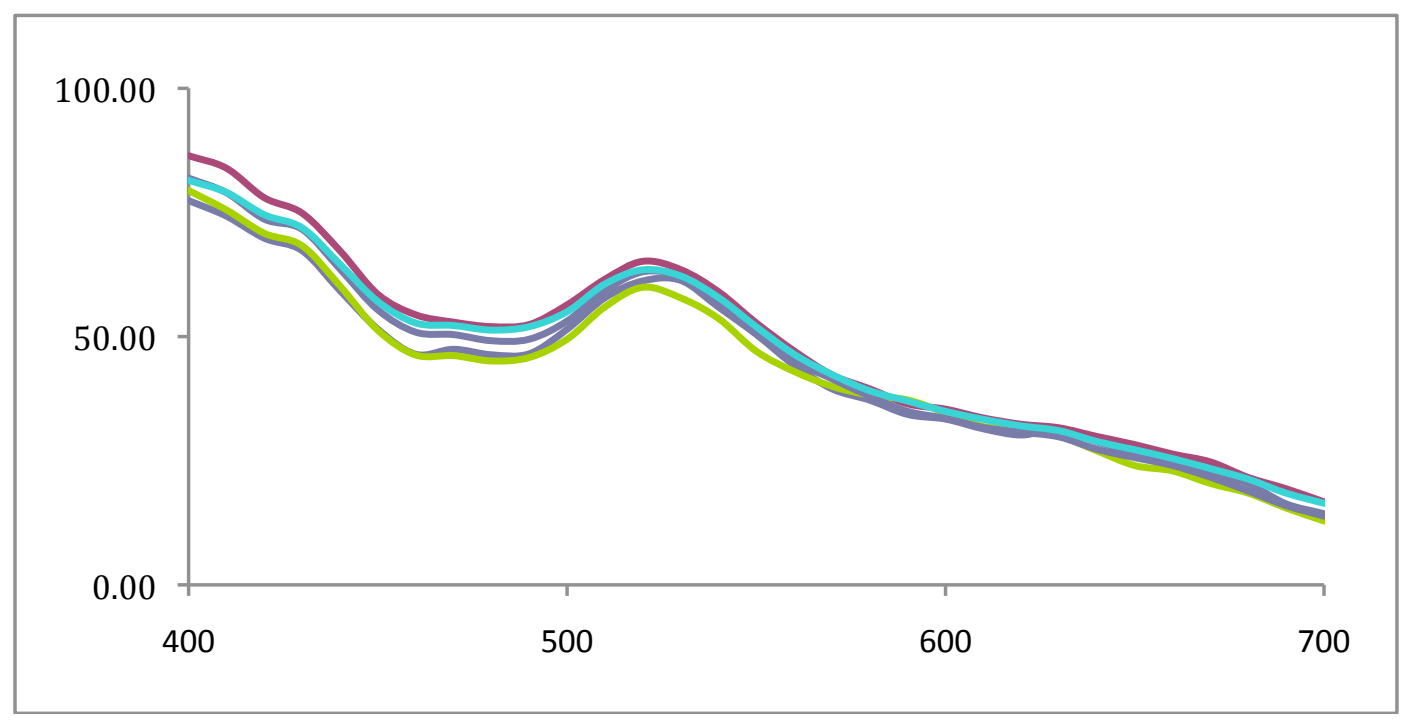

Figure 38 Smoothed data - Picture frame 


\section{Drinking Glass}

\begin{tabular}{|c|c|c|c|c|c|c|}
\hline & $\mathrm{L}$ & $\mathrm{A}$ & $\mathrm{B}$ & $\mathrm{rL}$ & $\mathrm{rA}$ & $\mathrm{rB}$ \\
\hline Area 1 & 73.68 & -15.18 & -9.085 & & & \\
\hline Area 2 & 75.63 & -14.27 & -12.52 & ST DEV & ST DEV & ST DEV \\
\hline Area 3 & 73.08 & -12.50 & -10.08 & 1.046 & 1.071 & 1.356 \\
\hline Area 4 & 74.44 & -15.04 & -11.49 & & & \\
\hline Area 5 & 75.17 & -14.41 & -11.55 & CONFIDENCE & CONFIDENCE & CONFIDENCE \\
\hline & 74.40 & -14.28 & -10.95 & 0.917 & 0.939 & 1.189 \\
\hline
\end{tabular}

Table $21 \mathrm{~L}$, $a$, and $b$ values for Drinking glass

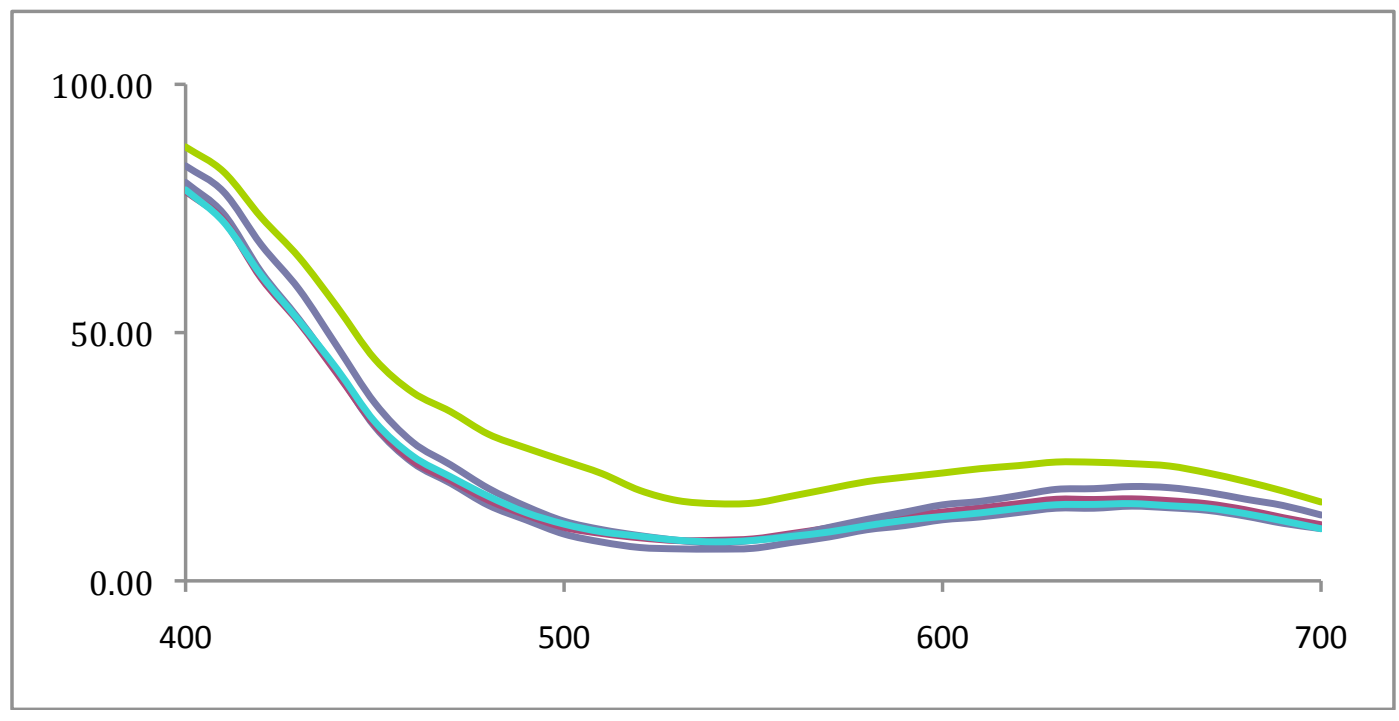

Figure 39 Smoothed data - Drinking glass 
G0237

\begin{tabular}{|c|c|c|c|c|c|c|}
\hline & $\mathrm{L}$ & $\mathrm{A}$ & $\mathrm{B}$ & $\mathrm{rL}$ & $\mathrm{rA}$ & $\mathrm{rB}$ \\
\hline Area 1 & 40.27 & 48.03 & -25.04 & & & \\
\hline Area 2 & 40.83 & 46.54 & -23.41 & ST DEV & ST DEV & ST DEV \\
\hline Area 3 & 40.84 & 46.40 & -22.95 & 0.664 & 0.653 & 2.178 \\
\hline Area 4 & 39.28 & 47.31 & -25.08 & & & \\
\hline Area 5 & 40.74 & 47.10 & -19.74 & CONFIDENCE & CONFIDENCE & CONFIDENCE \\
\hline & 40.39 & 47.08 & -23.24 & 0.582 & 0.572 & 1.909 \\
\hline
\end{tabular}

Table $22 L$, $a$, and $b$ values for $G 0237$

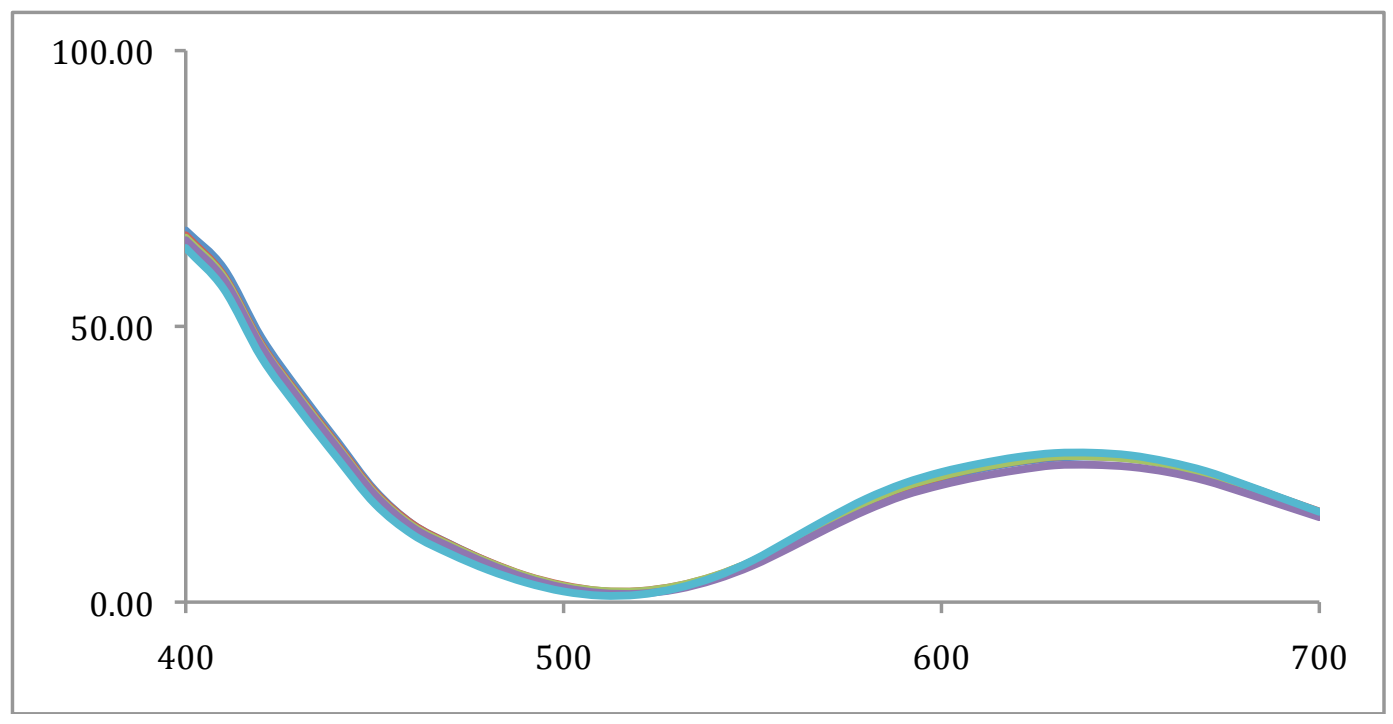

Figure 40 Smoothed data - G0237 


\begin{tabular}{|c|c|c|c|c|c|c|}
\hline & $\mathrm{L}$ & $\mathrm{A}$ & $\mathrm{B}$ & $\mathrm{rL}$ & $\mathrm{rA}$ & $\mathrm{rB}$ \\
\hline Area 1 & 39.25 & 43.60 & -28.53 & & & \\
\hline Area 2 & 39.61 & 45.23 & -29.27 & ST DEV & ST DEV & ST DEV \\
\hline Area 3 & 40.18 & 42.86 & -29.17 & 1.263 & 2.017 & 0.686 \\
\hline Area 4 & 37.75 & 47.41 & -29.99 & & & \\
\hline Area 5 & 41.18 & 42.51 & -28.23 & CONFIDENCE & CONFIDENCE & CONFIDENCE \\
\hline & 39.59 & 44.32 & -29.04 & 1.107 & 1.768 & 0.601 \\
\hline
\end{tabular}

Table $23 L$, $a$, and $b$ values for $G 1117$

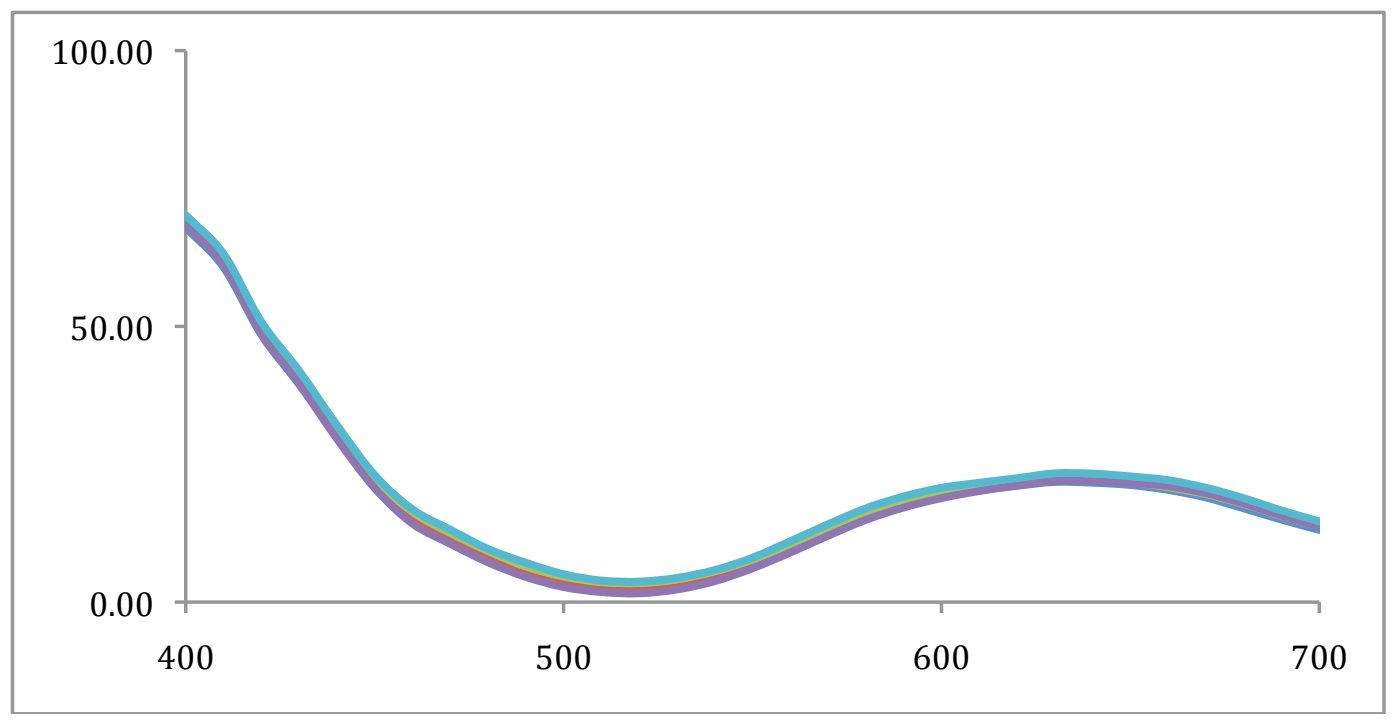

Figure 41 Smoothed data - G1117 


\section{5}

\begin{tabular}{|c|c|c|c|c|c|c|}
\hline & $\mathrm{L}$ & $\mathrm{A}$ & $\mathrm{B}$ & $\mathrm{rL}$ & $\mathrm{rA}$ & $\mathrm{rB}$ \\
\hline Area 1 & 32.27 & 45.97 & -57.83 & & & \\
\hline Area 2 & 35.85 & 40.10 & -53.31 & ST DEV & ST DEV & ST DEV \\
\hline Area 3 & 29.32 & 52.36 & -62.84 & 3.546 & 5.827 & 4.664 \\
\hline Area 4 & 29.60 & 50.21 & -62.26 & & & \\
\hline Area 5 & 37.09 & 39.39 & -51.92 & CONFIDENCE & CONFIDENCE & CONFIDENCE \\
\hline & 35.07 & 41.82 & -54.35 & 3.109 & 5.107 & 4.088 \\
\hline
\end{tabular}

Table $24 L$, $a$, and $b$ values for 10325

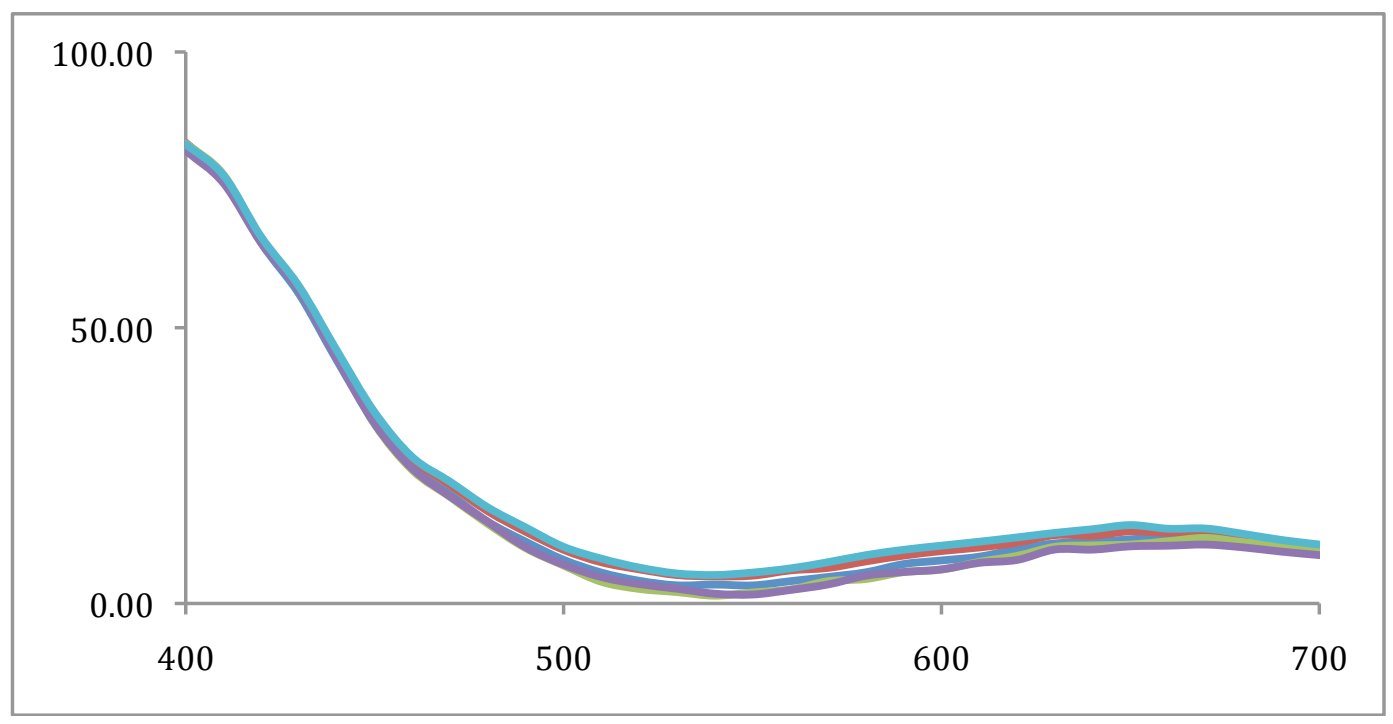

Figure 42 Smoothed data - 10325 
10680

\begin{tabular}{|c|c|c|c|c|c|c|}
\hline & $\mathrm{L}$ & $\mathrm{A}$ & $\mathrm{B}$ & $\mathrm{rL}$ & $\mathrm{rA}$ & $\mathrm{rB}$ \\
\hline Area 1 & 35.48 & 44.57 & -47.46 & & & \\
\hline Area 2 & 32.89 & 47.45 & -45.47 & ST DEV & ST DEV & ST DEV \\
\hline Area 3 & 32.84 & 49.76 & -52.61 & 1.510 & 2.600 & 3.683 \\
\hline Area 4 & 47.91 & 23.86 & -40.14 & & & \\
\hline Area 5 & 50.23 & 23.57 & -36.41 & CONFIDENCE & CONFIDENCE & CONFIDENCE \\
\hline & 33.74 & 47.26 & -48.51 & 1.323 & 2.279 & 3.229 \\
\hline
\end{tabular}

Table $25 L$, $a$, and $b$ values for 10680

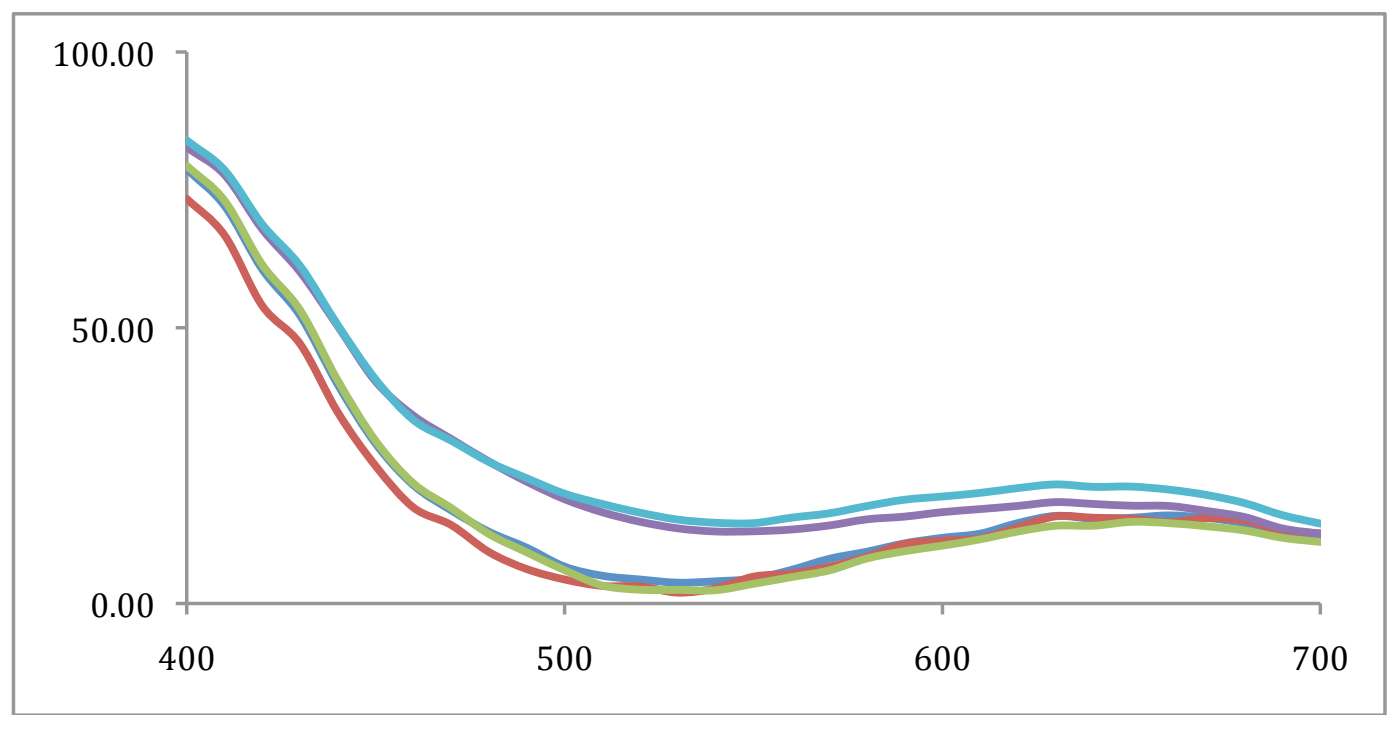

Figure 43 Smoothed data - 10680 


\section{9}

\begin{tabular}{|c|c|c|c|c|c|c|}
\hline & $\mathrm{L}$ & $\mathrm{A}$ & $\mathrm{B}$ & $\mathrm{rL}$ & $\mathrm{rA}$ & $\mathrm{rB}$ \\
\hline Area 1 & 34.52 & 40.47 & -54.97 & & & \\
\hline Area 2 & 35.62 & 41.61 & -53.43 & ST DEV & ST DEV & ST DEV \\
\hline Area 3 & 34.02 & 44.63 & -54.98 & 0.861 & 2.012 & 0.960 \\
\hline Area 4 & 36.06 & 39.66 & -54.76 & & & \\
\hline Area 5 & 35.65 & 43.17 & -52.94 & CONFIDENCE & CONFIDENCE & CONFIDENCE \\
\hline & 35.17 & 41.91 & -54.22 & 0.755 & 1.763 & 0.842 \\
\hline
\end{tabular}

Table $26 L$, $a$, and $b$ values for 10979

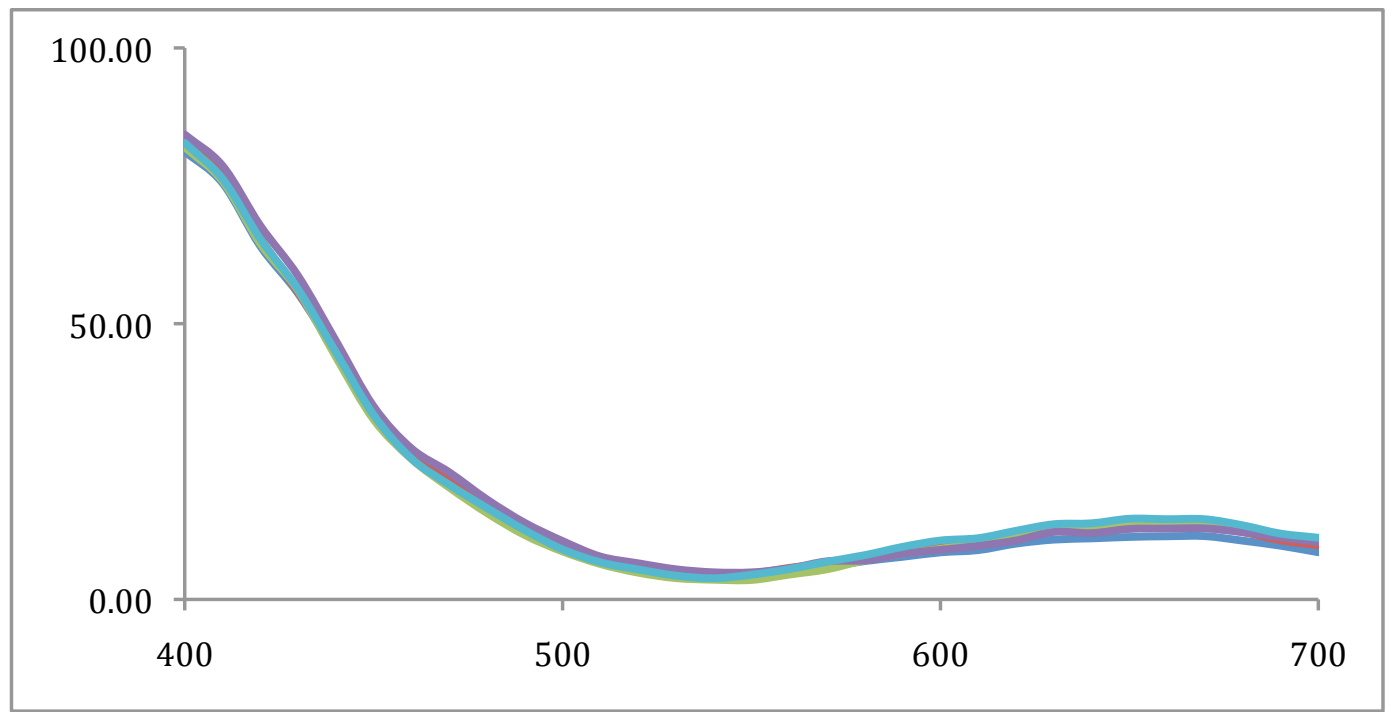

Figure 44 Smoothed data - 10979 
$\mid 1121$

\begin{tabular}{|c|c|c|c|c|c|c|}
\hline & $\mathrm{L}$ & $\mathrm{A}$ & $\mathrm{B}$ & $\mathrm{rL}$ & $\mathrm{rA}$ & $\mathrm{rB}$ \\
\hline Area 1 & 30.03 & 52.13 & -55.85 & & & \\
\hline Area 2 & 31.43 & 51.06 & -54.98 & ST DEV & ST DEV & ST DEV \\
\hline Area 3 & 37.43 & 40.81 & -45.97 & 2.963 & 5.003 & 4.361 \\
\hline Area 4 & 34.53 & 44.88 & -47.61 & & & \\
\hline Area 5 & 31.66 & 51.51 & -51.27 & CONFIDENCE & CONFIDENCE & CONFIDENCE \\
\hline & 33.02 & 48.08 & -51.14 & 2.597 & 4.385 & 3.823 \\
\hline
\end{tabular}

Table $27 L$, $a$, and $b$ values for $\mid 1121$

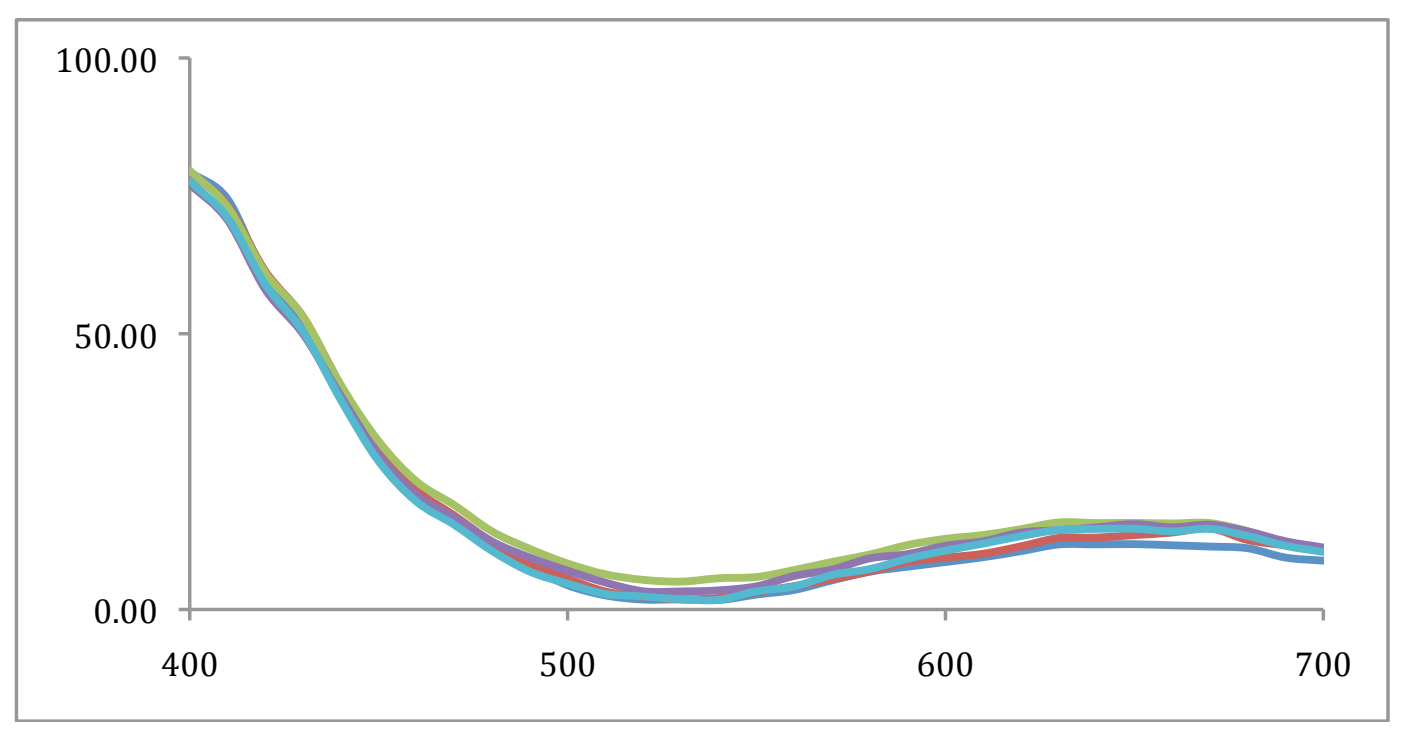

Figure 45 Smoothed data - I1121 
J0428

\begin{tabular}{|c|c|c|c|c|c|c|}
\hline & $\mathrm{L}$ & $\mathrm{A}$ & $\mathrm{B}$ & $\mathrm{rL}$ & $\mathrm{rA}$ & $\mathrm{rB}$ \\
\hline Area 1 & 35.45 & 37.69 & -51.14 & & & \\
\hline Area 2 & 39.54 & 35.91 & -46.05 & ST DEV & ST DEV & ST DEV \\
\hline Area 3 & 39.20 & 35.82 & -47.64 & 1.812 & 0.949 & 2.765 \\
\hline Area 4 & 39.97 & 35.85 & -44.90 & & & \\
\hline Area 5 & 38.88 & 37.48 & -50.69 & CONFIDENCE & CONFIDENCE & CONFIDENCE \\
\hline & 38.61 & 36.55 & -48.08 & 1.588 & 0.832 & 2.423 \\
\hline
\end{tabular}

Table $28 L$, $a$, and $b$ values for $J 0428$

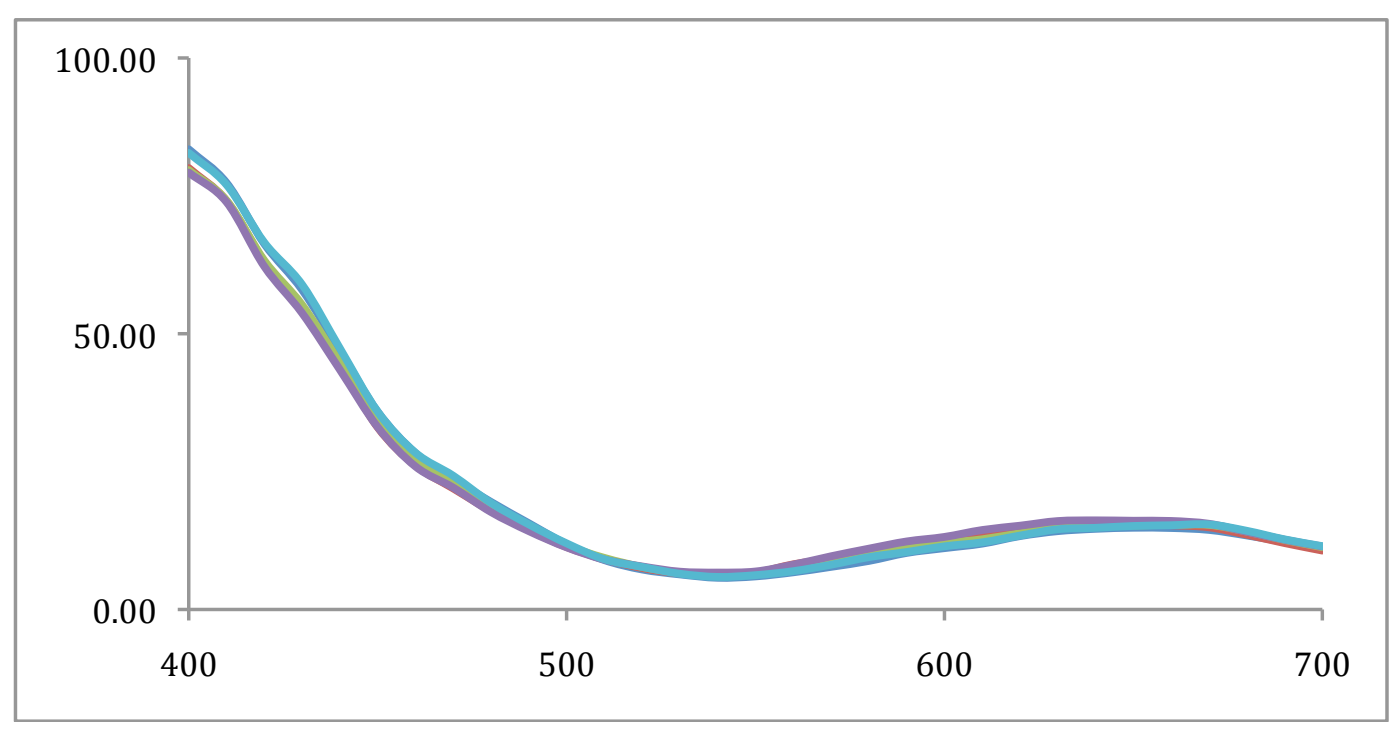

Figure 46 Smoothed data - J0428 


\section{G1966}

\begin{tabular}{|c|c|c|c|c|c|c|}
\hline & $\mathrm{L}$ & $\mathrm{A}$ & $\mathrm{B}$ & $\mathrm{rL}$ & $\mathrm{rA}$ & $\mathrm{rB}$ \\
\hline Area 1 & 32.43 & 52.04 & -47.29 & & & \\
\hline Area 2 & 31.08 & 51.48 & -49.86 & ST DEV & ST DEV & ST DEV \\
\hline Area 3 & 34.58 & 52.15 & -44.60 & 2.590 & 4.455 & 3.743 \\
\hline Area 4 & 34.39 & 44.08 & -41.10 & & & \\
\hline Area 5 & 37.92 & 43.48 & -41.56 & CONFIDENCE & CONFIDENCE & CONFIDENCE \\
\hline & 34.08 & 48.65 & -44.88 & 2.270 & 3.905 & 3.281 \\
\hline
\end{tabular}

Table 29 L, $a$, and $b$ values for $G 1966$

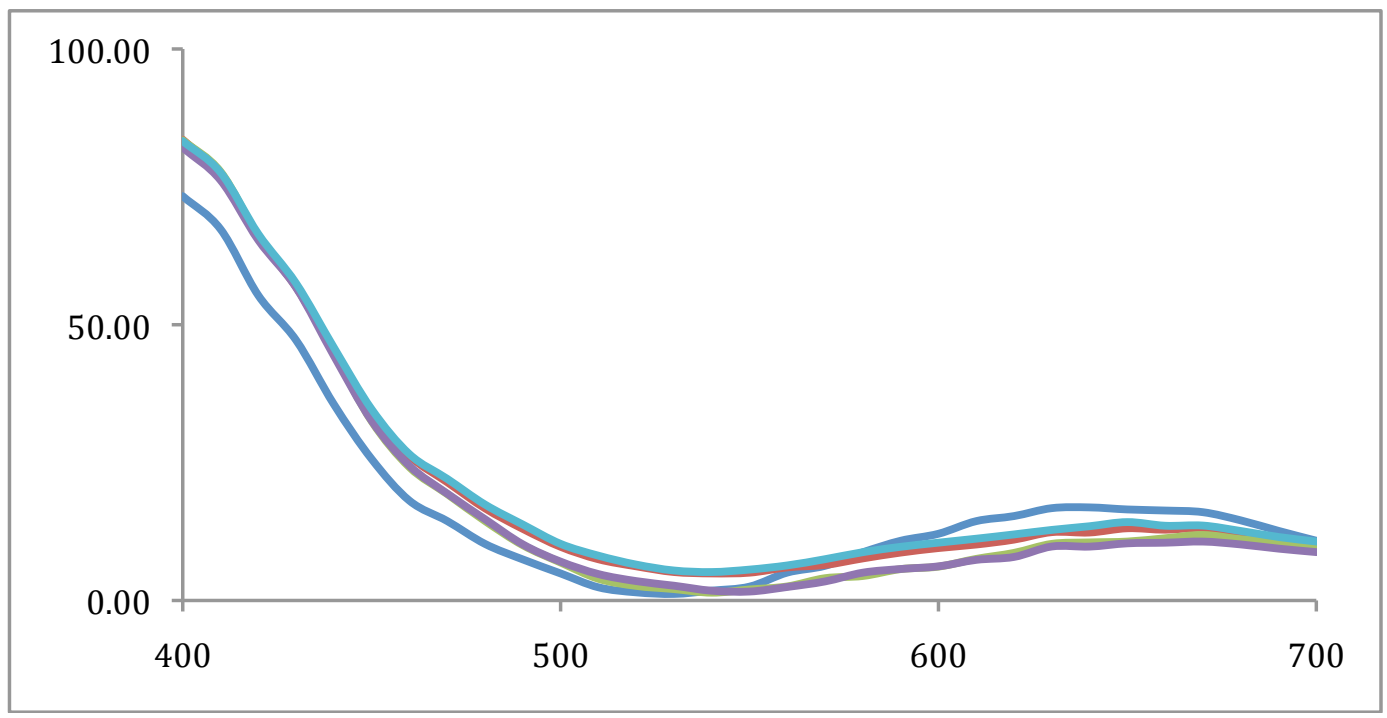

Figure 47 Smoothed data - G1966 


\section{K0138}

\begin{tabular}{|c|c|c|c|c|c|c|}
\hline & $\mathrm{L}$ & $\mathrm{A}$ & $\mathrm{B}$ & $\mathrm{rL}$ & $\mathrm{rA}$ & $\mathrm{rB}$ \\
\hline Area 1 & 35.46 & 44.81 & -59.02 & & & \\
\hline Area 2 & 35.04 & 46.74 & -57.68 & ST DEV & ST DEV & ST DEV \\
\hline Area 3 & 35.04 & 46.74 & -57.68 & 4.085 & 2.751 & 1.630 \\
\hline Area 4 & 26.63 & 51.55 & -61.67 & & & \\
\hline Area 5 & 29.20 & 50.08 & -58.86 & CONFIDENCE & CONFIDENCE & CONFIDENCE \\
\hline & 32.27 & 47.98 & -58.98 & 3.581 & 2.411 & 1.429 \\
\hline
\end{tabular}

Table 30 L, a, and $b$ values for $K 0138$

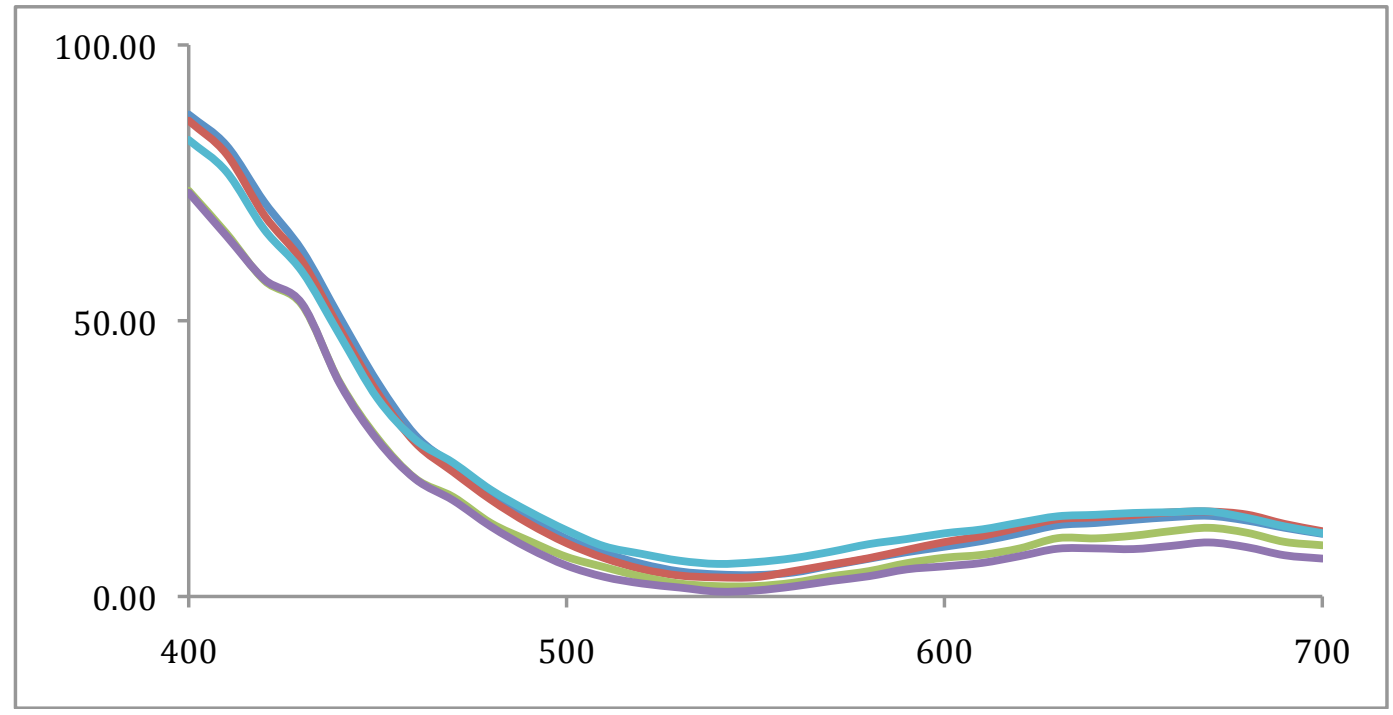

Figure 48 Smoothed data - K0138 